The emotional issue of stopping the MRS, and thus the State of Tennessee will not be subject to waste shipments, will not be true.

Highway Routing:

Effects of the Hazardous Materials Transportation Act (HMTA) and 49 CFR $171-177$

The Hazardous Materials Transportation Act (HMTA) and regulations issued under this act are codified as Parts 170-179 of Title 49 of the Code of Federal Regulations. The U.S. Department of Transportation (DOT) issued a final rule on highway routing of radioactive materials, commonly refered to as HM-164, in January 1981.

In general, HM-164 precludes states or local agencies from enacting laws, rules or regulations that are inconsistent with the HMTA, acting as a barrier or obstacle to carrying out the act. In the event of such laws, rules or regulations, HMTA, Section 112 (a) preempts them.

Under HM-164, specific routing requirements were established for highway shipments of route controlled quantity radioastive materials (spent nuclear fuel). 49 CFR 177.825 (b).

HM-164 requires carriers of highway route controlled quantity radioactive material to operate over Interstate System highways selected to reduce time in transit except where an available Interstate System beltway or bypass allows them to avoid city centers. Carriers are allowed off the Interstate System only under the circumstances described in $\$ 177.825(b)(2)$ :

1. To follow a State-designated alternate;

2. In a documented case of emergency;

3. To make necessary stops for rest, fuel or vehicle repairs; or 
4. To travel to and from a pick-up or delivery site not located on an Interstate System highway.

The State of Tennessee, in accordance with HM-164 may designate an alternate route, provided it offers an equal or greater level of safety than the primary route. A "State-designated route" must be selected in accordance with U.S. DOT "Guidelines for Selecting Preferred Highway Routes for Highway Route Controlled Quantity Shipments of Radioactive Materials."

A discussion paper "Highway Routing of Spent Muclear Fuel: The DOT Rule and Its Impacts" by Elaine Economides, Esq., Research and Special Programs Administration, U.S. DOT is being made a part of this report.

Also, due to the scarcity and difficult access a copy of "Guidelines for Selecting Preferred Highway Routes for Highway Route Controlled Quantity Shipments of Radioactive Materials" is attached for informational purposes.

Role of Tennessee Department of Transportation:

Authorization and construction of an MRS facility in Tennessee would involve the Tennessee Department of Transportation in possibly three (3) ways.

1. Highway Maintenance

Increased Maintenance costs on the local access routes.

2. Permitting of Overweight Movements

In the event DOE changes its concept from legal loads $(80,000$ 非) to overweight movements $(117,000$ 非) TDOT would issue overweight permits. TCA $-55-11-205$

3. Highway Improvement

Design \& Construction of highway improvements on the local access routes to provide an acceptable level of safety to the traveling public. 
Routing of Movements:

Routing of movements would come under authority of the "State-designated" agency. As TDOT does not have regulatory authority over common carriers, it would appear the Department would not be involved.

TDOT would need to advise the "State-designated" agency on the acceptability of any alternate route as to roadway conditions and acceptable bridge loadings.

\section{Regulating Movements:}

Regulation of movements by common carrier would fall under the jurisdiction of the Public Service Commission (PSC). TDOT would have no involvement in regulation of movements.

\section{Permits:}

Should DOE depart from its current plan of legal weight shipments $(80,000$ 非) to possible overweight shipments $(117,000$ \#) the TDOT would issue an Overweight Permit for each movement.

Cost of permit for each movement would be:

$\$ 15.00+\$ 0.05$ per ton mile for all weight in excess of 80,000 lbs.

Routing would become a part of the permit requirements, however, special routing would comply with HM-164 \& DOT Bouting Rules.

Conclusion:

Highway Improvements: 
Interstates:

Tennessee's Interstate system is anticipated to be in a condition to provide safe travel to the traveling public and any shipments to a possible MRS facility at either the Oak Ridge or Hartsville site.

No required improvements because of an MRS is expected.

Access Routes:

$\underline{\mathrm{SR}-58}$

There are two (2) bridges in Roane County between I-40 and the proposed MRS facilities in Cak Ridge. The following is a discussion of their ability to handle the proposed 85 loads of $80,000 \mathrm{lbs}$, or 117,000 lbs. per month beginning in 1998:

1. The bridge at L.M. 17.54 over the Clinch River is currently capable of handling the proposed loadings; however, it is not full shoulder width and widening should be considered; however, by 1998 when this proposed loading is to begin, the bridge will be 37 years old. It was built in 1961, and will have used up a major portion of its life span (50 yrs.). In the event the structural steel remains in its current good condition, the bridge could be widened, using a thicker deck and still carry the proposed loadings but for how long is unknown.

2. The bridge at L.M. 17.83 over Oak Ridge Turnpike is currently capable of carrying only the proposed 85 loads of 80,000 lbs. By 1998, when these loadings are to begin, it, too, will be 37 years old and will have used up a major portion of its estimated life span ( 50 yrs.). By 1998 , it is estimated this structure would have to be rehabilitated by 
replacing or reworking the complete superstructure and be widened, it then would be capable of handling either of the proposed loadings.

Thus, from the above, it should be clear that it is currently impossible to ascertain the conditions or the ability of these bridges to carry the proposed loads in 1998 and thirteen years hence.

SR-58 would probably require some type of upgrading to insure the best possible safety to the traveling public and the MRS shipments.

The Clinch River site is about 5.8 miles via SR-58, and the Oak Ridge Reservation site is about 9.8 miles via SR-58 \& SR-95 from I-40.

$\underline{S R-95}$

There is one (1) bridge over the Clinch River at the Loudon-Roane Co. Iine, between I-40 and the proposed MRS facilities in Oak Ridge.

Tris structure at L.M. 23.87 was built in 1962 and will be 36 years old by 1998. Again, as is the case of the SR-58 bridges, a major portion of its life span will have been used up. Some type of rehabilitation, i.e., widening, replacing deck, etc., will more than likely be required.

SR-95 will require some type of upgrading in width, grade and alignment should it be considered as a preferred route. This route was not considered in detail for this report.

The Oak Ridge Reservation site is about 5.2 miles via SR-95, and the Clinch River site is about 9.0 miles via SR-95 \& SR-95 from I-40.

\section{$S R-53, S R-24, S R-25$}

There are four (4) bridges on the subject routes between $\tau-40$ and the Hartsville TVA site. 
The most critical area is the bridge at L.M. 11.34 over the Cumberland River (Cordell Hull Memorial Bridge) built in 1936. This is a high steel truss bridge which is 49 years old and has almost reached its Iife span ( 50 yrs.). Currently, this structure is posted for loads of 15 tons for 2-axle vehicles and 25 tons for 3-axle vehicles. Under this posting, legal loads or 80,000 lbs. is prohibited.

The TVA site at Hartsville is about 16.7 miles from I-40 via SR-53, SR-24 \& SR-25. SR-25 would require upgrading, as this is a rural highway with many horizonal and vertical curves and steep roadway grades.

SR-10

The TVA site at Hartsville is about 25 miles from $I-40$ through Lebanon to Hartsville via SR-10.

This route was not examined for this report. Summary:

Should an MRS be authorized for Tennessee, certain highway improvements will be required. A decision as to type and extent of the improvements would need to be determined in the early 1990's.

There are so many variables that cannot accurately be estimated for the year 1998 and beyond, i.e., average daily traffic, pavement conditions, structure conditions, change in design standards, etc. Also, it would be impossible to project estimated costs for 1995 because it would require determination of costs for labor, equipment and materials, 10 years in the future.

All of the above would determine what the needed improvements would be and the cost. 
Estimated Costs $-\mathrm{SR}-58$ Improvements:

TDOT's 1985 Estimated cost to replace the bridge at L.M. 17.54, over the Clinch River, with a 4-lane structure is:

Approaches and Bridge - $\$ 11,200,000$.

At an average inflation rate (Assumed) $7 \%, 1995$ cost could increase to $\$ 22,000,000$.

The Estimated Replacement Cost of bridge at L.M. 17.83, over the Oak Ridge turnpike, with a 4-lane structure is approximately $\$ 501,000$.

At average inflation rate of $7 \%, 1995$ cost could increase to 985,000 . Estimated cost to replace current facility with a divided 4-lane facility for a distance of approximately 5.8 miles is approximately $\$ 7,900,000$.

At average inflation rate of $7 \%, 1995$ cost could increase to $\$ 15,500,000$. Estimated 1995 cost:

Bridges $\$ 22,985,000$

Roadway $\$ 15,500,000$

Total $\$ 38,485,000$

The above estimated cost is a very rough estimate of possible cost to the State of Tennessee, and as mentioned above, many variables, which are subject to change in the next 10 years, makes this a very argumentative item. However, DOE SHOULD BE REQUIRED TO AGREE TO FUND NEEDED INPROVEMENTS FOR SAFETY AS DETERMINED IN THE EARLY 1990'S.

Position of TDOT:

The Department of Transportation would probably view an MRS facility as just another industry using the State highway system as a method of transporting its materials. 
Currently, TDOT does not become involved with what types of materials are or are not shipped over the State highway system.

However, due to this being a highly emotional subject to the general public, TDOT would be involved with possible route upgrading that would be required in the mid 1990's to insure a safe environment to the traveling public and the local populace.

From information available, the author sees a very minimal impact to the Tennessee Highway System as a whole. 


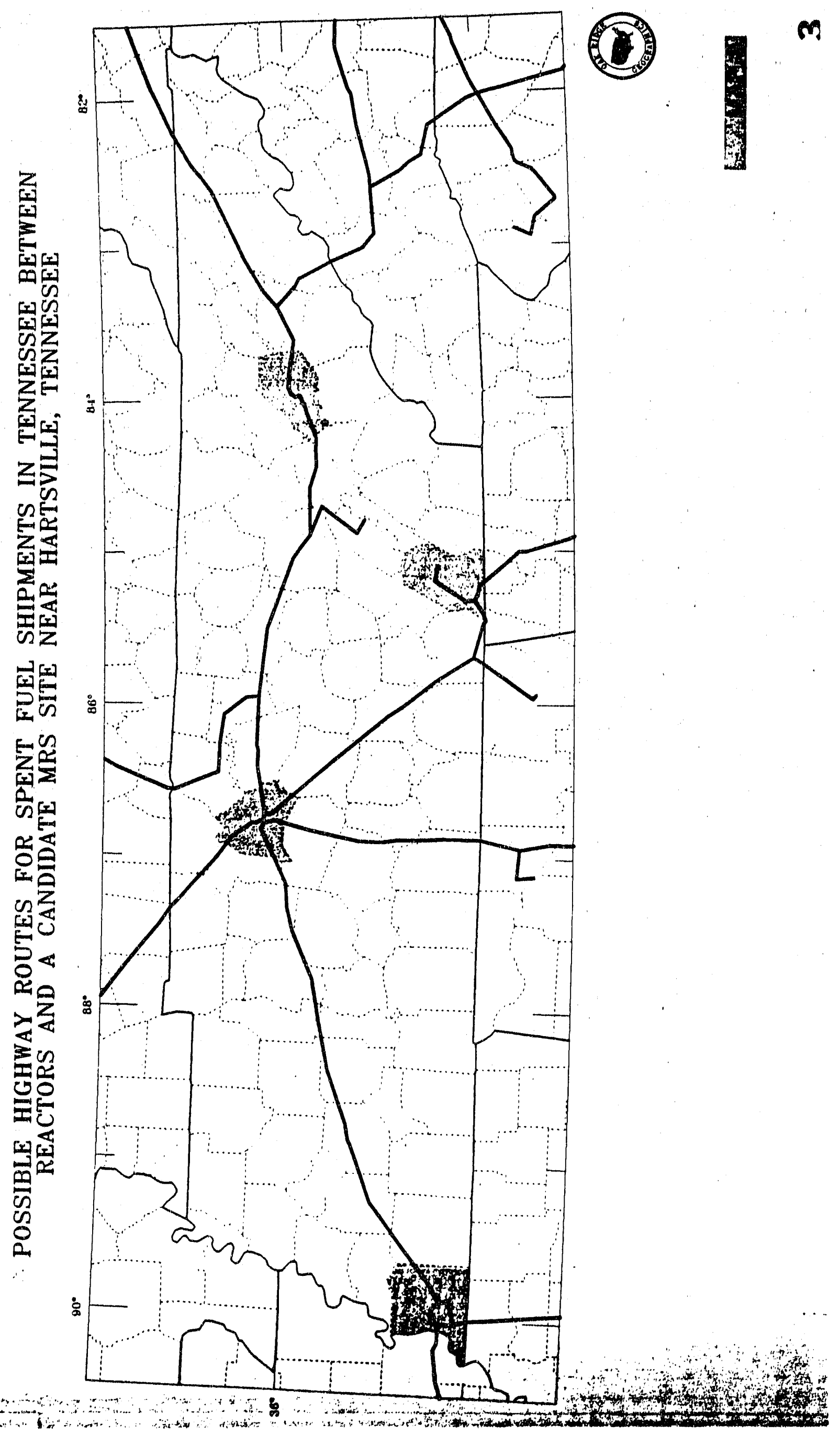




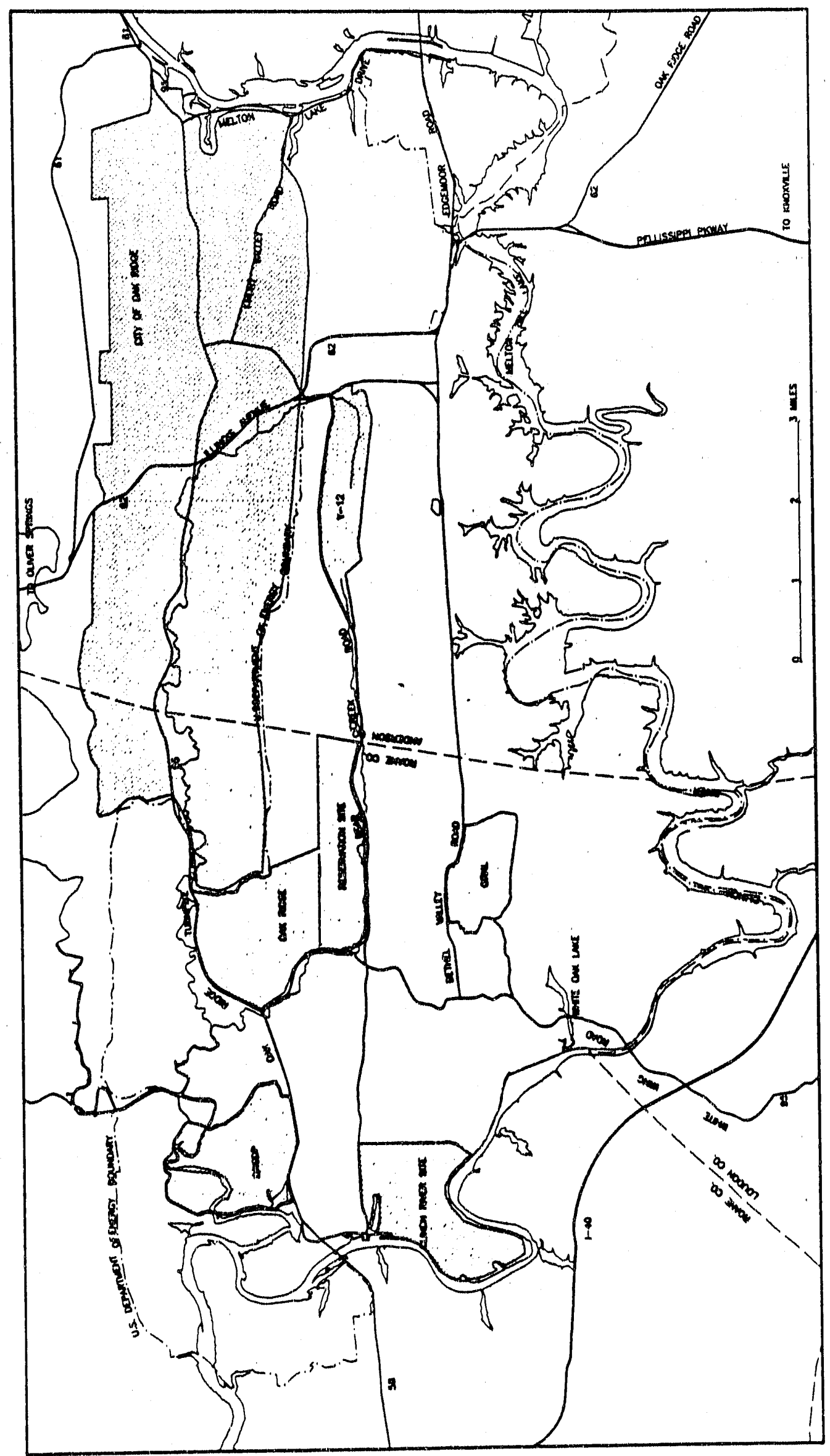

18 


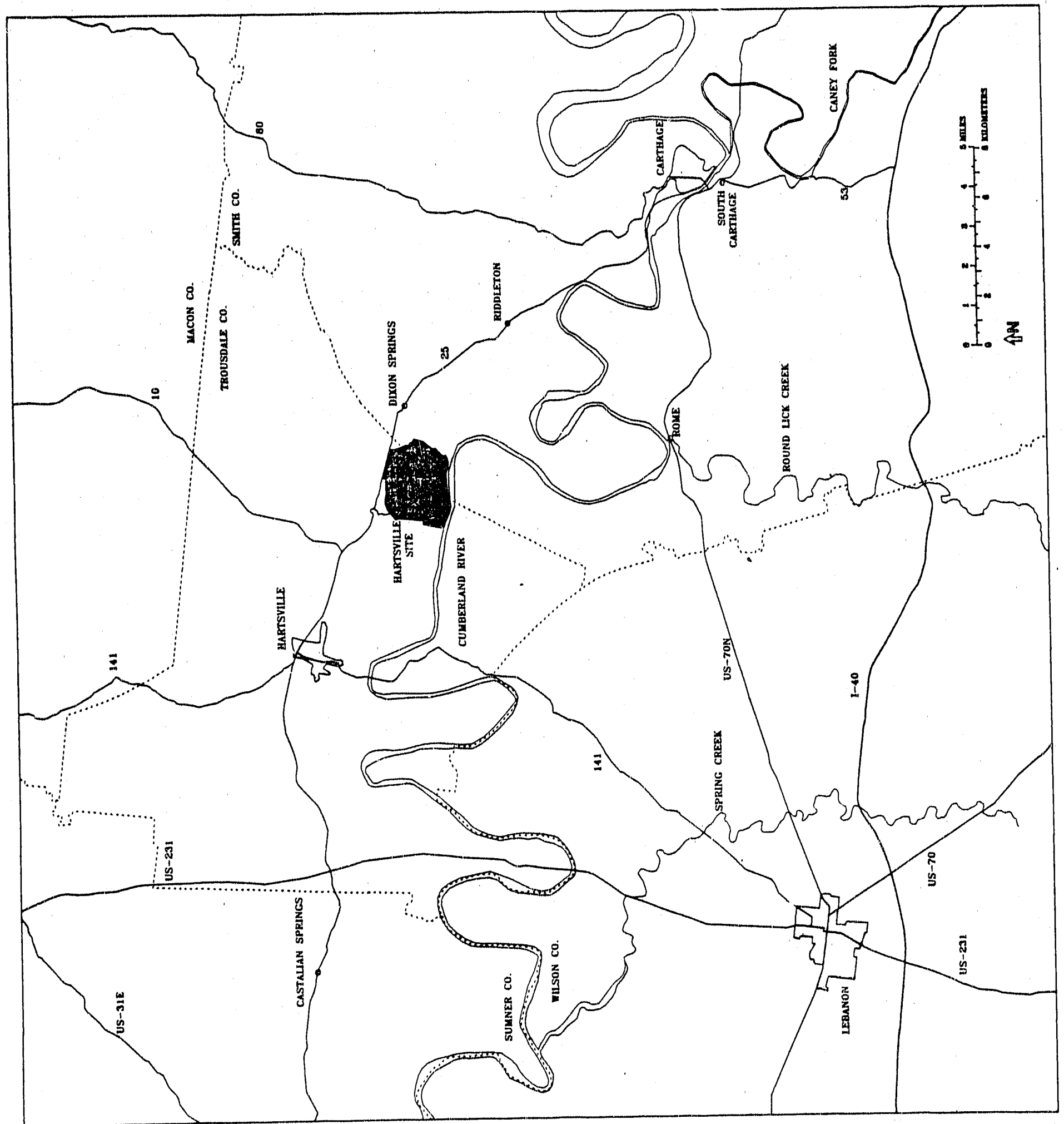


APPENDIX A 
HIGH WAY ROUTING OF SPENT NUCLEAR FUEL: THE

DOT RULE AND ITS IMPACTS

\author{
Elaine Economides, Esq. \\ Research and Special Programs Administration \\ U.S. Department of Transportation
}

\title{
INTRODUCTION
}

In January of 1981, the U. S. Department of Transportation (DOT) issued a final rule on highway routing of radioactive materials (Ref. 1), which is commonly referred to by its docket number, HM-164. The principal purpose of HM-164 was to establish nationally applicable standards for the safe highway routing of radioactive materials. This presentation reviews the legal history of HM-164, describes its substantive provisions, and discusses its impacts on certain state and local rules.

\section{GENERAL AUTHORITY AND PREEMPTION UNDER THE HMTA}

DOT's authority to regulate hazardous materials transportation safety is derived from the Hazardous Materials Transportation Act (HMTA) (Ref. 2). The HMTA authorizes the Secretary of Transportation to designate certain materials as hazardous and to issue and enforce safety regulations governing the transportation and handing of such materials. Section 105 of the HMTA (49 U.S.C. 1806) specifically includes routing among the types of regulations which the Secretary is authorized to issue.

Substantive regulations issued under the HMTA are known as the Hazardous Materials Regulations (HMR) and are codified as Parts 170-179 of Title 49 of the Code of Federal Rc gulations. Procedural regulations are codified at 49 CFR Parts 106-107. Within DOT, the primary responsibility for issuance and interpretation of the HMR has been delegated to the Materials Transportation Bureau (MTB) of the Research and Special Programs Administration. 
The HMTA expressly defines its relationship to state and local law. Section 112(a) states clearly that "any requirement, of a State or political subdivision thereof, which is inconsistent with any requirement set forth in (the HMTA) or regulations issued under (the HMTA), is preempted." The inclusion of this express preemption provision makes it clear that Congress did not intend the HMTA and its regulations to occupy the field so completely as to preclude any state or local action. The HMTA preempts only those state and local requirements that are "inconsistent." The legislative history of this provision indicates that Congress intended it "to preclude a multiplicity of State and local regulations and the potential for varying as well as conflicting regulations in the area of hazardous materials transportation." (Ref. 3)

Under Section 112(b) of the HMTA, the Secretary of Transportation may waive preemption of an inconsistent state or local requirement upon a showing that the requirement offers an equal or greater level of safety and does not unreasonably burden commerce. The inclusion of this waiver provision reflects the Congressional recognition that "certain exceptional circumstances may necessitate imm ediate action to secure more stringent regulations." (Ref . 4)

In 49 CF $\mathrm{R}$ Part 107, MTB has published procedures which implement the preemption language of the HMTA by providing for the issuance of inconsistency rulings. At the time that these procedures were published, MTB observed that "( $t$ )he determination as to whether a State or local requirement is consistent or inconsistent with the Federal statute or Federal regulations is traditionally judicial in nature." (Ref. 5) There are two principal reasons for providing an administrative forum for such a determination. First, an inconsistency ruling provides an alternative to litigation for a determination of the relationship between federal requirements and those of a state or political subdivision thereof. Second, if a state or political subdivison requirement is found to be inconsistent, 
such a finding provides the basis for application to the Secretary of Transportation for a determination as to whether preemption will be waived.

Since such proceedings are conducted pursuant to the HMTA, only the question of statutory preemption can be considered. A federal court may find a non-federal requirement not statutorily preempted, but, nonetheless, preempted by the Commerce Clause of the U.S. Constitution because of an undue burden on interstate commerce. However, the Department of Transportation does not make such determinations.

Given the judicial character of the inconsistency ruling proceeding, MTB has incorporated into it case law criteria (Ref. 6) for determining inconsistency:

(1) Whether con: pliance with both the (non-F ederal) requirement and the Act or the regulations issued under the Act is possible; and

(2) The extent to which the (non-F ederal) requirement is an obstacle to the accomplishment and execution of the Act and the regulations issued under the Act. (49 CFR 107.209(c))

The first criterion, commonly called the "dual compliance" test, concerns those non-federal requirements which are incongrwous with federal requirements; that is, compliance with the non-federal requirement causes the federal requirement to be vialated, or vice versa. The second miterion, the "obstacle" test, in a sense, subsumes the first and concerns those federal rules that, regardless of conflict with a federal requirement, stand as "an obstacle to the accomplishment and execution of the (HMTA) and the regulations issued under the (HMTA)." In determining whether a non-federal requirement presents such an obstacle, it is necessary to look at the full purposes and objectives of Congress in enacting the HMTA and the manner and extent to which those purposes and objectives have been carried out through the MTB's regulatory program. 
The standards by which the Secretary of Transportation determines whether to waive preemption are set forth in the HMTA. Section 112(b) authorizes waiver of preemption of an inconsistent non-federal requirement upon finding that such requirement:

(1) affords an equal or greater level of protection to the public than is afforded by the requirements of (the HMTA) or or regulations issued under (the HMTA) and

(2) does not unreasonably burden commerce. (49 U.S.C. 1811(b))

The foregoing discussion of DOT's regulatory authority, while somewhat lengthy, provides the backgrol.d necessary for an understanding of the development of both the substantive provisions of HM-164 and the appendix thereto.

\section{DEVELOP MENT OF THE RULE}

In 1976 the City of New York amended its Health Code in such a way as to effectively prohibit the transportation of most commercial shipments of radioactive materials in or through the City. Because all roads from Long Island pass through New York City, the amendment amounted to a ban on the use of motor vehicles for transporting spent nuclear fuel from nuclear reactors in Long reactors in Long Island. Brookhaven National Laboratory, which operates a research reactor on Long Island, responded to the City's action by petitioning DOT for an administrative ruling declaring the amendment to be inconsistent with, and thus preempted by, the HMTA.

In an Inconsistency Ruling published in April of 1978 (Ref. 7), DOT found that the amendment to the City's Health Code was not preempted by the HMTA. The basis for this finding was that, although the HMTA authorized the Secretary of Transportation to develop national standards for the routing of radioactive materials, the Secretary had not yet initiated any exercise of that authority. Consequently, in DOT's view, municipalities like New York City were free to enact their own routing rules until such time as DOT took action on the matter. 
Recognizing the implications of its ruling for the already growing number of State and local restrictions on nuclear trarsportation, DOT decided to investigate the need for federal rules governing highway carriers of radioactive materials. Accordingly, in August of 1978, DOT published an Advance Notice of Proposed Rulemaking (Ref. 8), opening Docket No. HM-164 and asking for public comment to assist in deciding whether rules governing highway routing of radioactive materials should be developed and proposed and, if so, what the rules should say. From the outset, DOT indicated that any proposed rulemaking would be limited to highway routing. The reason for this limitation wes that the highway mode offered the greatest number of routing possibilities and encountered the greatest number of immediate and significant disparities in state and local saf ety requirements. More than 550 comments were received in response to the Advance Notice.

In January of 1980, having analyzed all - the comments and tholoughly researched the subject, DOT published a Notice of Proposed Rulemaking (Ref. 9) which set forth DOT's preliminary assessment of appropriate routing and driver training requirements. One year later, after conducting eight (8) public hearings and reviewing more than $160 n$ comments on the proposed rule, DOT published HM164 as a Final Rule. As adopted, HM-164 closely resembled the proposed version.

\section{. PROVISIONS OF HM-164}

The preamble to HM-164 stated DOT's conclusion that, on the basis of the extensive public comment on the docket, documented risk studies and past experience for radioactive material transport, the public risks in transporting these mat vials by highway were too low to justify the unilateral imposition by local governments of bans and other severe restrictions on the highway mode of transportation. Moreover, other modes of transport were generally found not to offer alternatives which lowered public risks to such an extent as to warrant substantial restriction of the highway mode. However, DOT also found that these 
already low risk could be further reduced by the adoption of driver training requirements and provisions for a method of selecting the safest available highway routes for carriers of large quantity ractioactive materials. On this basis, DOT adopted the final rule whose provisions are described below.

General Routing Rule

The general routing rule applicable to highway shipments of radioactive materials which must be placarded is codified at 49 CFR 177.825(a):

(a) The carrier shall ensure that any motor vehicle which contains a racioactive material for which placarcing is required is operated on routes that minimize radiological risk. The carrier shall consider available information on accident rates, transit time, population density and activities, time of day and day of week during which transportation will occur. In performance of this requirement the carrier shall tell the driver that the motor vehicle contains racioactive materials and shall incicate the general route to be taken. This requirem ent does not apply when-

(1) There is only one practicable highway route available, considering operating necessity and safety, or

(2) The motor vehicle is operated on a preferred highway under conditions described in paragraph (b) of this section.

The general routing rule was adopted with some change in wording from the proposed rule. The basic objective, however, remained the same: that the carrier examine all available highway routes and select one which minimizes radialogical risk to the public. In making this determination, the carriar must consider available information on the most important factors which contribute to the minimization of radiological risk. The rule identifies these factors as population, accident rates of available highways, transit time, and the time of day and day of week during which the shipm ent occurs.

The proposed-rule had also included such factors as terrain, physical feat ures, weather conditions, and effectiveness of local emergency planning, but these were deleted from the final rule for various reasons. The influance of terrain and physical features on public risk from transportation is reflected in the documented 
accident rates of the alternative roadways. Since these are only two of several factors which may contribute to overall highway accident rates, Dor did not believe they should be singled out for consideration by the curnier. Similarly, chronic weather conditions (e.8: winter snowfall) are reflected in overall highway accident rates. Short-term weather conditions, however, are a factor which the carrier cannot contral, which the carrier has little advance knowledge of, and which can change during the course of transportation. Therefore, consideration of short-term weather conditions would be speculative at best. Determining the effectiveness of local emergency planning was deleted as a consideration in route selection because of the subjective judgment that would be necessary and the lack of information available to the carrier. DOT belleves that effective emergency response planning is an activity that all communities should be inval ved in and the preamble to HM-164 aited several federal efforts to assist communities in this area.

The last major change to the proposed ganeral routing rule involved the replacement of the phrase "routes that risk radiological exposure to the fewest persons" with the phrase "routes that minimize radiological risk." The basic gral of the gener al routing rule is risk minimization. While limiting exposure to the lewest people possible is one element of overall risk reduction, it is not the only consideration.

Many of those who commented on the general routing rule took exception to what they called the non-specific, unquantifiable criteria carriers and drivers must evaluate in choosing a route which will minimize radiological risk. There was general agreement that placarded vehicles carrying other than large quantity radioactive material should not be forced to comply with the very specific routing rules established for those shipments, but no one offered a more acceptable rule to govern general routing requirements. While many commenters suggested that the 
lack of precise, quantiflable factors would enable curriers to operate at their own ciscretion, one industry association expressed its concern that the requirement to "minimize" radiological risk implied that only one route could qualify. With regard to the latter comment, DOT expressly acknowledged that more than one route could qualify as an acceptable alternative and that it was not incumbent on the carrier or driver to make detailed calculations in selecting the most appropriate route. With regard to the comment that a vague rule amounted to no rule, Dor pointed out that a certain degree of vagueness was unavoidable.

The general routing rule applies to thousands of shipments involving relatively low-hazard raciopharmaceuticals and other medical and industrial isotopes. Their transportation frequently involves multiple pickups and daliveries, interchanges with other modes of transport, and commingling with non-hazardous materials on the same vehicle. A general routing rule which can accommodate such a great number of shipments in such a complex transportation environment, necessarily involves some vagueness. By adoption of the general routing rule, DOT intended to guide motor carriers by specifying those important factors to be considered in evaluating a number of available routes.

Routing of Large Quantity/Highway Route Controlled Quantity Shipments

While the general routing rule described above engendered a great deal of public comment, the most controversial feature of HM-164 was its establishment of specific routing requirements for "large quantity ractioactive material." The definition of this term was set forth in the HMR at $\$ 173.389(\mathrm{~b})$. However, in a subsequent rulemaking action (Ref. 10) which became effective July 1, 1983, the term "large quantity radioactive material" was deleted from the HMR and the term "highway route controlled quantity radioactive material" was adopted in its place. The definiton of the new term is codifled at 49 CFR 173.403(1). The revision was 
necessary to ensire the compatibility of the HMR with the latest revised international standards for transport of radioactive materials. While there are some differences between the values for "large quantity" and "highway route controlled quantit.y" radioactive material, the differences do not materially affect the implementation of $\mathrm{HM}$-164. Therefore, this paper will discuss the provisions of HM-164 as amended to include the new terminology.

Under HM-164, specific routing requirements were established for highway shipments of highway route controlled quantity racioactive material (such as spent nuclear fuel). These requirements are codified at 49 CF $177.825(\mathrm{~b})$ :

(b) Unless otherwise permitted by this section, a carrier and any person who operates a motor vehicle containing a package of highway route controlled quantity racioactive materials as defined in $\$ 173.403(1)$ of this subchapter shall ensure that the vehicle operates over preferred routes selected to reduce time in transit, except that an Interstate System bypass or beltway around a city shall be used when available.

(1) A preferred route consists of-

(i) An Interstate System highway for which an alternative route is not designated by a State routing agency as provided in this section, and

(ii) A State-designated route selected by a state routing agency (see 5171.8 of this subchapter) in accordance with the DOT "Guidelines for Selecting Freferred Highway Routes for Shipments of Large Quantity Radioactive Materials".

(2) When a deviation from a preferred route is necessary (including em ergency deviation, to the extent time permits), routes shall be selected in accordance with paragraph $(a)$ of this section. A motor vehicle may deviate from a preferred route under any of the falowing circumstances:

(i) Emergency conditions that would make continued use of the preferred route unsafe.

(ii) To make necessary rest, fuel and vehicle repair stops.

(iii) To the extent necessary to pick up, deliver or transfer a highway route controlled quantity package of radioactive materials.

Briefly stated, HM-164 requires carmiers of highway route controlled quantity radioactive material to operate over Interstate System highways selected to reduce time in transit except where an available Interstate System beltway or bypass 
allows them to avoid city centers. Carriers are allowed off the Interstate System only under the circumstances described in $5177.825(b)(2)$ :

1. To follow a State-designated al ternate route;

2. In a documented case of emergency;

3. To make necessary stops for rest, fuel or vehicle repairs; or,

4. To travel to and from a pick-up or delivery site not located on an Interstate System highway.

In its notice of proposed rulemaling, DOT had discussed the technical basis for its reliance on the Interstate System of highways. Generally, the designation of these highways as preferred routes was based on an overall performance rating with respect to lower accident rates and their capacity for reducing transit times. For the most part, public comment expressed support for this proposal as well as the related provision allowing states the prerogative of modifying the preferred status of Interstate highways by designating other roads as acceptable alternatives.

Several commenters pointed out, and DOT acknowledged, that each of the 42,500 miles of Interstate highway is not sufficiently consistent in design, engineering or accident history to provide an even correlation between the statistical safety of the system's parts and that of the whole. This was one of the reasons for enabling the states to modify the preferred status of Interstate segm ents for which more acceptable al ternatives exist. As a basic routing system, however, even in the absence of state action, the Interstate highways are wellsuited $f \times x$ the use required by HM-164. They provide a baseline measure for states to use il determining whether potential alternative routes offer an equivalent or greater level of safety. This basic system of primary routes also supports emergency response planning by increasing the confidence of planners in their knowledge of routes to be traveled. 
The requirement that carriers of highway route controlled quantity shipm ents of radioactive material use an Interstate bypass or beltway to avoid urban centers was generally recognized by commenters to be a reasonable precaution. This requirem ent did not, however, receive unanimous approval.

Some commenters suggested that the use of beltways would not automatically result in the avoidance of all heavily populaied areas and that, during peak traffic hours, it may be less hazardous to direct shipments over an Interstate through route rather than a beltway. Another commenter pointed to situations where there were multiple beltways around a metropolitan area and expressed concern that HM-164 might allow carriers to operate over the shorter circumferential route, despite the availability of a second route with superior design standards and lower population density.

DOT responded to these concerns in two ways: First, it reaffirmed its belief that packages of highway route controlled quantity radioactive material could be transported over any Interstate highiway, and most other comparable routes, with a confident level of saf ety. Then, it stated forcefully that its reaffirmation was in no way intended to discourage state governm ents from adopting reasonable routing rules which increase this level of confidence. It was for this reason that HM-164 incl ided a mechanism for state designation of alternate routes.

\section{State Designation of Alternate Preferred Routes}

As stated earlier, DOT recognized that not all segments of the Interstate System of highways were of equal calibre and that in certain areas non-Interstate routes were available which could provide an equal or greater level of safety. DOT further acknowledged that the task of identifying preferable alternative local routes was best performed by the states and developed the mechanism for statedesignation of alternate routes which was referred to previously. 
As set forth in 49 CF $\mathrm{R} 177.825(\mathrm{~b})(1)(\mathrm{ii})$, carriers may operate over a statedesignated alternate route which is selected: (1) by a state routing authority and (2) in accordanca with DOT guidelines. These requirements are described below.

The term "state routing agency" is defined at 49 CFR 171.8 as follows:

"state routing agency" means an entity (including a common agency of more than one State such as one established by Interstate compact) which is authorized to use State legal process pursuant to $\$ 177.825$ of this subchapter to im pose routing requirements, enforceable by State agencies, on carriers of ractionctive materials without regard to intrastate jurisdictional boundaries. This term also includes Indian tribal authorities which have police powers to regulate and enforce highway routing requirements within their lands.

This definition does not include a bridge/tunnel/turnpike authority unless that authority is empowered to impose routing rules on state highways generally. This definition, however, may apply to more than one agency in a single state sharing responsibility for designating preferred highways. Routes designated by a state routing agency may be enforced by that agency or by any other appropriate state agency.

Many sommenters felt that local governments should be responsible for routing within their jurisaictions. First, they argued that local governments have the primary responsibility for protecting the health and safety of their citizens and therefore should determine whether routes through their jurisdictions are acceptable. Secondly, they argued that route selection was a site-specific process and that local officials were most knowledgeable about local road conditions. However, DOI saw both practical and safety problems associated with placing ultimate routing authority in the tens of thousands of local jurisdictions in this country.

DOT noted that local juriscictions are inherently limited in perspective with respect to establishing routing requirements. Because they are accountable only to their own citizens, local governments may not take sufficient account of the 
adverse impects of their routing decisions on surrounding juriscictions. Uncoorcinated and unilateral restrictions on the highway transportation of radioactive materials would simply not be conducive to safe transportation. Indeed, it was the proliferation of such restrictions which provided the impetus for DOT's developm ent of $H M-164$.

DOT believed that state governments could provide the key to ensuring that the safest routes were used to transport high-level radioactive materials. A state government has a much broader perspective than local governments because it is responsible for the safety and welfare of all its communities. A state can not only assess the safety impacts of a routing decision on all communities, but can also address the concerns of tunnel, tumpike and bridge authorities. States thus have the capability, through existing administrative and lawmaking procedures, to incorporate local input arectly into their routing analyses. At the same time, states have the capability of working with the federal government and are famillar with implementing regulations under a variety of federal programs.

Many local officials expressed concern that the states would not actively pursue local interests before designating routes. DOT considered establishing specific guidelines to ensure a formal procedure for local consideration, but found that this approach was impractical given the variations in organizational structure and administrative processes from state to state. Instead, DOT took two steps to ensure consideration of local viewpoints. First, it established a general requirement that states consult with affected local jurisoi ctions before designating an alternate preferred route. Second, it developed a set of guidelines to assist states in assessing the saf ety of potential alternate routes. DOT included both steps in its definition of what constitutes a state-designated route: 
"State-designated route" means a pref erred route selected in accordance with U.S. DOT "Guidelines for Selecting Pref erred Highway Routes for Large Quantity Shipments of Radioactive Materials" or an equivalent routing analysis which adequately corisiders overall risk to the public. Designnation must have beran preceded by substantive consultation with affected local juristictions and with any other af fected States

: to ensure consideration of all impacts and continuity of designated routes. (49 CF R 171.8).

One other change to the HMR affects the selection of highway routes for radioactive materials. It concerns the use of urban vehicular tunnels used for mass transportation. Prior to the adoption of HM-164, S177.810 of the HMR stated explicitly that no requirement of the HMR should be so construed as to nullify or supersede state or local regulations regarding the kind, character or quantity of any hazardous material permitted to be transported through any such tunnel. Under HM-164, \$177.810 was revised to except radioactive materials from state and local requirements that restrict their transportation through urban vehicular tunnels used for mass transportation. This action was taken to facilitate accomplishment of the basic objective of the general routing rule to minimize racialogical risk and to allow the states flexibility to designate preferred routes for large quantity shipm ents.

With regard to highway route controlled quantity shipments, DOT took the position that tunnel restrictions should not be based merely on the nature of the facility but on the overall risks between available routes, and that such restrictions should be imposed only by an agency with state-wide responsibilities which permit adequate consideration, of nther alternative routes. Therefore, use restrictions on tunnels should not be determined solely by facility operators. Instead, the use of tunnels should be available for consideration as possible alternatives in the state process of route designation. The amendment to $\$ 177.810$ was necessary to enable states to evaluate the site-specific risks involved over various routes without being hampered by locally imposed constraints which could be counterproductive. 
In the absence of a state routing agency's action to review the status of tunnels located within its jurisdiction, carriers of highway route controlled quantity radioactive material are generally limited to such facilities that are part of an Interstate System highway. Other placarded carriers can use such facilities only after considering the safety factors specified in $\$ 177.825(\mathrm{a})$, the general routing rule.

Shipping Papers

For purposes of identification and enforcement, HM-164 added a requirement that shippers enter "Large quantity" as part of the hazardous material description on the shipping paper. This requirement, set forth at $\$ 172.203$ (d)(1)(iii) of the HMR, was subsequently amended by $H M-169$ to reflect adoption of the term "highway route controlled quantity." The purpose of the additional description on the shipping paper is to alert the carrier that he has received a package of radioactive material for which routing controls are required and that a route plan must be prepared.

Placarding

Under $H M-164$, vehicie identification requirements were added to Part 172 of the HMR to require a white background for the RADIOACTIVE warning placard. The white background was devised to aid enforcement personnel in distinguishing highway route controlled quantity shipments from other placarded shipments for which the use of preferred routes is not required. 
Route Plans

An essential component of $\mathrm{HM}-164$ is the route plan which must be prepared by the carriar (or his agent) for each shipment of highway route controlled quantity radioactive materials. This requirement is codified at 49 CFR 177.825(c):

(c) A carrier (or his agent) who operates a motor vehicle which contains a package of highway route controlled quantity racioactive materials as defined in $\$ 173.403(1)$ of this subchapter shall prepare a written route plan and supply a copy before departure to the motor vehicle driver and a copy to the shipper (before departure for exclusi ve use shipm ents, or otherwise within fifteen working days following departure). Any variation between the route plan and routes actually used, and the reason for it, shall be reported in an amendment to the route plan delivered to the shipper as soon as practicable but within 30 days following the deviation. The route plan shall contain-

(1) A statement of the origin and destination points, a route selected in compliance with this section, all planned stops, and estimated departure and arrival times: and

(2) Telephone numbers which will access em ergency assistance in each State to be entered.

DOT acknowledged that a great number of variables had to be considered in route planning when one looked at the aggregate of total packages, multiple shipping locations and widespread destinations. However, for any particular shipment, the routing possibilities are limited by the safety criteria established under HM-164 and the practical alternatives such as available roadways. For these reasons, DOT did not believe that the requirement imposed any severe administrative burdens beyond the capacity of the carriers, nor did it have cause to expect that carriers woul be indiscriminate in their selection of routes. Furthermore, DOT recognized that the interest of shippers in ruuting decisions would be very influential in the final selection.

Under the provisions of $\$ 177.825(c)$, the carrier is responsible for peparing a route plan and proviaing copies to the driver of the transport vehicle and to the shipper. Under the provisions of $\$ 173.22$, the shipper is responsible for providing a copy of the route plan to DOT within ninety days following the shipment. The 
- purpose for this requirement was to enable DOT to consolidate the information contained in the route plans for use by interested parties, especially state and local governments.

During the course of the rulemaking, there was an almost unanimous call from state and local officials seeking information contained in the route plan prior to the actual transfer of the radioactive materials. None of these suggestions was adopted. DOr stated that the call for prenotification would be satisfied by the then-on-going rulemaking of the Nuclear Regulatory Commission (NRC). That rulemaking (Ref. 11) has since been adopted by the NRC and provides for advance notification of each state through which spent nuclear fuel or other high-level waste is to be transported.

Driver Training Requirements

Requirements for driver training and certification, as adopted under HM-164, are codtfied at 49 CFR 177.825(d). Restated briefly, the driver of a vehicle transporting highway route controlled quantity radicactive material is reguired to have been trained, and to have in his immediate possession a certificate evidencing his having trained, in the following:

(1) The requirem ents of the HMR pertaining to radioactive materials in Parts 172 (hazardous materials communications), 173 (general requirements for shipments and packagings), and 177 (carriage by publie highway t:

(2) The properties and hazards of the radioactive materials being transported; and

(3) Procedures to be followed in case of an accident or other em ergency.

Evidence of such training is also required to be placed in the diver's qualification file which the motor carrier must maintain in accordance with the Peder al Motor Carrier Safety Regulations (49 CF R 391.51). 
These requirements were besed on DOT's established policy regarcting hazardous materials driver training, i.e. to require that training be provided for the material involved and that the training program be implemented within the general guidelines provided by DOT. Any driver training requirement must be able to accommodate the many variables involved in hazardous materials transportation such as: the different materials and hazards associated therewith; differences among drivers! knowedge and experience; and the wide differences in the effectiveness of various training methods. For this reason, DOT determined that the driver training requirements of HM-164 should be of a general nature, thereby allowing the flexibility to develop individualized training programs that will accomplish the Department's stat ed saf ety objectives.

\section{Physical Security Plan}

HM-164 requires motor carriers to transport shipments of irradiated reactor fuel in compliance with a physical protection plan established by the shipper:

(e) A person may transport irradiated reactor fuel only in compliance with a plan if required under $\mathbf{S} 173.22(\mathrm{~b})$ of this subchapter that will ensure the physical security of the material. Variation for security purposes from the requirements of this section.is permitted so far as necessary to meet the requirem ents imposed under such a plan, or otherwise imposed by the U.S. Nuclear Regulatory Commission :' 10 CF R Part 73. (49 CFR.177.825(e)).

Under $\$ 173.22(b)$, shippers are required to provide physical protection under either a plan required by the NRC (Ref. 12) or an equivalent plan approved by MTB. These plans, as approved by NRC or $\mathrm{N}^{\prime} \mathrm{I}^{\prime} \mathrm{B}$, may sometimes invalve transportation requirements different from those specified in $\$ 177.825$ but designed to assure at least an equal measure of protection to public safety, and they take precedence over the other rules published in $\$ 177.825$.

Shipments affected by this requirement include those made by any NRC licensee, and consignments from the Department of Defense (DOD) and the 
Department of Ẹnergy (DOE) transported by for-hire carriers (except defenserelated shipments accompanied by personnel specifically designated by or under the authority of those agencies to preserve national security). This exception was not newly created under HM-164. The HMR (at SS 173.7(b) and 177.806(b)) previously established an exception in the case of shipments escorted by personnel specifically designated by or under the authority of DOD or DOE, for the purpose of national security, which freed common and contract carriers from compliance with the HMR. Consequently, HM-164 requires the respective departments (unless they perform the transportation with their own vehicles) to either submit copies of their physical protection plans to MTB for approval, or, when necessary to preserve the national security, provide an escort of personnel specifically designated by or under their authority. Shipments of irraciated reactor fuel by DOE in support of its research and development activities are not generally considered by DOT to be carried out to preserve national security (as opposed to defense-related shipments made by both DOD and DOE) and are therefore subject to the HMR.

Appecix A

In addition to the requirements described above, HM-164 contained an Appendix A to Part 177 of the HMR which set forth the Department's views regarding the preemptive effects of the routing rules. The Appendix provides that the Department generally regards state and local requirements to be inconsistent if they:

- prohibit the highway transport of large quantity radioactive materials without providing for an alternative highway route for the duration of the prohibition;

- require additional or special personnel, equipm ent, or escort;

- require additional or different stripping paper entries, placards, or other hazard warning devices; 
- require fling route plans or other docum ents containing information that is specific to individual shipments;

- require prenotification;

- roquirement accident or incident reporting other than as Immediately necessary for emergency assistance; or

- unnecessarilly delay transportation.

Appendix $A$ is not a regulation which imposes obligations to act. It is the Department's interpretation of the general preemptive effect of its regulation on state and local requirements. It was not intended to replace the two-prong test for determining the inconsistency of an existing state or local rule. Rather, it was intended to advise state and local governments contemplating rulemaking action as to the likelihood of such actions being deemed inconsistent.

\section{RECENT INCONSISTENCY RULINGS}

Following DOT's adoption of HM-164 and the flurry of litigation it prompted, questions inevitably arose as to the consistency or inconsistency of specific state and local rules on transportation of radioactive materiais. More than a dozen inconsistency ruling proceedings have been initlated. In November of 1984, DOT lasued nine related rulings (Ref. 13) dealing with state and local restrictions in Michigan, New York and Vermont which had effectively blocked the transportation of spent nuclear fuel which Canada was treaty-bound to return to the United States.

Those rulings expanded and refined DOr's earller statements or what it regards as appropriate or inappropriate matters for state and local regulation. A review of the findings made in those rulings should provide a better understanding of DOT's view of the regulatory rale of state and local governments. It will also reveal what might be anticipated in future inconsistency rulings. 
Of the rilne rulings, two resulted in a finding of no inconsistency. These were decided primarily on procedural groinds and are not particularily instructive. The other seven rulings involved substantive regulatory schemes whitch had many factors in common and can best be summarlzed by topic.

Definition of "Radioactive Materlalg" - Three furlsdictions established their own distinctive definition of radioactive materlal. In earliex inconsistency rulings, DOI' had found the Federal role in hazard class defintition to be exclusive. ("The key to hazardous matertals transportation safety is precise commuication of risk. ") Therefore, those provisions which defined "radioactive materlal" otherwise than defined in the Federal regulations were found to be inconsistent.

Assertion of Intent to Regulate - All seven Jurlsdictions elther implited or expressly stated an intent to regulate the transportation of radfoactive materials. The language of the IMIA's premption proviston clearly indicates that Congress did not intend to preclude all state or local regulations, but only those that are inconsistent. Therefore, those provisions which express an intent to regulate were found to be filly consistent with the IMTA.

Prenotification/Permit Requirement - All sever jurisdictions required some form of transportation permit linked to a prenotification requirement. Where the state/local prenotiffcation requirement was the same as the Federal requirement, the provision was found to be, in effect, an adoption of the Federal. mule and, therefore, fully consistent. Where it differed from the Federal requirement, either by requiring the same information to be submitted to different parties, or by requiring submission of additional imformation, documentation and/or certifications, the provision was foumd to be inconsistent. Provisions which prohibited the Interstate transportation of radioactive materials without a state/local permit were found to be inconsistent per se. 
In reaching these findings DOT relied on the ex/4" enacting the preemption provision of the HMTA: "...to preclude a multiplicity of state and lọeal regulations and the potential for varying as well cos conflicting regulations in the ares of hazardous materials transportation." By adoption of HM164, the Department established a national system of highway routing for racioactive materials, one in which the low and equitably distributed level of risk from transportation is far outwelghed by the societal benefits derived from that transportation. This natlonally uniform system of highway routing would be completely nullified if interstate carriers of racioactive materials were unable to proceed until they had satisfied the inflinitely diverse advance notiflcation and permit application requirements of every jurisciction along the route to be traveled.

Additional Personnel, Equipment, Escorts, etc. - Six jurisciations called for transporters of radiouctive materials to devote additional resources in the form of personnel and equipment or reimbursement for those additional resources the jurisciletion chose to provide. In each case, the state/local requirement differed from the Federal requirement and was, therefore, found to be inconsistent. The basis for these rulings is the same as described in the foregoing discusston of prenotification/permit requirements. Absent the showing of a unique local safety problem, no justification exdsts for requiring personnel, vehiales or equipment in excess of that level of resources deemed to be adequate for transportation safety on a national basis.

Additional Packagmg/Container Reguirements - In one case a state agency imposed additional design and test criteria on shipping casks used to transport spent fuel over certain major bridges and waterways. Asserting that the Federal standards 
were Inadequate to meet. local conditions, the state chose this method to overcome the perceived Federal Inadequacy. Prior inconsistency rulings have firmly established the exclusive Federal role in hazardous materials containment systems. Such unilateral imposition of design changes on a shipping container as complex as a spent fuel cask is incompatible with safe, efficient interstate transportation. If, as the state alleged, the Federal standards are inadeguate, the state has recourse to three (possibly concurrent) alternatives to the imposition of independent design requirements: (1) petition for a waiver of preemption; (2) petition for rulemaking to change the Federal standard; and (3) designation of alternate highway routes which avoid major bridges. For these reasons, the additional design and test requirements were found to be inconsistent.

Insurance Requirements - Five jurisdictions required levels of insurance which exceeded those established by Federal law. In the course of developing $\mathrm{HM}-164$, the Department examined the issue of indemnification and concluded that Federal law provided adequate coverage. In the absence of a clear showing that the transportation of radioactive materials through the enacting jurisctiction poses a financial risk which exceeds the level of indemnification provided by Federal law, such requirements impede the nationally uniform system of highway routing established under the HMTA. By denying use of preferred routes to transporters who have not met local insurance requirem ents, such requirements have the effect of diverting such shipments into other juriscictions. While a community may seek to reduce its exposure to the risks inherent h. such transportation, it may not do so by exporting that risk to its neighbors. For the foregoing reasons, the requirem ents for additional insurance coverage were found to be inconsistent. 
Transport Inspection - In two cases the state requirements included express provisions concerning inspection of radioactive materials transports to ensure compliance with applicable state and Federal laws. While noting that a state rule was "applicable" only if consistent, the Department found that such provisions represented a legitimate exercise of the state's inherent police powers. State enforcement of Federal and (consistent) state regulations on hazardous materials transportistion is a critical element of a regulatory system of national applicability. Accordingly, both provisions were found to be funy consistent with the HMTA and the Federal regulations.

\section{CONCLUSION}

DOT has devoted several years to developing HM-164 and defending various challenges to its validity. To date, no evidence has been presented which rebuts the Department's conclusion that, when federal sules are complied with, high level radioactive waste can be transported over aniy Interstate highway, and most other comparable routes, with a confident level of safety.

\section{REFERENCES}

1. "Radioactive Materials; Routing and Driver Training and Routing Exemptions," Final Rule, 46 FR 5298, January 19, 1981.

2. Hazardous Materials Transportation Act, 49 U.S.C. 1801 et seg.

3. Senate Report No. 1192, 93d Congress $2 d$ Session (1974).

4. Ibid., pp. 37-38.

5. 41 FR 38167 , September 9, 1976.

6. Ray v. Atlantic Richfield Co., 435 U.S. 151, 158 (1978).

7. IR-1, 43 FR 16954, April 20, 1978.

8. "Highway Routing of Radioactive Materials; Inquiry", 43 FR 36492, August 17, 1978. 
25

9. "Highway Routing of Radioactive Materials; Proposed Rulemaking." 45 FR 7140, January $31,1980$.

10. "Requirements for Transportation of Radioactive Materials" 48 FR 10218, March 10, 1983.

11. Advance Notification to Governors Concerning Shipments of Irradiated Reactor Fuel", 47 FR 603, January 6, 1982; codified at 10 CFR, Part 73.

12. "Physical Protection of Irradiated Reactor Fuel in Transit", 45 FR 37399, June 30, 1980; codified at 10 CFR, Part 73.

13. IR -7 through 15, 49 FR 46632, November 27, 1984. 
APPENDIX B 


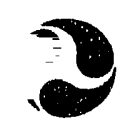

1.S. Department If. Transportation :esearch and pecial Programs :dministration

\section{Guidelines for Selecting Preferred Highway Routes for Highway Route Controlled Quantity Shipments of Radioactive Materials}




\section{GUIDELINES FOR SELECTING PREFERRED HIGHWAY ROUTES FOR HIGHWAY ROUTE CONTROLLED QUANTITY SHIPMENTS OF RADIOACTIVE MATERIALS*}

"NOTE: This publication was formerly titled "Guidelines for Selecting Preferred Highway Routes for Large Quantity Shipments of Radioactive Materials (DOT/RSPA/MTB-81/5), dated June 1981. 
FOREWORD 1

1.0 INTRODUCTION 1

2.0 METHODOLOGY OVERVIEW 2

2.1 Route Comparison Factors 3

2.2 Route Selection 7

3.0 METHODOLOGY APPLICATION $\quad 9$

3.1 Identifying Alternative Routes 11

3. 2 Evaluation of Comparison Factors 11

PRIMARY ROUTE COMPARISON FACTORS

3.2.1 Norma1 Radiation Exposure 13

3.2.2 Public Health Risks from Accidents 15

3.2.3 Economic RIsks from Accidents 20

SECONDARX ROUTE COMPARISON FACTORS

3.2 .4 Emergency Response 21

3.2 .5 Evacuation $\quad 23$

3.2 .6 Special Fac1lities $\quad 25$

3.2.7 Traffic Fatalities and Injuries 27

3.3 Selection of Preferred Route 28

4.0 SAMPIE CASE 29

4.1 Calculation of Primary Factors 33

4.2 Estimation of Secondary Factors 35

4.3 Route Selection in Sample Case 36

APPENDIX A - BLANK, REPRODUCIBLE WORKSHEETS A-1

APPENDIX B - DERIVATION OF REIEASE CONSEQUENCE ESTIMATE B-1

APPENDIX C - DERIVATION OF ECONOMIC COMPARISON FACTOR C-1

APPENDIX D - DERIVATION OF NORMAL EXPOSURE MODEL D-1

APPENDIX E - DERIVATION OF EVACUATION COMPARISON FACTOR E-1.

APPENDIX F - BIBLIOGRAPHY AND REFERENCES F-1 


\section{TABLES}

$\because 2-1$ CONVERSION FACTORS FOR USE IN ESTIMATING NORMAL $\frac{\text { PAGE }}{14}$
RADIATION EXPOSURE FACTOR

3.2-2 RELEASE CONSEQUENCE MEASURE

3.2-3 ECONOMIC CONSEQUENCE MEASURE

3.2-4 EMERGENCY RESPONSE PARAMETER SCALING SYSTEM

3.2-5 EVACUATION PARAMETER EVALUATION

3.2-6 SPECIAL FACILITY EXAMPLE

4.1 DESCRIPTIVE DATA FOR ROUTE A

4.2 DESCRIPTIVE DATA FOR ROUTE B

FIGURES

4.1. ROUTES USED IN SAMPLE CASE APPLICATION 


\section{FOREWORD}

The Department of Transportation has established specific highway routing requirements for certain radioactive materials. These requirements are extensively discussed in the January 19, 1981, Federal Register (Docket HM-164, 46 FR 5298). In addition to the requirement that carriers follow "preferred routes" which will be discussed further, the carrier must prepare and file route plans, provide specialized driver training related to radioactive materials and emergency response, and comply with security requirements of the Nuclear Regulatory Commission (or equivalent requirements as approved by DOT) when appropriate.

"Preferred routes" are defined in the rules as any route designated by a "State routing agency" (see definition in 49 CFR Sec. 171.8) and any Interstate System highway for which an alternate highway has not been designated by a State agency. In recognition of the many site-specific factors involved in selecting the safest available highway routes, DOT is strongly encouraging the States to examine their own highway network and designate "preferred routes" to supplement the Federally-prescribed Interstate highway system, or provide suitable alternatives to portions of the Interstate system. The purpose of this document is to provide State officials with a set of guidelines which will identify the important factors involved in a routing analysis, and assist in their selection of routes which result in the lowest public risks from the transportation of highway route controlled quantity radioactive materials.

The routing requirements apply to highway shippers and carriers of "highway route controlled quantity" packages of radioactive materials. "Highway route controlled quantity" is a term specifically defined in the Federal Hazardous Materials Regulations (49 CFR Parts 171-179) in Section 173.403(1). Whether or not a package contains a highway route controlled depends upon the radionuclide in the package, the activity of the radionuclide as measured by the number of curies present, and the form of the radionuclide (dispersible or not). These packages can be identified by the shipping paper, which must accompany each shipment, and the warning placard on the vehicle. The shipper paper must contain the term "highway route controlled quantity" in association with the material description required for any shipment of radioactive material. A highway route controlled quantity shipment can also be uniquely identified by the square white background which is required for the standard 
radioactive material vehicle placard. Although many different radioactive materials could be packaged such that they would meet the definition of highway route controlled quantity, most of these shipments can be identifled as either irradiated reactor fuel (spent fuel) from a nuclear power plant, certain large source medical shipments such as Cobalt-60 for teletherapy uses, and possibly some other large source industrial isotopes.

These guidelihes were development in part under contract with DOT by Battelle Pacific Northwest Laboratories, a research organization which has conducted numerous risk studies in radioactive material transportation. The Department also received helpful information in developing the guidelines through pilot tests conducted with the help of State officials in Oregon and California. The U.S. Nuclear Regulatory Commission provided some useful guidance in their review of the draft guidelines.

It is important to emphasize that the guidelines presented in this document do not represent the only method of conducting an adequate routing analysis. Under the regulatory scheme established by the routing requirements, the States are extended considerable flexibility in carrying out the routing function as exemplified by the following definition found in Sec. 171.8:

"State-designated route" means a preferred
route selected in accordance with U.S. DOT
"Guidelines for Selecting Preferred Highway
Routes for Highway Route Controlled Quan-
tity Shipments of Radioactive Materials" or an
equivalent routing analysis which adequately
considers overall risk to the public (emphasis
added). Designation must have been pre-
ceeded by substantive consultation with
affected local jurisdictions and with any other
affected States to ensure consideration of all
impacts and continuity of designated routes.

The important point is that the State adequately considers public risk to all those who may be affected by radioactive material transportation. The Department believes that these guidelines identify the important risk ractors to consider and provide one methodology of estimating these risk factors for the purpose 
of Identifying the lowest risk route. States may be able to develop a better method of risk assessment or Identify other important risk factors relating to pecullar situations,

It is also important to emphasize that the methodology presented in this document is not a true risk analysis in that actual risk figures are not developed. As will be covered in more detall, risk factors developed under these guidelines are for comparative purposes only. Risk index figures are developed in order to compare routes and identify the highway which is likely to minimize the transportation impact associated with these materials. The comparative figures are computed by simplifying certain factors that are not route-specific. Nevertheless, the risk factors are representative of the actual risk involved and are believed to be valld for the purpose of route selection.

Various studies have been conducted to assess the actual risk involved in the transportation of radioactive materials. Perhaps the most comprehensive study was completed for the NRC by Sandia National Laboratorles entitled "Final Environmental Statement on The Transportation of Radioactive Materials by Air and Other Modes" (NUREG-0170). In order to estimate risk to the U.S. population, this study required the development of sophisticated computer models to account for such factors as the health effects resulting from both external and internal radiation sources; the atmospheric dispersion of materlals released from a damaged package; the severity of an accident involving nuclear shipments and the resulting damage to a package; and the fraction of material released from the damaged package. This type of analysis is far beyond the capacity and resources available to a State routing agency and is beyond the scope and purpose of these routing guidelines. NUREG-0170 and other risk studies have concluded that the risk from the transportation of radioactive materials are quite low by any measure of comparison. The intent of the Department's routing regulations and the guidelines presented here is to minimize the public risk even further by providing for the use of the safest available highway routes.

States are required to solicit and consider input from other jurisdictions which are likely to be impacted by a routing decision. This will necessitate coordination with local government authorities along the prospective routes of travel and with other adjacent State Authorities to ensure continuity of designated routes. 
The manner of consultation with local governments as well as publle participation is left to the discretion of the State governiment. However, DOT encourages the State to provide public notice, opportunity to comment and a hearing if justifled. The State should consider making individual notifications to appropriate local jurisdiotions. One possible procedure to ensure adequate local consultation would be to establish a State advisory group composed largely of elty and county officials. The purpose of this group would be to provide oversight of the route designation proces to ensure meaningiul State/local cooperation.

Coordination with other State routing authoritles may be a orucial factor in selecting highway routes for large quantity radioactive materials. Obviously it is essential that designated routes match up a State borders. It is DOT's opinion that interstate or regional coalltions for the designation of routes may be the most effective way of ensuring continuity. Also, States may want to enter into an agreement designating as a portion of the preferred route a ferry route for the transport of motor vehioles on waters within the Jurisdictionis of those States. 


\section{INTRODUCTION}

This document presents guldelines for use by state offlolals in selecting preferred routes for highway controlled quantity shipments of radloactive materials. A methodology for analyzing and comparing safety factors of alternative routes is described. Technical Information on the impacts of radioactive material transportation needed to apply the methodology is also presented. Applloation of this methodology will identify the route (or set of routes) that minimizes the radiological Impacts from shipments of these radioactive materials within a given State. Emphasis in this document is on practical application of the methodology. Some detalls of the derivation of the methods and data are pregented in the appendices. All references in the body of this report can be found listed in the Blbllography (Appendix F).

This guide is organized in three main sections. The route selection methodology is reviewed in Section 2. Section 3 describes the application of the methodology and presents technical data needed to evaluate the safety factors that form the basis for the route selection process. The use of these safety factors to select preferred routes is also discussed. A sample case lllustrating the application of the methodology is presented in Section 4. Worksheets to facilitate application of the method and documentation of the analysis are contained in an appendix. A bibliography of general reference materials on radioactive material transportation is also provided. 


\section{METHODOLOGY OVERVIEW}

Implementation of the routing regulations for highway shipments of radioactive materials necessitates a methodology for seleoting preferred routes. This methodology is needed to provide a basis for State agencles to select among alternative routes avallable within the state. A number of factors can be important in comparing avallable routes. The methodology needs to provide a comprehensive treatment of these factors. It may also be that some comparison factors important in choosing preferred routes may vary acoording to the circumstances in the State in which they are being applied. The methodology therefore needs to provide the flexibility to treat these varied situations, as well as provide for consistent application from State to State. The methodology needs to be straight-forward to apply and should not require expertise beyond that normally found in State regulatory agencles.

The general methodology developed to meet these needs is based on a common decision-making approach consisting of six basic steps. These steps and their application to a routing analysis are outlined below:

Steps

1. Define objective

2. Identify courses of action to meet the objective

3. Identify factors (attributes) that could affect the objective

4. Evaluate the attributes in relation to the objective for each course of action

5. Select the alternative that best satisfies the objective

6. Document each step in the analysis
Routing Analysis

- Determine highway route that minimizes Impacts

- Identify alternative highway routes avallable

- Develop list of route comparison factors

- Evaluate route comparison factors for each alternative highway route

- $\quad$ Select route that best minimizes impacts based on evaluation of route comparison factors

- Document entire routing analysis to serve as the basis for the routing decision 
The application of this methodology will be discussed in more detall in Section 3. First, however, it is appropriate to introduce two key elements of the routing analysis -identification of the route comparison factors and the process of selecting a preferred route based on these factors.

\subsection{Route Comparsion Factors}

The risk from transportation of radioactive materials can be affected by a number of factors. These factors can be categorized as elther radiological impacts or non-radiological impacts. Also, certain actions which have the potential of mitigating exposure to radioactive materials.

Radiological impacts are those associated with the accidental release of radioactive materials during transportation and its effect on the surrounding population and property. It also includes a consideration of the effects on surrounding population of low levels of radiation emitted during accident-free transportation (of ten called normal exposure).

Non-radiological impacts are those associated with transportation by any heavy truck and its effect on surrounding population (primarly other motorists) and property. These impacts are unrelated to the radiological nature of the cargo. An example is a truck accident resulting in death, injury or property damage when there is no release of radioactive material.

Other factors, although not directly related to either radiological or nonradiological risk, can be important to consider for the purpose of selecting a highway route. These factors, such as effectiveness of emergency response activities, evacuation capabilities, and avoidance of certain special facilities, can serve to reduce radiological consequences, primarily consequences from accidents. These actions however, are most important after an accident has already occurred. 
The objective of this routing analysis is to determine the route which will minimize the radiological impacts. It is believed that the primary emphasis in route selection should be placed on the risk which is associated with the radiological nature of the cargo. This approach will result in the selection of a route that will minimize both normal exposure and the accidental release of radioactive materials so that mitigating factors such as emergency response may not be necessary. Consequently, the following factors are considered the primary route comparison factors:

- Radiation exposure from normal transport

- Public health risk from accidental release of radioactive materials

- Economic risk from accidental release of radioactive materials.

All other factors are considered secondary to the basic goal of minimizing the radiological risk from transportation. These factors may be useful to consider in the route selection process, but only after careful analysis reveals that alternative routes have essentially the same level of risk based on the three primary comparison factors. The following are therefore considered secondary comparison factors:

- Emergency response effectiveness

- Evacuation capabilities

- Location of special facilities such as schools or hospitals

- Traffic fatalities and injuries unrelated to the radioactive nature of the cargo

Each of these factors is discussed in more detail below. Suggested methods for evaluation of these factors are described in Section 3.2 of this report. It is believed that these seven factors represent the most important impacts to consider for the purpose of conducting a comparative risk assessment to identify preferred routes. Other factors that may be important in a particular application of the methodology may be identified by the state agency responsible for the route 
selection process. It is important that the State document the reasons for considering additional factors and that consistent methods for evaluating these factors be developed. It is also expected that some of the secondary factors identified above may not be important in all applications. These factors may be deleted from the analysis as the case may be.

A brief discussion of each of the route comparison factors follow.

\section{PRIMARY RISK FACTORS}

- Normal radiation exposure. Shipping packages containing radioactive materials emit radiation during transport. Sufficient shielding must be contained in the package to reduce this radiation to safe levels as specified in DOT regulations. These levels still result in exposure of people along the route to small amounts of radiation. Although these levels of radiation are not expected to adversely affect the exposed population, it is still prudent to minimize the exposures. The exposures could vary significantly among available routes and therefore is one impact to consider for route selection.

- Public health risks from accidents. Highway route controlled quantity shipments contain amounts of radioactive materials that are potentially harmful to the public if released. For this reason, these materials may only be transported in shipping packages designed to isolate the materials from the public, even in severe transportation accidents. It is theoretically possible, however, that a truck carrying $a_{1}$. of these packages could be involved in an accident that creates forces beyond the package design standards. Principal differences affecting public health risk from one route to another are: 1) the frequency of severe transportation accidents, and 2) the number of people that could be affected by a release of radioactive material in an accident. 
Economic risk from accidents. A very severe transportation accident could also result in contamination of nearby property. If contamination exceeds safe levels, it would have to be removed or otherwise reduced to safe levels before that property could be returned to normal use. The cost of these decontamination operations varies considerably for the kinds of property that could become contaminated. The fraction of each kind of property along each route provides a way of determining potential differences in economic consequences from accidents. The frequency of severe transportation accidents which could cause contamination must also be considered.

\section{SECONDARY FACTORS}

Emergency response capabilities. If a severe transportation accident results in radioactive material being released from the shipping package, actions by emergency response personnel can mitigate the potential consequences from the release. The effectiveness of these measures is generally dependent on the time required for emergency response units to reach the accident scene. Response times could vary significantly among available routes.

- Evacuation. One method of mitigating the consequences of a radioactive material release is to evacuate the people that could potentially be exposed to the material. The time and effort required to evacuate a segment of the population may be different among the available routes. Evacuation is often ordered as a precautionary measure if an accident occurs, even if a release has not been confirmed. Evacuation has economic impacts which may also be considered in comparing available routes.

- Location of special facilities. Some private and public facilities along transportation routes contain populations requiring special consideration when analyzing the potential effects of accidental 
releases of radioactive materials or exposure during normal transport. These facilities contain populations that are either large (such as stadiums), may be more sensitive to radiation (such as schools) or are difficult to evacuate (such as hospitials). The number and type of such facilities provides a basis for comparing alternative routes.

- Traffic fatalities and injuries. Trucks carrying radioactive materials can be expected to be involved in traffic accidents, just like other vehicles. Only very severe accidents have the potential to result in release of radioactive materials. Many accidents will result in injuries and fatalities, however, similar to any heavy truck accident. Routes that minimize these accidents may be preferred because these accidents could result in negative effects on public attitudes concerning these shipments. Public safety officials may be more inclined to initiate precautionary "evacuations" in accidents that have resulted in injuries or fatalities even in cases where thele is no release of radioactive material.

\subsection{Route Selection}

Previous risk studies on radioactive material transportation have shown that the most important impacts are associated with normal radiation exposure, radiation exposure from releases of radioactive materials in transportation accidents and economic impacts from property cleanup following such accidents. These "primary" route comparison factors will form the basis for route selection decisions. The remaining' or "secondary" factors could be used if no clear-cut choice emerges from evaluation of the primary factors or if unusual conditions exist in the State that increase the importance of one or more of the secondary factors.

In many applications of the route selection methodology, one of the primary factors may favor one route, while others favor a different route. A method is needed to combine the various route selection parameters to arrive at an overall figure of merit for each route. In the approach used in this guidebook, the values 
of the primary comparison factors are converted to unitless fractions and then summed for each route to arrive at the overall figure of merit. Because the comparison factors measure levels of potentially adverse impacts, the route with the lowest figure of merit would be selected as the preferred route. This process will be demonstrated in the sample case presented in Section 4.

In some cases there may be very little difference between the figures of merit computed for alternative routes. In other words, the level of radiological risk to public health and property may be essentially the same for the prospective routes. In this case, it may appropriate to consider one or more of the more subjective secondary factors to distinguish between the routes. This is an. important decision to be made by the State of ficials conducting the analysis based upon the particular circumstances involved. 


\section{METHODOLOGY APPLICATION}

The methodology described in the previous section will facilitate the selection of preferred routes for highway route controlled quantity shipments of radioactive materials. The methodology provides the flexibility needed for the variety of situations that will be treated under the routing regulations. It parallels the decision-making process normally followed by a regulatory agency in making these decisions. It should facilitate documentation of the decision-making process and participation of the public, other State agencies and local jurisdictions in the route selection process. Application of the methodology would follow the basic steps outlined below:

1) Determine routes potentially available for shipping materials between the points being considered in the analysis.

2) Evaluate each primary comparison factor for each route, using the information presented in Section 3.2, data on the routes being considered and input from other agencies and local jurisdictions impacted by the decision.

3) Apply the route selection approach presented in Section 3.3 to select the "preferred" route.

4) Document the route selection process.

5) Obtain public comment and appropriate reviews or approvals of other agencies and affected local jurisdictions.

The information needed to perform the analysis may be held by a number of different State or local agencies. The lead agency for the route selection process will need to establish liaison with other involved agencies early in the route selection process. Some basic information needed to evaluate the primary route comparison factors includes: 
- Accident frequencies (accidents/vehicle mile) for each route.

- Traffic counts on each route

- Average vehicle speed on each route

- Population distribution along each route

- Land use data along each route

In addition, if secondary factors are to be evaluated, information such as the following is needed:

- Location and capabilities of organizations near the routes that would be involved in emergency response or evacuation

- Location of special facilities such as schools, hospitals, stadiums and nursing homes.

The agencies that collect and use this information will vary from State to State but may include the equivalent of the state highway or transportation department, the state police or highway patrol, the public utility commission, the radiological protection agency, state and local emergency service units, state and county planning agencies, and the state energy agency. Other information needed in the route selection process is included in this guide.

The methodology can be applied whenever two or more routes are potentially available for designation as a preferred route connecting two points in the State. The Interstate system highways are Federally preferred routes unless the State wishes to designate alternate routes in accordance with these guidelines or an equivalent routing analysis. Consequently, although not necessary, the State may wish to apply this methodology to all Interstate highways for comparison to other available non-Interstate alternatives. The route selection method deseribed in this guide would also be useful when it is desired to designate additional preferred routes. An example of a situation where additional preferred routes might be beneficial is the case of a nuclear power plant that is located some distance from an Interstate highway. Designating a preferred route from the plant would assure that these shipments are made over a route that has been shown by analysis to 
minimize the radiological impacts resulting from the shipments. Another example is the situation where an Interstate beltway route does not exist around a large urban area. The State, in cooperation with the city, may want to identify a non-Interstate by-pass route as an alternative to the Interstate route through the city.

\subsection{Identifying Alternative Routes.}

It is expected that identification of available alternative routes will be straight-forward, because the agency applying these guidelines will have detailed knowledge of the highway systems in the State. Information on routes currently being used in the State for radioactive material shipments may be useful in identifying alternatives for consideration. Interstates connecting the points being considered may be included in the analysis in cases where it is desired to remove the preferred status from a segment of the Interstate system. Such a removal can only be cione if the comparative analysis shows that there is an alternative route that results in lower overall impacts from highway route controlled quantity shipments than the available Interstate route.

Routes selected for consideration as alternatives for designation as preferred routes should meet minimum requirements for heavy truck use. Fuel and repair stops should be available and the routes should be maintained for year-round use in the same manner as other major highways in the State. Preferred routes in one State must also match up at the borders with preferred routes in other States. This will require coordination with State agencies responsible for route selection in neighboring States.

In some peculiar situations, States may want to include consideration of an existing ferry route which crosses a body of water separating available highway segments. This could be done for the purpose of comparing a combination highwayferry route with an all highway route in cases where a body of water may limit the number of available highway routes to be considered.

\subsection{Evaluation of Comparison Factors.}

This section contains suggested procedures and non-route-specific data needed to evaluate the comparison factors for the routes being considered. As discussed previously, the three primary factors are always included in the analysis. 
Additional secondary parameters may be included for completeness of the evaluation process or to establish a preference among routes with little variation in the primary parameters. It may also be necessary to identify other secondary factors. It is expected that the agency designated to carry out the route selection process will determine which secondary factors are appropriate for the analysis being performed. The reasons for selecting these factors would be included in the documentation of the route selection process. If other factors are added to the route comparison study, methods for evaluating these factors will need to be developed. This should also be included in the documentation of the selection process.

The numerical results from the computations are only valid for use in comparison with similar numbers for alternative routes. In most cases the number used in the comparison will be proportional to the actual value of the factor being evaluated. For exarnple, the routing exposure factor is proportional to the actual radiation exposure that would result from a shipment of radioactive material traveling along that route, but is not numerically equal to the actual exposure. Because the numerical value obtained from the evaluation factor will only be used in comparison with similar values for other routes, it has been simplified for calculation purposes by factoring out constants and variables that do not change from one route to another.

Each of the primary comparison factors in the analysis must be evaluated for each of the routes being considered. Methods for combining these factors to select the route that minimizes the impacts from highway route controlled quantity shipments of radioactive material are discussed in the next section. Many of the comparison factors utilize data (such as vehicle speeds, accident rates or population densities) that are averaged over the entire route being considered. In some cases, it may be advantageous to break a route down into segments and evaluate one or more factors for these segments, rather then for the whole route at once. Route segmentation results in a more valid and detailed analysis when there is wide divergence in accident rates or population along different portions of a prospective route. 


\subsubsection{Normal Radiation Exposure}

Shipping packages containing radioactive materials emit low levels of radiation during normal transportation. The amount of radiation emitted depends on the kind and amount of material being carried. DOT regulations require that the shipping packages containing radioactive materials have sufficient radiation shlelding to reduce the levels of radiation emitted to safe levels. Persons residing along a transportation route, passengers in other vehicles, people at truck stops, and the truck drivers will all receive small doses of radiation from these shipments. These doses are not expected to adversely affect these people. However, federal regulatory agencies such as the Environmental Protection Agency, the Nuclear Regulatory Commission and DOT have adopted policies based on a position that it is prudent to avoid unnecessary radiation exposure and to eliminate or minimize exposure when practicable. Routes that minimize radiation exposure would therefore be preferred if all other comparison factors were equal.

The method for evaluating normal exposure from highway shipments of radioactive material is summarized below. The method is derived in Appendix $D$. In general, the radiation dose (D) from normal highway transport of radioactive materials is given by the following equation (Greenborg 1980):
dose to persons dose to passengers dose to
$D=$ residing along + in other vehicles + truck crew + route $\left(D_{1}\right)$
$\left(D_{2}\right)$
$\left(D_{3}\right)$
dose to people at truck stops
$\left(D_{4}\right)$

The exposure is a function of parameters that depend on characteristics of the particular shipment and parameters that vary with the route being used. Because the dose factor is being used for route comparison purposes only, the shipment-specific factors can be factored out, or representative values used. The normal radiation exposure factors then reduce to the following equations. (calculations in Appendix D).

$$
D_{1}=\frac{P L}{v} C_{1} ; \quad D_{2}=\frac{L T}{v} C_{2}+\frac{L T}{v} ; \quad D_{3}=0.8 \frac{L}{v} \text { and } D_{4}=0.2 \frac{L}{v}
$$


where,

$D=$ normal radiation exposure comparison factor

$P=$ average population density along the route (people per sq. mi.)

$L=$ length of route (miles)

$v=$ average speed of vehicles on the route (mph)

$c_{1}$ is a constant $=6.7 \times 10^{-5}$

$T=$ average traffic count on the route (vehicles $/ \mathrm{hr}$ )

$\mathrm{C}_{2}=$ conversion factor determined from Table 3.2-1

$\mathrm{C}_{3}=$ conversion factor determined from Table $3.2-1$

These doses can be combined into a single comparison factor given by the following expression:

$$
D=\frac{P L}{v} C_{1}+\frac{L T}{v} C_{2}+\frac{L T}{v} C_{3}+\frac{L}{v}
$$

TABLE 3.2-1. Conversion Factors for Use in Estimating Routine Radiation Exposure Factor

\begin{tabular}{c} 
Distance Between \\
Opposing Traffic \\
Lanes (ft) \\
\hline 10 \\
20 \\
30 \\
40 \\
50 \\
60 \\
70 \\
80 \\
90 \\
100 \\
150 \\
200 \\
300
\end{tabular}

\begin{tabular}{lc}
$C_{2}$ & $\begin{array}{c}\text { Vehicle Separation } \\
\text { Ofstanioan }\end{array}$ \\
\hline $1.9 \times 10^{-9}$ & 10 \\
$9.5 \times 10^{-10}$ & 50 \\
$6.0 \times 10^{-10}$ & 100 \\
$4.4 \times 10^{-10}$ & 200 \\
$3.7 \times 10^{-10}$ & 300 \\
$2.9 \times 10^{-10}$ & 400 \\
$2.5 \times 10^{-10}$ & 500 \\
$2.2 \times 10^{-10}$ & 600 \\
$1.9 \times 10^{-10}$ & 700 \\
$1.6 \times 10^{-10}$ & 800 \\
$1.0 \times 10^{-10}$ & 900 \\
$7.4 \times 10^{-11}$ & 1000 \\
$4.0 \times 10^{-11}$ & 1200
\end{tabular}

$\frac{c_{3}}{1.8 \times 10^{-5}}$
$1.6 \times 10^{-5}$
$1.5 \times 10^{-5}$
$1.3 \times 10^{-5}$
$1.0 \times 10^{-5}$
$8.6 \times 10^{-6}$
$7.3 \times 10^{-6}$
$6.0 \times 10^{-6}$
$5.0 \times 10^{-6}$
$4.0 \times 10^{-6}$
$3.3 \times 10^{-6}$
$3.0 \times 10^{-6}$
$1.3 \times 10^{-6}$


Conversion factor $\mathrm{C}_{2}$ in the equation for normal exposure is a function of the distance between opposing lanes of traffic on the route. A centerline to centerline measurement would provide the most acourate estimate of $\mathrm{C}_{2}$. For a two-lane road, this would reduce to the width of a traffic lane. For a four-lane road, this measurement would be the distance from the line dividing the two traffic lanes on one side of the road to the corresponding line for traffic moving in the other direction. Conversion factor $\mathrm{C}_{3}$ is a function of the distance between vehicles in a traffic lane. This average vehicle separation distance can be estimated by dividing the average vehicle speed by the average hourly traffic count and converting the results from iles to feet for entry into Table 3.2- . The average population density, $P$, can be obtained from the total population in a 0-5 mile band along the highway. This band is identifled and explained in the next section. Dividing the total population by the area of the band (10xL) will provide a reasonable estimate of the population density for use in the normal exposure calculations.

\subsubsection{Public Health Risks from Acoidents}

A release of radioactive material during transportation accidents will occur only when the package carrying the material is subjected to accident forces that exceed the package design standards. Packages containing highway route controlled quantity radioactive material are required by DOT and NRC regulations to be designed to retain their contents in severe transportation accidents. Accidents that could cause release of material from these packages are therefore expected to occur very infrequently. A number of studies have found that public risks are quite low from accidental releases of radioactive materials from the type of packages used for large quantity shipments (BNWL-1846, BNWL-1996, PNL-2030, PNL-211, PNL-2588, NUREG-0170).

Because accidental releases of radioactive material could occur however, it is appropriate to include consideration of the public health risks from these accidents in the selection of preferred routes. Risks from accidental release of radioactive material depend on two factors: 1) the frequency of accidents that could result in release and 2) the consequence from such accidents in terms of the number of people that could be exposed to radioactive materials if a release 
occurs. Both of these factors are expected to vary among avallable routes for radloactive material shipments. Suggested methods for determining these factors. are discussed below. The release consequence measurement is presented in greater detail in Appendix B. The overall acoident risk factor for each route is determined by multiplying the release frequency number by the acoident consequence number. The method presented here yields a result that will indicate differences in risks among the routes being analyzed. The numerical results are not equal to the risk, because of the simplifying assumptions that are possiblia in a comparative measure.

\section{Release Frequencies}

Exact determination of the frequeney of radioactive material releases from these shipments would require detalled information on the forces that could be produced in transportation accidents and on the response of the shipping packages to these forces. Development of this information would require extensive data analysis and detailed engineering evaluations. This level of effort is beyond that necessary for routing decisions (State routing agencies are encouraged to conduct such a detalled evaluation if believed appropriate). NUREG-0170, a document mentioned in the Foreword and listed in the bibliography, provides an example of a more sophisticated method of computing both release frequencies and consequences. Because routing decisions are based on comparative assessments of the available routes, the analysis can be greatly simplified. It is sufficient to obtain an accident frequency measure that will be representative of the actual release frequency measure for each route. Accident frequencies that inherently include a measure of accident severity are preferred for the comparative analysis.

Accident rate information and damage estimates based on observations of actual accidents are generally available from State and local agencies with responsibilities for highway safety. It is suggested that the comparative assess" ments be based on this data. Accident rates in units of accidents per vehicle mile are most convenient to use in the assessment. If they are not avallable directly, they can usually be developed from accident frequency and traffic volume information. The accident rate is multiplied by the route length to obtain the release frequency measure for use in the comparative analysis. 
It is believed that rates for accidents that result in the death of the driver of a truck carrying hazardous materlals provide the best overall indicator of accldent frequency for use in the comparative assessment. Suggested accident frequency measures in decreasing order of desirablilty include:

- Hazardous Material Truck Driver Fatallty Rate

- General Truck Driver Fatality Rate

- Hazardous Material Truck Fatal Accident Rate

- General Truck Fatal Accident Rate

- General Vehicle Traffic Fatality Rate

- General Traffic Accident Rate

- Accident Rate Predictive Models.

Fatalities are used as a ineasure of accident severity because of data availability and the implication that damage is sustained by the vehicle. Narrowing the class of venicles considered to those most like the shipments of interest results in more realistic estimates.

The quality of data available should also be considered in selecting an accident frequency measure for use in the analysis. Development of several accident rates would permit evaluation of the data quality. A study of accident frequency information and truck traffic volumes could require the rejection of very narrowly defined accident rates due to a lack of data in these categories. An indication of poor data would be equal accident rates for several of the above classifications. Accident rates, in general, will increase from the top of the list to the bottom with the exception of the accident rate predictive model. The predictive models are intended for use when little data is available locally. One such model is described in a report entitled "Guidelines for Applying Criteria to Designate Routes for Transporting Hazardous Materials" (Peat, Marwick, Mitchell and Co. 1980). 
The consequences of an accidental release of radioactive material depend on a large number of factors. Many of these factors would be essentially identical for two alternative routes. These would include atmospheric conditions and quantity and type of material transported. Differences between alternative routes that contribute to a preference of one over another on the basis of accident consequences result primarily from differing levels of population and types of property along the routes. Population has therefore been selected as the comparative measure for release consequences relating to public health risk. Types of property and land use is the comparative measure for release consequence relating to economic risk which is considered further in Section 3.2.3.

If a radioactive material is released in a transportation accident, it will generally be dispersed downwind. The typical consequences from such a release are the exposure of the people in an approximately 25 square mile area of land to low levels of radioactivity. Because radioactive materials can disperse relatively large distances, it is necessary to examine the population along alternative routes out to distances of about 10 miles. A suggested method for accomplishing this is summarized in Table 3.2-2.

TABLE 3.2-2 Release Consequence Measure

Population Band

Boundary

$0-5 \mathrm{mi}$

$5-10 \mathrm{mi}$
Health Consequences

Band Multipliers

\subsection{5}

0.25 
The health consequences multipliers were developed from atmospheric dispersion calculations for radioactive material releases (see Appendix B). They account for the fact that concentrations of radioactive materials in the air will be higher near the accident site, resulting in a somewhat higher radiation dose to persons nearer the highway.

To apply this method, the number of persons within each of the population bands in the table is determined from maps, census data, or othel available information. Counting by thousands or tens or thousands will not af fect the results provided each of the routes under consideration are counted in the same way. Note that the bands cover the indicated distance on either side of the highway, i.e., the first band is $10 \mathrm{mi}$. wide, centered on the highway. The population count for each band is then adjusted by the multiplier and the band totals are added to obtain the release consequence measure.

In many applications of the route selection methodology, the number of people in each band can be determined by adding the population of cities, counties, towns, and villages that lie within the band. This method will usually be appropriate when relatively long routes are being compared that pass through or near a number of population centers of various sizes. More detailed data, using census districts, for example, may be required when comparing shorter routes. This type of analysis would generally be associated with comparisons of Interstate through routes with alternative bypass routes for a major city.

If a closer evaluation of large urban areas is believed necessary, a simplified method of computing the release consequence measure can be used. Because distances are much more limited than in the case of a Statewide analysis, the 10mile band is not practical. In some cases, alternative routes through and around urban areas may not even be 10-20 miles a part. Therefore, a 5-mile band (on either side of highway) is more practical. When using the 5-mile band for examining urban alternative routes, the health consequence band multiplier can be considered 1.0 since all individuals in that proximity may be considered as receiving the same dose of radioactivity if a severe accident did occur. Consequently, the release consequence measure in this limited analysis would simply be the population count in the 5 -mile band unadjusted by the multipliers. 


\subsubsection{Economic Risk from Accidents}

An accidental release of radioactive materials could also have economic impacts. The economic risk is determined by considering the release of frequency (probability of an accident) and the release consequences similar to the determination of public health risk. The release frequency measure will be the same as used for public health risk, i.e. the accident rate along the prospective route. It is important to apply the same accident rate (hazardous material truck driver fatality, general truck driver fatality, etc.) that is used for public health consideration.

The release consequence measure for economic risk is based on the type of property along the prospective route. Property in the vicinity of an accident could become contaminated with radioactive materials. When contamination exceeds safe levels, it would have to be removed or otherwise reduced to safe levels before the property could be returned to normal use. The expenses associated with decontamination are expected to be the primary economic consequence of a transportation accident that releases radioactive materials.

Decontamination costs vary with the type of property being decontaminated (WASH 1400 1975). The fractions of various property types along a transportation route can be used along with information on the relative decontamination costs for each property type to develop a comparative economic consequence measure for alternative radioactive material transportation routes. A suggested method for performing this analysis is summarized in Table $3.2-3$. The consequence multipliers are derived in Appendix C.

\section{TABLE 3.2-3 Economic Consequence Measure}

Land Use Type

Farmland

Residential

Single Family

Multi-Family

Commerical

Parks

Public Areas
0-5 mi Band

0.001

0.1

2.0

0.15

0.03

0.5
5-10 mi Band

0.0001

0.04

0.2

0.01

0.02

0.05 
The multipliers presented in the table are proportional to the anticipated decontamination cost for each land use type. The bands of land along the route are used in analyzing the economic risk factor because areas closer to the accident site generally become contaminated to higher level, requiring more extensive decontamination efforts. To apply this method, the amount of area within each band occupied by each of the six land use types is determined from maps, local land use planning information or other available data. The area may be measured in square miles, square kilometers, acres or any other convenient unit. The measures must be consistent over the entire route, for all land use types and between alternative routes. The land use areas are multiplied by the appropriate consequence multiplier for that band. These products are then multiplied by the accident rate for each route considered to yield the economic risk factor for that route. This process will become clear in Section 4 when applied to a sample case.

\section{SECONDARY ROUTE COMPARISON FACTORS}

If alternative routes cannot be clearly distinguished by consideration of the primary risk factors, State of ficials may want to consider other factors which have the potential of mitigating the consequences of a release of radioactive materials. These secondary route comparison factors are inherently subjective in nature and therefore much more difficult to quantify and estimate. The following methodology provides a useful approach ior considering these factors. The process involves the establishment of arbitrary scaling systems which are totally dependent upon the judgement of the State officials performing the analysis.

\subsubsection{Emergency Response}

Timely action by emergency response units has the potential for reducing the magnitude and extent of a radioactive material release in a transportation accident. The primary factors influencing the effectiveness of emergency response 
are manpower, timing, planning and equipment. Each of these parameters is location dependent. The time to get the first personnel to the accident site is important to establish control of the immediate area and determine the nature of the hazard. First order response times are limited by the accident locations and access to the accident site. These times are typically on the order of a few minutes.

Secondary response to accidents includes the mobilization of police to aid evacuations if needed, contacting specialized technical personnel and obtaining radiation monitoring and cleanup equipment at the accident site. These secondary times depend on adequate pre-accident planning, local equipment availability and distances to be traveled. Minutes to hours are required for these operations.

Route comparisons can be based on a relative ranking of available routes. Exact determination of all the parameters that affect emergency response is therefore not required. If emergency response is to be evaluated as a secondary route comparison factor, it is suggested that arbitrary scales be established for each emergency response parameter and each route be ranked on these scales. An example of such a ranking scale is presented in Table 3.2-4. Evaluation parameters selected for use in this example include the time required for emergency response personnel to reach potential accident sites; the availability of specialized equipment such as radiation detection instruments; the amount of training that local public safety personnel have received in dealing with hazardous material spills; and the availability of trained manpower to respond to an incident. The scales assign low numbers to routes that are most favorable for that parameter.

To illustrate, an overall factor is determined for each land development type that a route may pass through. This is accomplished by evaluating each parameter for parts of routes representing the different land development types and summing them to obtain the overall factor. An overall comparison factor for alternative shipping routes can be developed by determining the fraction of land area by 
development types within 5 miles of the route, multiplying by the overall factor for those development types and summing the results. For example, a route that passes by 5 square miles of cities, 3 square miles of town, 90 square miles of rural areas and 2 square miles of industrial areas would have an emergency response comparison factor of $11.6(.05 \times 7+.03 \times 10+.9 \times 12+.02 \times 6)$.

It should be emphasized that the parameter ranking system presented in Table $3.2-4$ is intended only as a starting point for any particular route selection case. Of necessity, the scaling system is arbitrary in nature. It is expected that the scales and ranking of the land development types may need to be adjusted to best describe local conditions.

TABLE 3.2-4 Sample Emergency Response

Parameter Scaling System

\begin{tabular}{|c|c|c|c|c|c|}
\hline & $\begin{array}{l}\text { Respense } \\
\text { Iime }\end{array}$ & $\begin{array}{l}\text { Equipment } \\
\text { Avallabilitey }\end{array}$ & $\begin{array}{l}\text { Personnel } \\
\text { Hazardous } \\
\text { Matertal } \\
\text { Trainine } \\
\end{array}$ & $\begin{array}{l}\text { Manpower } \\
\text { Ava } 11 \text { ab } 11+\text { tey }\end{array}$ & $\begin{array}{l}\text { Area } \\
\text { Iotal } \\
\end{array}$ \\
\hline city & 2 & 2 & 2 & 1 & 7 \\
\hline Town & 1 & 3 & 3 & 3 & 10 \\
\hline Rural & 3 & 3 & 3 & 3 & 12 \\
\hline Industrial & 2 & 1 & 1 & 2 & 6 \\
\hline
\end{tabular}

\subsubsection{Evacuation}

Public exposure to radiation during a transportation accident would not result in immediate fatalities because the radiation dose received by any individual would be relatively low. Public dose can be further reduced, however, through evacuation of persons in the affected areas. A method for considering evacuation in route selection is summarized below. Further details are presented in Appendix E. 
Factors contributing to an effective evacuation include the type of area to be evacuated (i.e. residential, industrial, etc.); means of egress; level of pre-accident planning; effectiveness of implementing these plans by responsible authorities; and the nature of the threat. Radioactivity is not detectable by human senses. Large amounts of manpower may be required to communicate the need for evacuation in the absense of an apparent threat. Communication is more difficult in areas of low population density and results in longer evacuation times. The most common means of evacuation is the private automobile. Routes away from the accident site are required for its use. Large public and private facilities pose special problems in an evacuation. Examples include schools, hospitals, prisons, nursing homes, churches, stadiums, and theaters. Detailed plans for the evacuation of special facilities are essential to the minimization of injuries and confusion.

The evaluation of evacuation capabilities can be simplified by using a relative ranking scheme similar to emergency response. Arbitrary scales are established to rank route alternatives relative to each other for each of the important evacuation parameters. An example of one approach is shown in Table 3.2-5. Parameters selected for use in this evaluation include the number of people affected; the availability and capacity of egress routes; the availability of evacuation coordination personnel; the time required for effective evacuation; and the economic and other impacts of the evacuation on the af fected population.

Using Table 3.2-5 to illustrate, evacuation parameters are evaluated for each major land use type along the routes being compared. The values of the ranking factor for each parameter are added to provide a single factor for each land use type. An overall comparison factor for each route can be developed by determining the fraction of land area by development type within 5 miles of the route, multiplying these fractions by the respective factor totals in Table 3.2-5, and summing the results. For example, a route that passes 90 square miles of rural area, 4 square miles of suburban development, 1 square mile of urban area, 3 square miles of commercial development and 2 square miles of industrial area would have an overall evacuation factor of $11.5(.9 \times 11+.04 \times 13+.01 \times 28+.03 \times 15+.02 \times$ 18). 
Again, it should be emphasized that the parameter ranking, system presented in Table 3.2.-5 requires subjective judgement and is intended only as a starting point for any particular route selection case. It is expected that the parameter ranking scales and the relative ranking of the land use types on these scales may need to be adjusted to fit local conditions for the routes being analyzed.

\section{TABLE 3.2-5 Evacuation Parameter Evaluation}

\begin{tabular}{|c|c|c|c|c|c|c|}
\hline & $\begin{array}{l}\text { No. of } \\
\text { Persons } \\
\text { Affected }\end{array}$ & $\begin{array}{l}\text { Egress } \\
\text { Ava11. }\end{array}$ & $\begin{array}{l}\text { Evac. } \\
\text { Manpower } \\
\text { Avell. } \\
\end{array}$ & $\begin{array}{l}\text { Evac. } \\
\text { Iime }\end{array}$ & $\begin{array}{l}\text { Evac. } \\
\text { Impoets }\end{array}$ & $\begin{array}{l}\text { Factor } \\
\text { Totals }\end{array}$ \\
\hline Rural & 1 & 3 & 3 & 3 & 1 & 11 \\
\hline Suburben & 5 & 2 & 2 & 2 & 2 & 13 \\
\hline Urben & 20 & 1 & 1 & 1 & 3 & 28 \\
\hline Conmerefal & 8 & 1 & 2 & 1 & 3 & 15 \\
\hline Industrtal & 10 & 2 & 2 & 1 & $j$ & 18 \\
\hline
\end{tabular}

\subsubsection{Special Facilities}

Certain localized areas have sufficient economic or public safety importance to require special consideration in the route selection process. These facilities or areas could be unique and vital to local economies. Examples would be a factory employing a large fraction of the local population. Other facilities have enhanced potential for public health consequences. These facilities contain populations that are either large, sensitive to radiation, or difficult to evacuate. For example, an occupied stadium would be difficult to evacuate quickly. Experts in radiation health effects believe children are more sensitive to radiation than adults (BEIR Report 1972). Schools would therefore be considered special facilities for route selection purposes. Hospitals and nursing homes are examples of populations that are difficult to move without threat of injury.

Parameters that effect the importance of special facilities in the route selection process include the radiation dose sensitivity of the people normally ccupying the facility, the economic importance of the facility to the local community, and difficulty associated with evacuating people from the facility. 
Relative ranking scales are suggested for evaluating special facilities in relation to these parameters. Each facility is evaluated on all criteria. Points are assigned for each factor and facility type. They are then combined into an overall facility factor. Table 3.2.-6 illustrates the use of relative scales to rank each factor. In this example, an arbitrary scale of 1 to 5 was chosen to indicate relative degrees of impact for the listed facilities. Higher values were assigned to facilities with higher potential impacts. Scale size and values assigned to each factor could vary depending on local situations. Only relative rankings are important. Larger scales could be used to weight some factors more than others. Factors in Table 3.2-6 were all weighted equally and then summed to obtain the facillty factor.

\section{TABLE 32-6. Special Facility Example}

\begin{tabular}{|c|c|c|c|c|}
\hline & Dose Response & $\begin{array}{c}\text { Acelfient } \\
\text { Evacuotion }\end{array}$ & Economics & $\begin{array}{l}\text { Factlify } \\
\text { Factor } \\
\end{array}$ \\
\hline Gildren's Hospltal & 5 & 5 & 2 & 12 \\
\hline Hospitul & 4 & 5 & 2 & 11 \\
\hline Prison & 1 & 1 & 2 & 7 \\
\hline Mursing Home & 2 & 5 & 1 & 8 \\
\hline School & 5 & 3 & 1 & 9 \\
\hline Churehes & 2 & 2 & 1 & 5 \\
\hline Stadiun & 3 & 3 & 3 & 9 \\
\hline Shopping Center & 1 & 1 & 3 & 5 \\
\hline Theacers & 2 & 2 & 1 & 5 \\
\hline Factory & 2 & 2 & 5 & 9 \\
\hline
\end{tabular}

To apply this method, special facilities that could be encountered along any of the alternative routes are identified. An overall facility factor is then assigned to each type of facility using the procedure outlined above. The special facility comparison factor is determined for each route by counting the special facilities along the route, multiplying by the facility factor for each type of facility, and summing the results. For example, using the facility factors in Table 3.2-6, a route that passed near one hospital, three churches, two schools, and a shopping center would have a special facility comparison factor of 49 ( $1 \times 11+3 \times 5+2 \times 9+1 \times$ 5). In general, special facilities would only be considered if they are within 5 
miles of a route. A distance of 5 miles is selected to be consistent with the emergency response and evacuation factors. The special facllity comparison factor may be most useful when comparing shorter routes, for example routes through or around a major city.

\subsubsection{Traffic Fatall ties and Injuries}

Trucks carrying shipments of these radioactive materials can be expected to. be involved in traffic accidents at about the same rate as other large trucks carrying hazardous materials. Because the packages of highway route controlled quantity radioactive materials are designed to survive very severe accidents, the consequences of most accidents involving trucks carrying these materials will be the same as any other accident involving a large truck. Vehicles involved in the accident will be damaged and vehicle occupants may be injured or killed. This factor accounts for accident impacts which are not related to the radiological nature of the cargo.

Involvement of these vehicles in fatal and injury accidents also could produce negative public reactions. The public may tend to associate the fatalities and injuries with the cargo, even though this association is not accurate. There may also be a tendency on the part of local officials to order precautionary evacuations in accidents that result in fatalities or injuries. This could be especially true in cases where these of ficials do not have radiation detection equipment readily available to monitor for releases of radioactive materials. These factors provide incentive to route radioactive material shipments on routes with low fatal and injury accident rates.

If it is desired to include this factor in the route selection process, numerical estimates for route comparison purposes should be straightforward. Data on the frequency of fatal and injury accidents is usually available from State and local agencies with highway safety responsibilities. Rates expressed in fatalities and injuries per vehicle mile are the easiest to apply in the analyses. If these rates are not readily available, they can usually be calculated from the number of fatalities and injuries that have occured on a given route and the traffic counts for the route. 
Rates for accidents involving hazardous materials truaks would provide the most accurate estimates. If the rates are not avallable, rates for truck transportation in general or for all vehicle traffic can be used. Multiplying the rate per mile by the route length will provide a reasonable comparative measure for this factor.

\subsection{Selection of Preferred Route}

The route comparison factors provide the technical basis for selecting the shipping route that minimizes the impacts from shipments of highway route controlled quantity radioactive materials. The selection of a preferred route is based on the primary route comparison factors-public health risks from aceidents, economic risks from accidents and normal radiation exposure. If all three of the primary factors clearly favor one route, that route would be selected as the preferred route. If one primary factor favors one route, while the other primary factors favor other alternatives, an overall figure of merit for each route can be developed. The route selection is then based on a comparison of the figures of merit for the routes. The figure of merit is developed by normalizing each comparison factor. The normalization is accomplished by dividing each comparison factor by the sum of the values for that factor for all the routes being considered. For example, in a route selection case comparing three alternative routes, the normal exposure factor might be .25 for Route A, 1.5 for Route B and 6.5 for Route C. The total of these values is 8.25. The normalized comparison factors then become .03 for Route A, .18 for Route B and .79 for Route C. This factor is th en added to the normalized comparison factors for public health accident risks and economic accident risks for that route to obtain the overall figure of merit. This will be more clearly shown in the sample case in Section 4.

Using this approach, the route with the lowest figure of merit will produce the least impacts from transporting large quantity radioactive materials. In cases where the figures of merit are extremely close, it may be desirable to examine secondary comparison factors to assist in the route selection process. 


\section{SAMPLE CASE}

A sample case has been constructed to demonstrate the analysls presented in these guldelines. Two hypothetical routes have been assumed between points $x$ and $y$, as shown in Figure 4.1. The routes are represented in the figures as light and heavy solid lines. A corridor 10 mlles to either side of each route is shown by dashed lines. Areas common to both routes inside the 10-mile bands exists near the ends of each route. Analysis of the impacts in these areas will not contribute to the differentiation between routes unless substantial differences exist in aceident rates for the two routes at their end points.

In this sample case, Route $A$ is a.n Interstate highway 490 miles long. Route $B$ is a two-lane U.S. highway with a total length of 320 miles. Because Route $A$ is an Interstate highway, it would be a preferred route under the DOT routing requirements. In this sample case, the analysis is undertaken because the shorter length and lower population along Route $B$ may result in lower overall impacts from radioactive material shipments.

For this sample case, a number of secondary route selection factors will be analyzed in addition to the three primary factors. This will illustrate the analysis of these factors and their use in the route selection process. The factors analyzed in the sample case include:

- Normal radiation exposure

- Public health risk

- Economic risk

- Emergency response

- Evacuation

- Traffic fatalities

Tables 4.1 and 4.2 present a summary of data used to describe the two routes considered in the analysis. Route $\mathrm{A}$ is divided into four segments to provide better accuracy by accounting for differences in accident statistics. Segment 1 of Route $A$ is six-lane urban highway, segment 2 is a six-lane rural highway and segments 3 
and 4 are four-lane rural highways. All segments are limited access highway. There are twelve population centers along Route $A$ and the land is divided among urban, suburban, commerclal, and rural uses. Undeveloped land is considered the same as farmland. Route $B$ is primarily twa-lane with opposing traffic flow. Because of the consistent road type the route is not broken into segments. If local data on population, accident rates, etc. were avallable, then segmentation of the route might have been desirable. Land uses are divided into the same categories as for Route A.

Much of the information needed to compute the route comparison factors is presented in the tables. This includes population counts within the two highway bands, average truck speeds, traffic volume for both general and truck traffic, and accident information pertaining to each route segment. The basio accident unit of measure chosen for the sample case is the truck driver fatality rate (measured in accidents per million truck miles). This is converted into truck accidents per thousand shipments as will be discussed further .

The remainder of this section consists of a sample evaluation package for this route selection case. Worksheets have been filled out for each route in accordance with the discussions in Section 3. (Blank work sheets are furnished in the Appendix.) The filled-in svork sheets form part of the official documentation of the route selection process. 


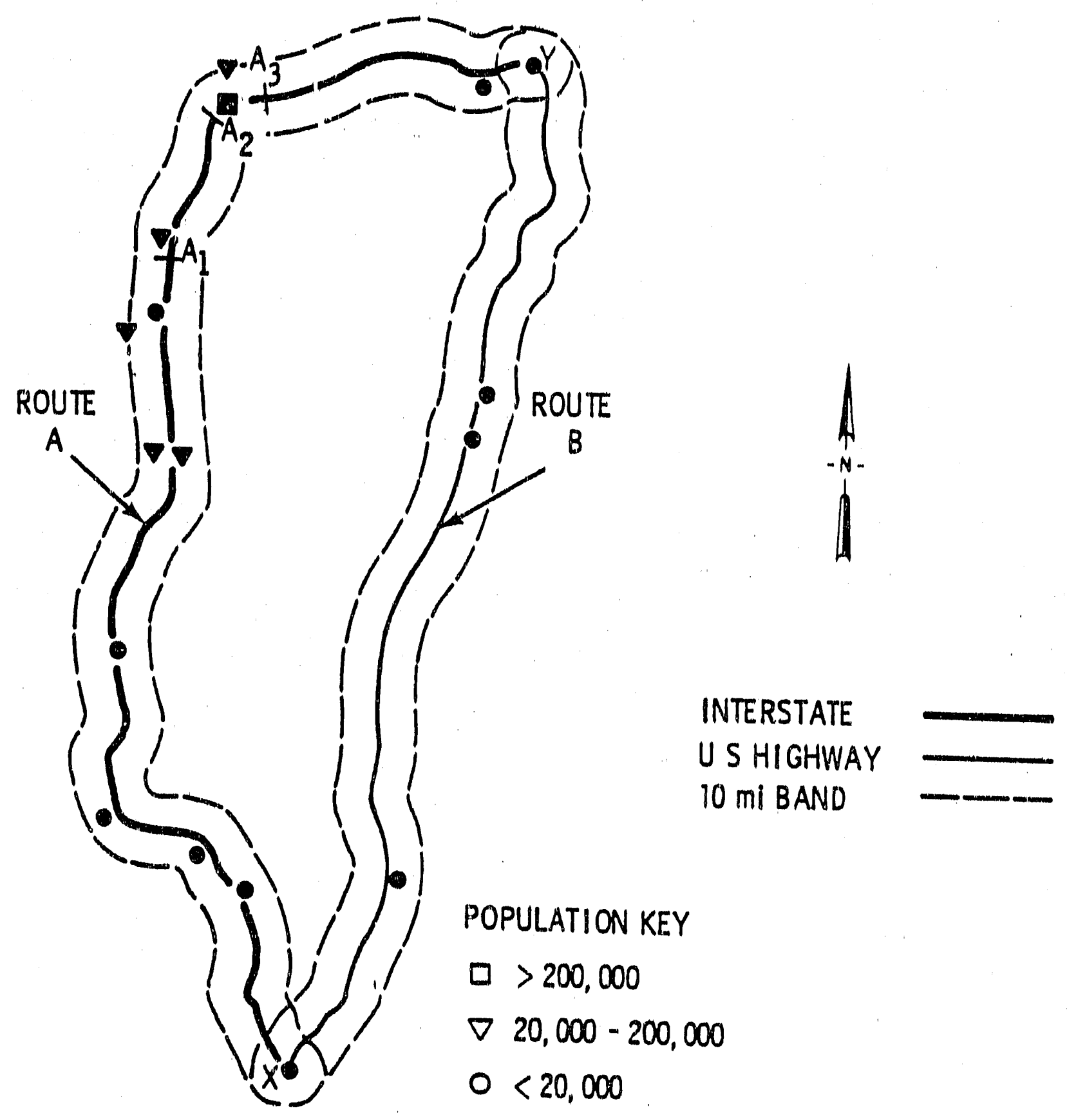

i FIGURE 4.1 Routes Used in Sample Case Application of Route Selection Methodology 

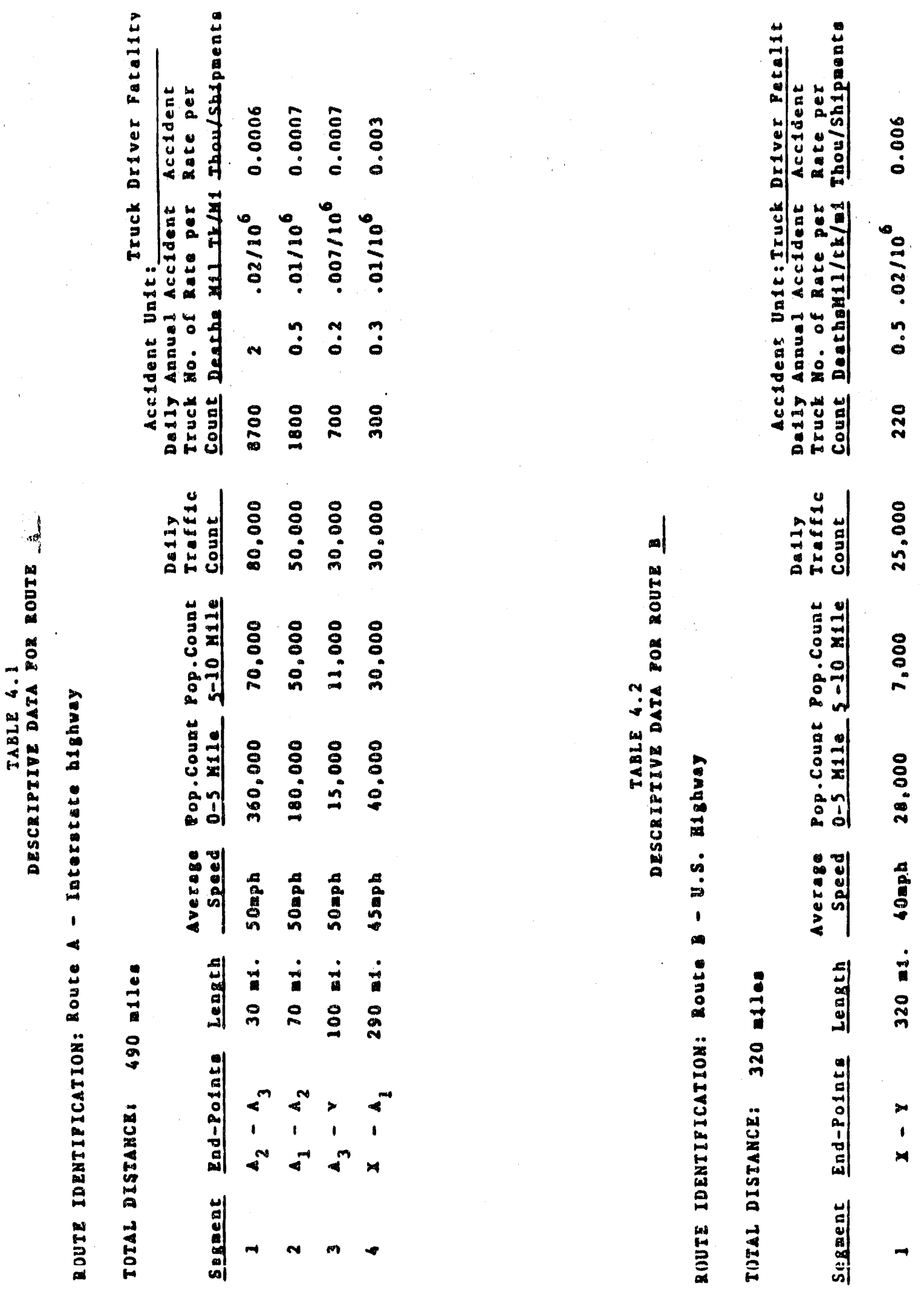


\subsection{Calculation of Primary Route Comparison Factors.}

The first six work sheets show evaluation of the primary comparison factors for both Routes $\mathrm{A}$ and $\mathrm{B}$.

Worksheet 1 examines normal transport exposure for Route A. Several pieces of information are needed for this evaluation. If a route is divided into segments, the data must be developed for each segment. The comparison factor for the route will be sum of the factors for each segment. The first data necessary for this evaluation is the average population density $(P)$ along the route. This is found by determining the number of persons inside the 5-mile band and dividing that number by the area inside the band. The area is 10 times the segment length ( $\mathrm{L}$ ) since the band lies on both sides of the pathway. For example, from Table 4.1 we obtain the population count inside the 0-5 mile band and divide by 300 ( $30 \mathrm{mi}$. $\mathrm{10}$ ) to obtain a population density of 1200 people per square mile.

Also needed for this calculation is the traffic density $(T)$ in number of vehicles per hour. The number of vehicles per hour is found by dividing the daily vehicles count from Table 4.1 by 24 hours. For Route $A$, the daily vehicle counts for the four segments are $80,000,50,000,30,000$ and 30,000 respectively. These yield vehicle per hour values of $3333,2083,1250$ and 1250 vehicles per hour. The average speeds (v) for each of the segments can also be found in Table 4.1.

As stated previously, $C_{1}$ is a constant ( see derivation in Appendix $D$ ) which is always $6.7 \times 10^{-5}(0.000067)$ in the route comparison analysis. Values for the variables $\mathrm{C}_{2}$ and $\mathrm{C}_{3}$ come from Table 3.2-1. $\mathrm{C}_{2}$ is dependent upon the distance between opposing traffic lanes. For Route A, these distances are 50, 40, 40 and 50 feet for the four segments. This results in the values for $\mathrm{C}_{2}$ shown on the worksheet. The value for $\mathrm{C}_{3}$ is dependent upon the separation distance between vehicles. The separation distance is calculated by dividing the average vehicle speed by the traffic density $(T)$. Since the traffic density is expressed in vehicles per hour, the average speed must be converted to feet per hour before the division. For Route A, the results of these calculations are 79, 126, 211, and 190 as shown on Worksheet 1 . The value for $C_{3}$ can then be obtained from Table 3.2-1 and are then entered on the worksheet. 
Each segment is then evaluated using the equation shown on the worksheet and the values are summed at the bottom of the worksheet to yield the route total. This total is the comparison factor value for the route and is entered in the appropriate location on the route comparison worksheet (Worksheet 11).

Worksheet 2 shows the calculations for determining public health risk from accidental releases of radioactive material for Route $A$. The segment risk factors are determined by tabulating the population count inside each of the bands of interest. For segment 1 these values are 360 for the 0-5 mile band and 70 for the 5-10 mile band. All population counts are given in thousands. Each population count is multiplied by the appropriate band multipliers. This results in health consequence factors for segment 1 of 270 and 17.5. Release consequences are then calculated for segments 2,3 and 4 as shown.

The total public health consequence factor for each segment must be multiplied by the accident rate to determine the segment risk factor. In this example, data for truck accidents that resulted in driver fatalities was available. The accident rate shown on the worksheets includes consideration of the segment lengths. This is done by converting truck accidents per million truck miles to accidents per thousand shipments. To make this conversion, the accident rate per million truck miles shown in Table 4.1 are multiplied by the segment length. This product is then multiplied by one thousand to arrive at the accident rate per thousand shigiments shown in the last column of Table 4.l. Accidents per thousand shipments was chosen for the accident rate units on the health risk worksheet because it resulted in convenient sized numers. Accidents per shipment or per million shipments would be just as valid a number as long as all segments and alternative routes are figured the same way.

After each of the segment health risk factors are calculated, they are totaled to yield the comparison factor value. This number is found at the bottom of the public health risk worksheet. It is also entered on the comparison worksheet.

Worksheet 3 consists of two pages and shows calculation of the economic risk factor for Route A. The area inside two bands (Sheet \# 1 for the 0-5 mile band and 
Sheet \# 2 for the 5-10 mile band) on either side of the highway is examined to determine the area in each of the land use types shown on the worksheet. It is important to remember to consider both sides of the pathway. The amount of land in each of the use types is entered on the worksheet for each segment and band. The areas are multiplied by the appropriate weighting factor and entered in the weighted total column. Weighting factors used in the example were taken from Table 3.2-3. The bottom of the first page of Worksheet 3 tabulates the weighted totals for each band and for each segment. For each segment, the band totals are added to obtain the economic consequence factor. This is multiplied by the segment accident rate to obtain the segment economic risk factors. Finally, the segment factors are summed to obtain the route total. This total is entered in the appropriate location on the route comparison worksheet.

The next three worksheets show calculations of the primary comparison factors for Route $B$. All the variables in the Route $B$ calculations must have the same units as the Route $A$ calculations. If truck accident rates were described as the number of accidents per thousand shipments for Route $A$, then Route $B$ rates must be described as accidents per thousand shipments. Data for these calculations will come primarily from Table 4.2 .

Once all of the primary comparison factors have been computed for each alternative route, the route selection process can proceed. However, before the primary factors are evaluated and compared for the purpose of route selection, several secondary factors will be computed to illustrate the process.

\subsection{Estimation of Secondary Route Comparison Factors}

Worksheets 7 and 9 illustrate the use of the arbitrary scaling systems for the purpose of quantifying the very subjective secondary factors relating to emergency response and evacuation. As emphasized previously, these estimates amount to nothing more than approximations which could be useful if the primary comparison factors for alternative routes are computed to be essentially the same. Also included in this analysis is the traffic fatality factor (Worksheet 8 and 10) which is directly dependent on available accident rates and therefore less judgemental in nature than other secondary factors. 
Worksheet 7 evaluates the emergency response and evacuation factors for Route A. Completion of this worksheet is similar to the economic risk worksheet. The land areas (in square miles) for the categories shown are determined for a band extending five miles on either side of the route. (Only the 0-5 mile band is considered for these factors.) When a route consists of more than one segment, the areas are summed across the segments for each land development type. This is necessary because the weighting factors need to be a applied to the entire route at one time. The route fraction of land area for each development type are then multiplied by the appropriate weighting factor and these products are summed to arrive at the route comparison factor. For Route $A$, the emergency response comparison factor is 11.0 and the evacuation comparison factor is 12.4. These values are entered in the appropriate location on the route comparison worksheet.

Calculations for the traffic fatalities comparison factor for Route A are presented in worksheet 8 . The accident unit of measure chosen for this analysis is truck accidents resulting in a fatality (truck accident fatalities per million truck miles). The emphasis in this comparison factor is on deaths or injuries that could result from a normal truck accident with no release of cargo. For this reason, any truck accident that results in death (either driver or persons in other vehicles) was chosen as a comparative measure. If a route is broken into segments, each segment will have a separate accident rate. The mileage in each of the segments is multiplied by the accident rate to yield a segment comparison factor. The segment comparison factors are summed to arrive at the route comparison factor. This value is entered onto the route selection worksheet in the appropriate location.

Worksheets 9 and 10 evaluate these same three secondary factors for Route B.

\subsection{Route Selection in the Sample Case}

Worksheet 11 is a summary sheet for the data developed during the sample case analysis. It is clear from the sample case that Route $B$ would be the preferred route since all three primary factors favor Route B. However, in many situations such a clear-cut choice may not be evident. In most cases it will be necessary to 
combine the factor values for each primary factor into one representative risk value. This can be accomplished by "normalizing" the factor values for each alternative route and then adding the normalized values to obtain one "figure of merit."

The third column of numbers on Worksheet ll shows the total of factor values for each primary comparison fuctor. For example, the normal radiation exposure factor was computed to be $10.5 \mathrm{fd}$ Route $A$ and 8.0 for Route $B$. This totals to 18.5 as shown in the third column. The "normalized value" for Route $A$ is simply the factor value for Route $A$ divided by the total factor value for all routes $(10.5 / 18.5=$ 0.57 ). The normalized value for Route $B$ for radiation exposure is 0.43 (the sum of the normalized values must be 1.0 ). The same process is followed for the public health risk and economic risk factors and the results are shown in the normalized value column for each route.

The reason for normalizing the factor values is that the factor values are disparate numbers, computed using different units of measure, and therefore cannot be combined into a final figure which represents anything. For example, the factor values for public health accident risks are very small numbers because of the units of measure. Compare these numbers with the high units of measure for the normal exposure factor. Normalizing the factor values produces unitless fractions of the same magnitude. These fractions also retain the same relative magnitude for each comparison factor between the two routes.

The normalized values for each route are then added to obtain the figure of merit. Worksheet 11 shows the figure of merit for Route $A$ to be 1.87 and for Route $B$ to be 1.13. The lowest figure of merit identifies the route that is most likely to minimize the impacts from transporting large quantity radioactive materials using the criteria developed in this guidebook. Once again, if the figures of merit computed for alternative routes are essentially the same, secondary factors may be considered in making the final choice of a preferred route.

\section{NOTE ON WEIGHTING OF THE COMPARISON FACTORS}

Underlying this method of combining the comparison factors to select a route, is the assumption that the three primary factors are of equal importance in 
reducing impacts and are therefore weighted the same. The figure of merit can be simply characterized as a number which is representative of the relative risk from transportation between Route $\mathrm{A}$ and Route $\mathrm{B}$, given that the three primary factors contribute equally to that risk.

Past risk studles indicate that normal exposure of ten contributes a greater share of the health risks from transportation of radioactive materials than accidents resulting in public health impacts. This may suggest a greater weighting tactor for normal exposure to recognize the difference in magnitude of impacts when compared to public health risk resulting from accidents. However, the primary purpose of these studies was to assess the actual risk in transportation, not the development of comparative risk figures for the narrower purpose of assessing routing alternatives. As demonstrated by NUREG-0170, a great deal of specific information is needed to develop actual risk numbers for both normal exposure and accident risks. If such numbers are developed, actual risk estimates could then be converted into comparable units to determine a weighting factor. If a State has the resources and capability to conduct a true risk assessment, and believes weighting factors should be assigned based on the risk figures developed during that assessment, they are encouraged to do so.

However, weighting factors would be difficult, if not impossible, to quantify for general use in a generic route selection guidebook such as this document. It could vary significantly depending on data such as population distribution and density, accident sto.tistics, and other site-specific factors that vary from one routing situation to another. Therefore, relative weights have not been assigned to the three primary factors in these guidelines. It is believed that the route identified as having the lowest figure of merit as calculated in the mannel described in this document, will be the route most likely to minimize impacts from the transportation of large quantity radioactive materials. 


\section{NORMAL TEANSPORT EXPOSORE}

$$
D=\frac{P L}{v} c_{2}+\frac{L T}{v} c_{2}+\frac{L T}{v} c_{3}+\frac{L}{v}
$$

\section{Segmedt 1}

$P=360,000 / 300=1200 / 8 q \mathrm{ml}$

L. 30 m11es

$\nabla=50 \mathrm{mph}$

$T-80,000 / 24=3333 \mathrm{veh} / \mathrm{hr}$

$$
D_{1}=\frac{0.65}{2}
$$

Segment 2

$P=180,000 / 700=257 / 8 q \mathrm{ml}$

I. 70 miles

$v=50 \mathrm{mph}$

I $=50,000 / 24=2083 \mathrm{veh} / \mathrm{hr}$

$$
D_{2}=-2.42
$$

\section{Segment 3}

$P=15,000 / 1000=15 / 8 \mathrm{q}$ m1

I. 100 miles

$v=50 \mathrm{mph}$

$I=30,000 / 24=1250 \mathrm{veh} / \mathrm{hr}$

$$
B_{3}=2.0
$$

\section{Sexment 4}

$P=40,000 / 2900-14 / 8 q=1$

I. 290 111es

$v=45 \mathrm{mph}$

I $=30,000 / 24=1250 \mathrm{veh} / \mathrm{hr}$

$$
D_{4}=\frac{6.45}{-2}
$$

$c_{1}=6.7 \times 10^{-5}$

Avg D1at Opposiug Lanes $50 \mathrm{ft}$.

$c_{2}(\operatorname{Tab} 1 \cdot 3.2-1)-3.7 \times 10^{-10}$

Avg Veb Separation DIet $-79 \mathrm{ft}$.

$c_{3}(\mathrm{rab}=3.2-1)=1.6 \times 10^{-5}$

$c_{1}=6.7 \times 10^{-5}$

Avg D1Et OPPOSIng Lades - $40 \mathrm{ft}$

$c_{2}$ (rable $\left.3.2-1\right)=4.4 \times 10^{-10}$

Av8 Veh Separation D1st = $126 \mathrm{ft}$.

$c_{3}(\mathrm{Iab} 1 \mathrm{e} .2-1)=1.5 \times 10^{-5}$

$c_{1}=6.7=10^{-5}$

Avg D18t Opposing Lanes-40 ft.

$c_{2}(x a b 1 \cdot 3.2-1)=4.4 \times 10^{-10}$

Avg Veh Separation D1st = 211 ft.

$c_{3}($ Iable $3.2-1)=1.5 \times 10^{-5}$

$C_{1} \cdot 6.7 \times 10^{-5}$

Av8 D1Et Opposing Lene - $50 \mathrm{ft}$.

$c_{2}(I \wedge b d e 3.2-1)=3.7 \times 10^{-10}$

AvB ven separation D18t $=190 \mathrm{ftr}$

$c_{3}(\mathrm{Table} 3.3-1)=1.5 \times 10^{-5}$ ROOTE IOTAL $D_{1}+D_{2}+D_{3}+D_{4}=10.52$ 
YORKSBEET 2

PUBIIC BEALIB RISR

Relares Coneequence

$0-5$ M11e Band

Segment Pop.Count Rultlplier Total

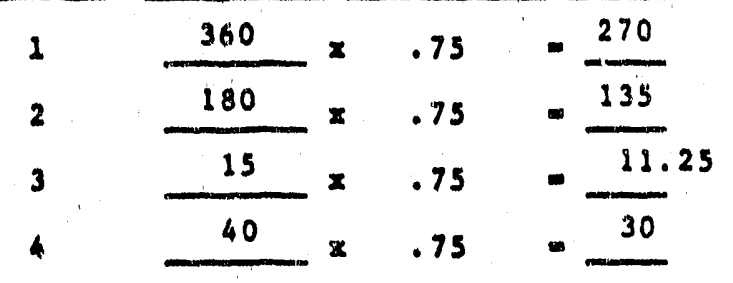

\section{$5-10$ M11e Band}

P'R. Count Multiplier Total

\begin{tabular}{cc}
$\frac{70}{50} \times .25$ & $-\frac{17.5}{12.5}$ \\
$\frac{11}{30} \times .25$ & .25 \\
\hline
\end{tabular}

SUMMARY

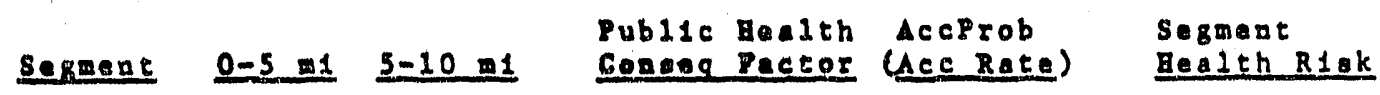

$1 \quad 270+17.5 \times 287.5 \times \underline{0.0006}=0.17$

$2135+12.5 \times 147.5 \times 0.0007 \times 0.203$

$3 \quad 11.2+2.75=\frac{14.0}{2} \times \frac{0.0007}{3}=\frac{0.001}{0.003}$

$4 \quad 30+7.5 \times \frac{37.5}{0.003} \times \frac{0.11}{-1}$

ROUTE TOTAL 
WORKSEEET 3

0-5 M110 Band Segmeat 1 Waighed
Land Uee Type Area We1ght Total

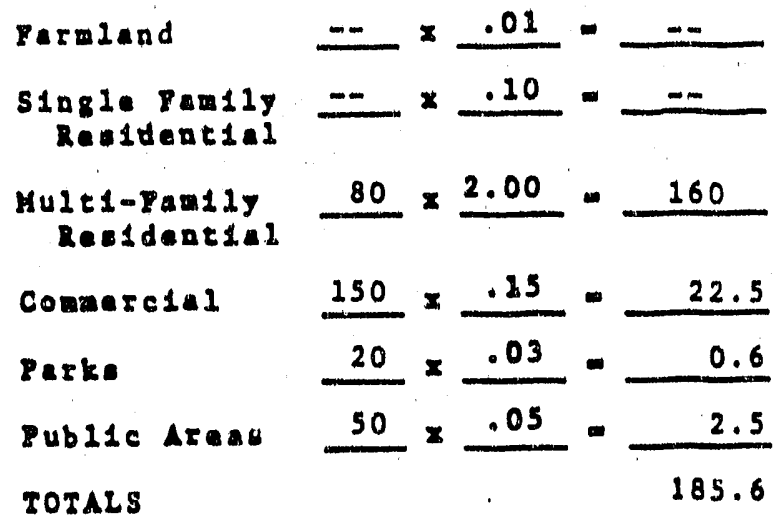

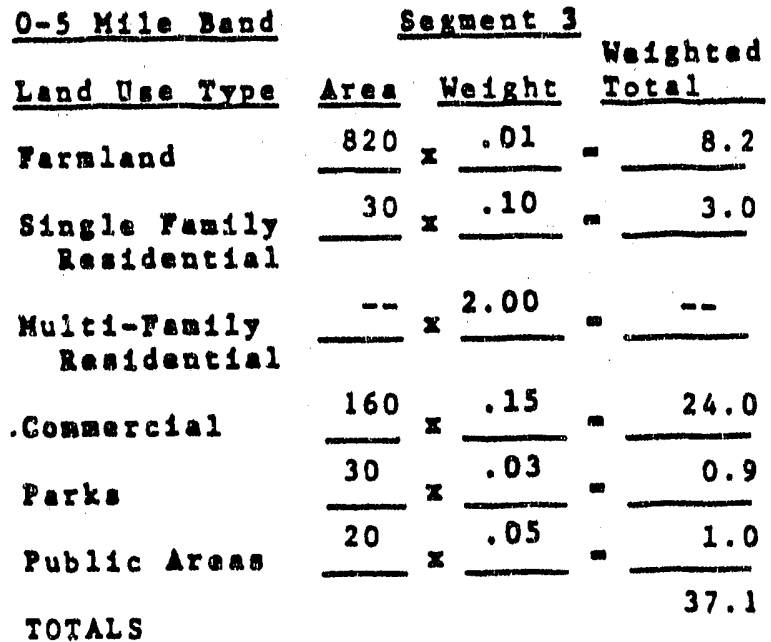
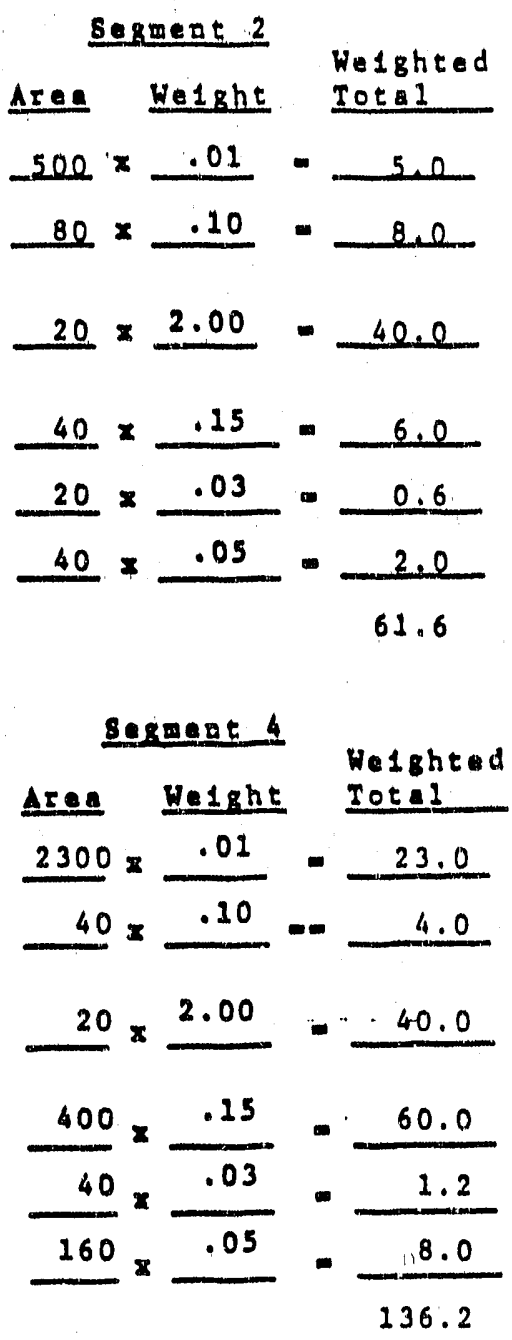

$$
\begin{aligned}
& \text { SOMMARI } \\
& \text { Seguent } \\
& 3 \\
& 4 \\
& \begin{array}{l}
\frac{0-3 \times 11 e}{1856} \\
\frac{61.6}{37.1} \\
136.2
\end{array} \\
& \text { (From Page 2) Econ Conaeq Zcon Prob Segment } \\
& \text { 5-10 Mile : Factor (Ace Rate) Econ Riak } \\
& +202 \\
& 100+62 \\
& \frac{0.06}{0.12} \\
& -716 \times 0.007-0.05 \\
& \text { - 45.4 } x \text {. } \\
& \text { - 166.2 } 2.003 .0 .5 \\
& \text { Noute Total } 2 \text {. }
\end{aligned}
$$




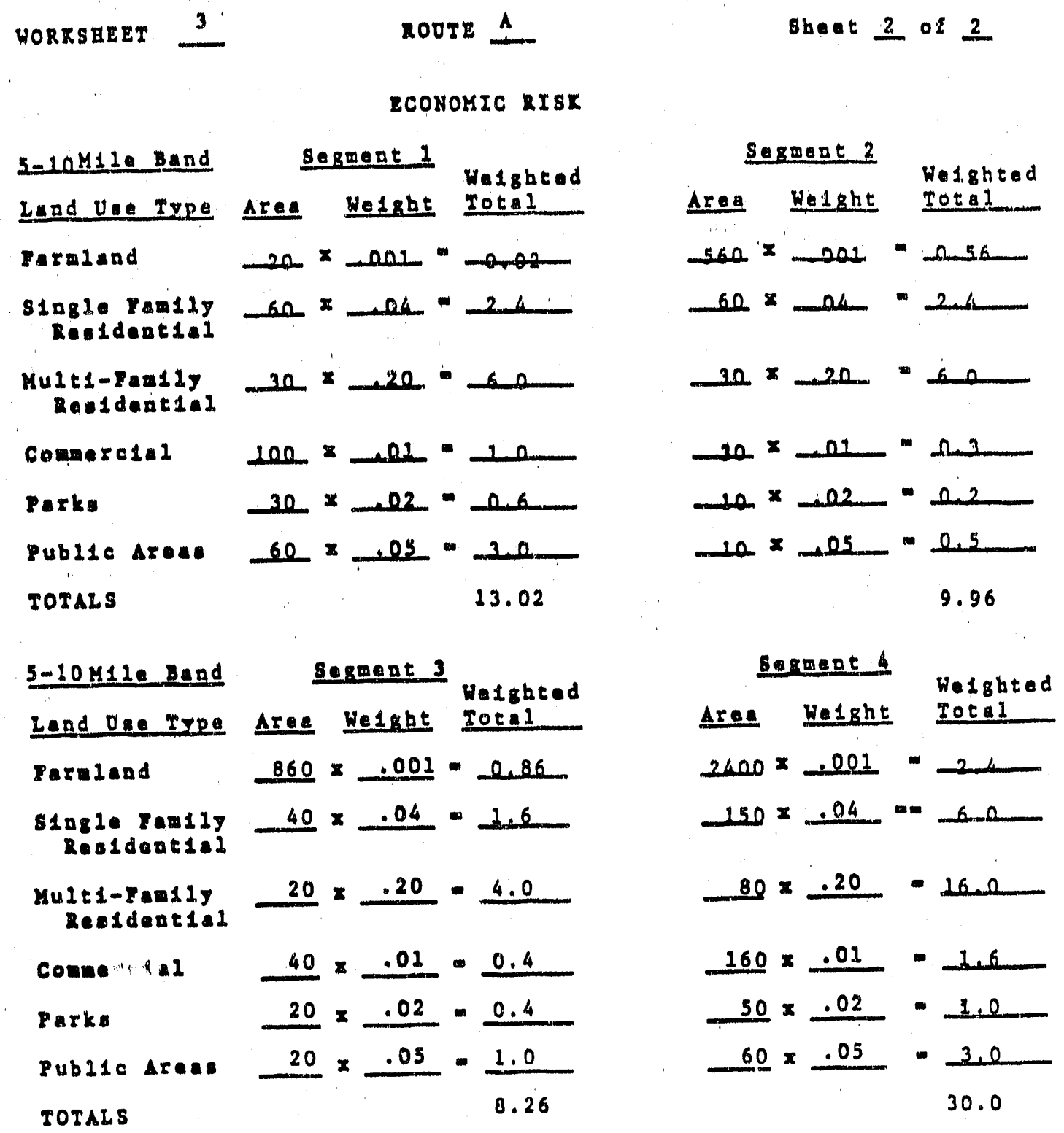




\section{NORMAL TRANSPORT EXPOSURE}

$$
D-\frac{P L}{v} c_{1}+\frac{L T}{v^{2}} c_{2}+\frac{L F}{v^{3}} c_{3}+\frac{L}{v}
$$

\section{Sereent 1}

$p=28,000 / 3200-9 / 2=1$

I. 320 a11a

$\checkmark-40$ aph

I. 25,000/24.1042 vah/hr

$$
D_{1}=\frac{8.0}{2.0 .}
$$

sereent 2

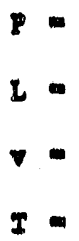

$$
\mathrm{D}_{2}=
$$

\section{ecreant 3}

$$
\begin{aligned}
& P= \\
& 2= \\
& x=
\end{aligned}
$$

$$
B_{3}=
$$

\section{sereent 4}

$7=$
$7=$
1

$$
D_{4}
$$

$c_{1}=6.7 \times 10^{-5}$

Av8 D1at Oppoeing Lanes - $50 \mathrm{ft}$.

$c_{2}(T a b 103.2-1)=3.7 \times 10-10$

Arg Veh separation DIat - $100 \mathrm{ft}$.

$c_{3}(\operatorname{rab} 1 \cdot 3.2-1)=1.5 \times 10^{-5}$

$c_{1}=6.7 \times 10^{-0.5}$

Avg Dist Opposiag danes -

$c_{2}(\operatorname{tab} 2 \cdot 3.2-1)=$

Avg Veh Separation D1He. -

$c_{3}(\operatorname{Tab} 1 \cdot 3.2-1)=$

$c_{1}=6.7 \times 10^{-5}$

Avg D1at Opposing Lana: -

$c_{2}(\operatorname{rab} 1 \in 3.2-1)=$

Av8 Veb Separation D1Bt -

$C_{3}(T a b 1 * 3.2-1)=$

$c_{1}-6.7 \times 10^{-5}$

AVB D1at Oppoeing Inaes

$c_{2}(\operatorname{rab} 1 \cdot 3.2-1)$.

Av8 Pek Separation D1at =

$c_{3}(r a b 1 \bullet 3.2-1)=$

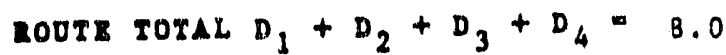


WORKsEEET

ROUTE I

sheot 1 - 021

POZRIO REALTE RISX

Relenve Concequence

$0-5$ Y110 Band

5-10 M11e Band

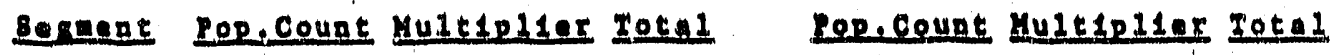

1

$28=.73 \times 21.0$

$7 \times .25$

$-1.75$

2

$\times \quad .73$

-

$[\times 23$

3

$\times \quad .73$

-

$-23$

4

$\times \quad .75$

-

$=.25$

SDMMARY

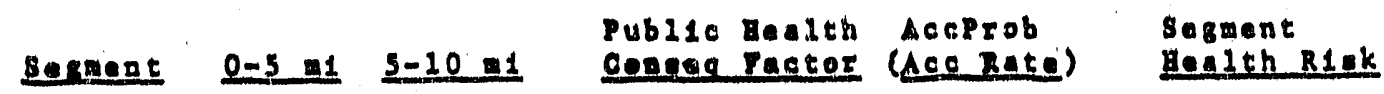
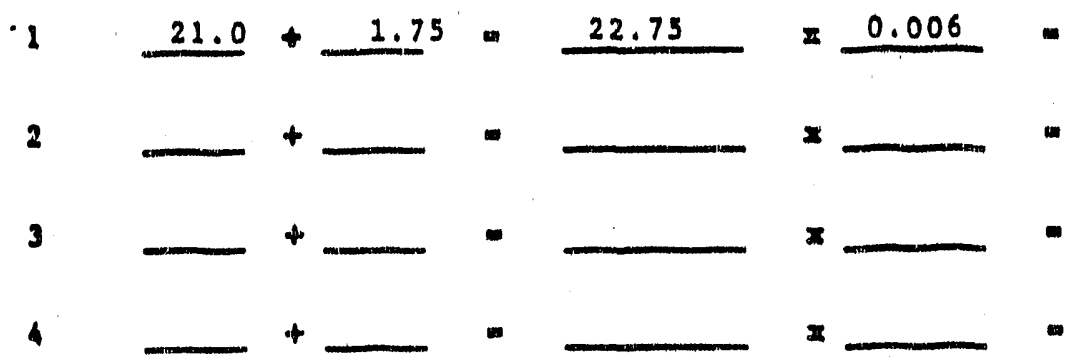

ROOTE SOTAL

$\underline{0.14}$ 


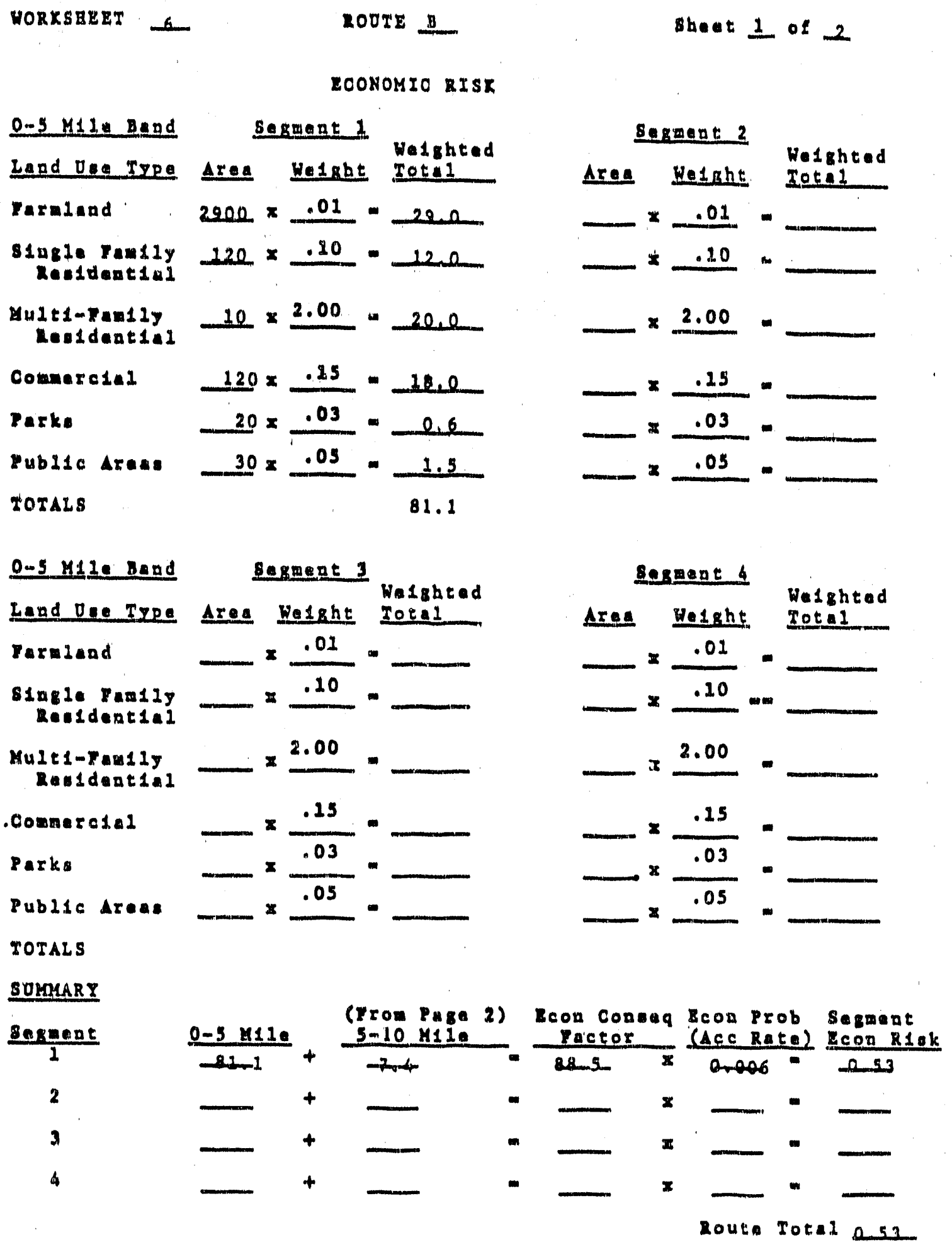




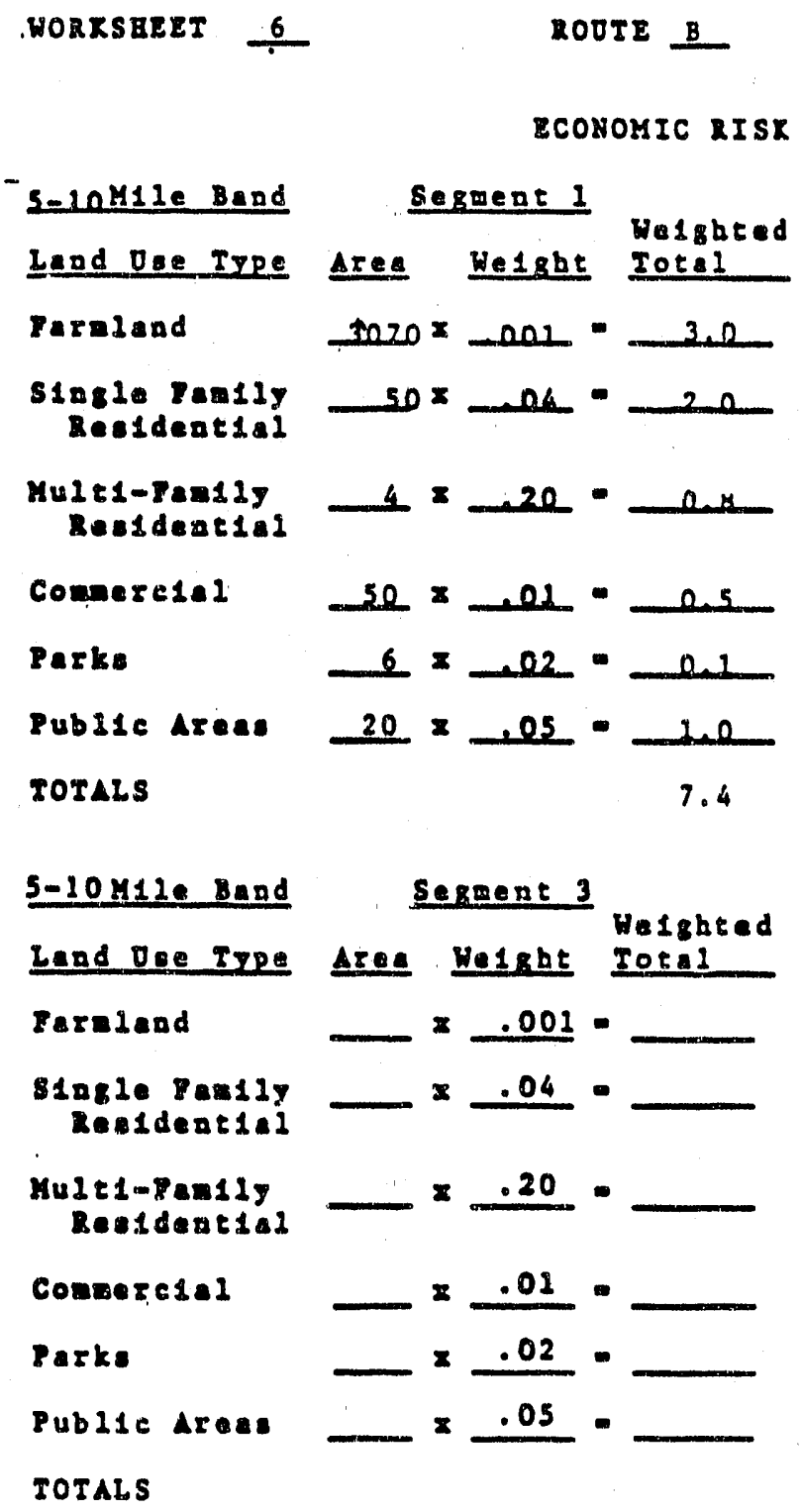

5-10411e Band

Lend Ooe Trpe

Farelend

single Pand1y Rendeatsel

Hude1-7an11y Bealdenesal

Comaercsal

Parks

Public Areas

TOTALS

sheet 2 of 2

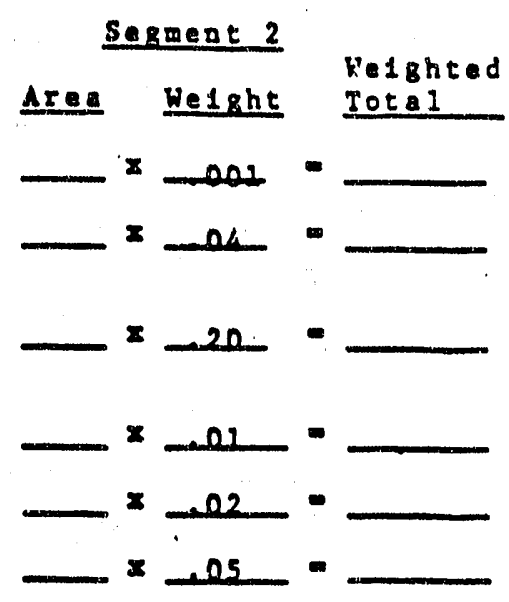

\section{Sesment 4} Aree We1ght Wolghted $-]^{x} \times \frac{.001}{.04}-=$ $-120 \times-$ $-\frac{.01}{.02}=-$ 
WORKSBEET ?

ROUTE A

Sheet 1 of 1

\section{RMERGENCY RESPONSE AND EVACOATION}

EMERGENCY RESPONSE

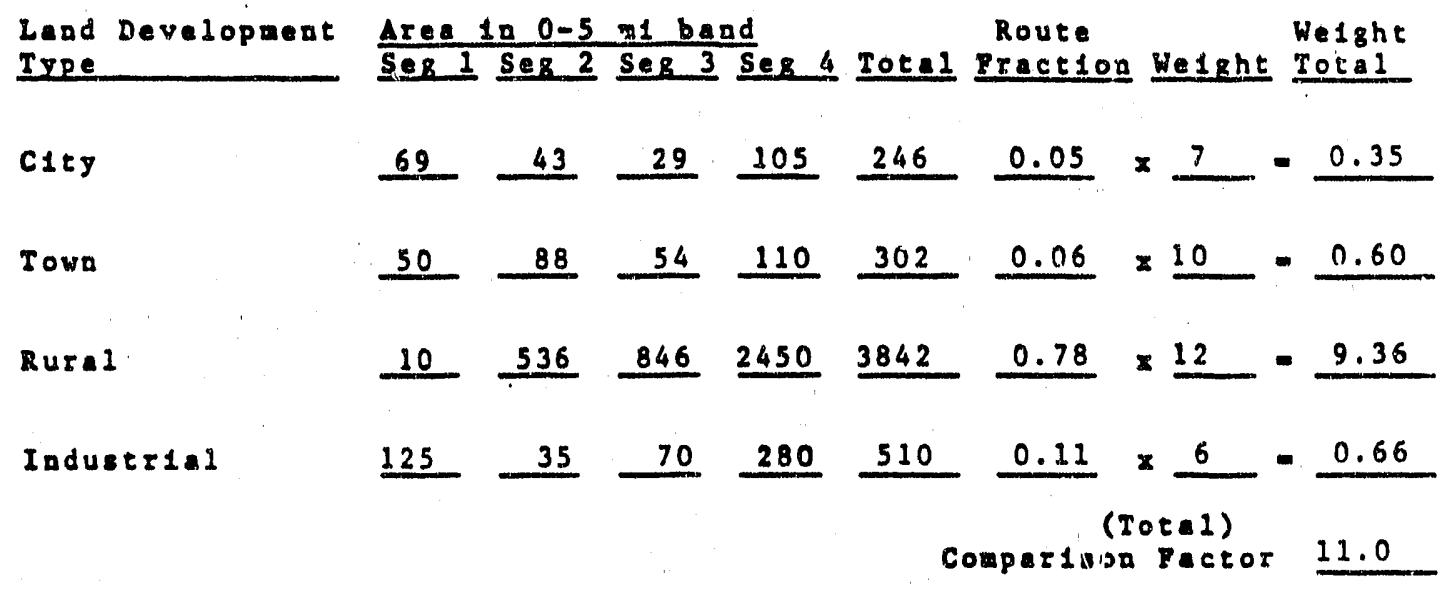

\section{RVACUATION}

Land Development Irpe

Aree 10 $0-5$ m 1 band

Route

Helght

Rura 1

$10 \quad 536 \quad 846 \quad 2450 \quad 3842 \quad 0.78 \times 11=8.58$

Suburban

$50 \quad 88 \quad 54 \quad 110 \quad 302 \quad 0.06 \times 13=0.78$

Urban

$69 \quad 23 \quad 29 \quad 205 \quad 246 \quad 0.05 \times 28=1.40$

Commerc1e1 $\ldots \quad 62 \quad 18 \quad 35 \quad 140 \quad 255 \quad 0.05 \times 15 \quad 0.75$

Induetr 1 a 1

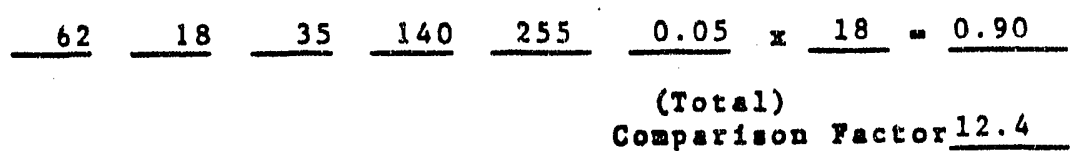




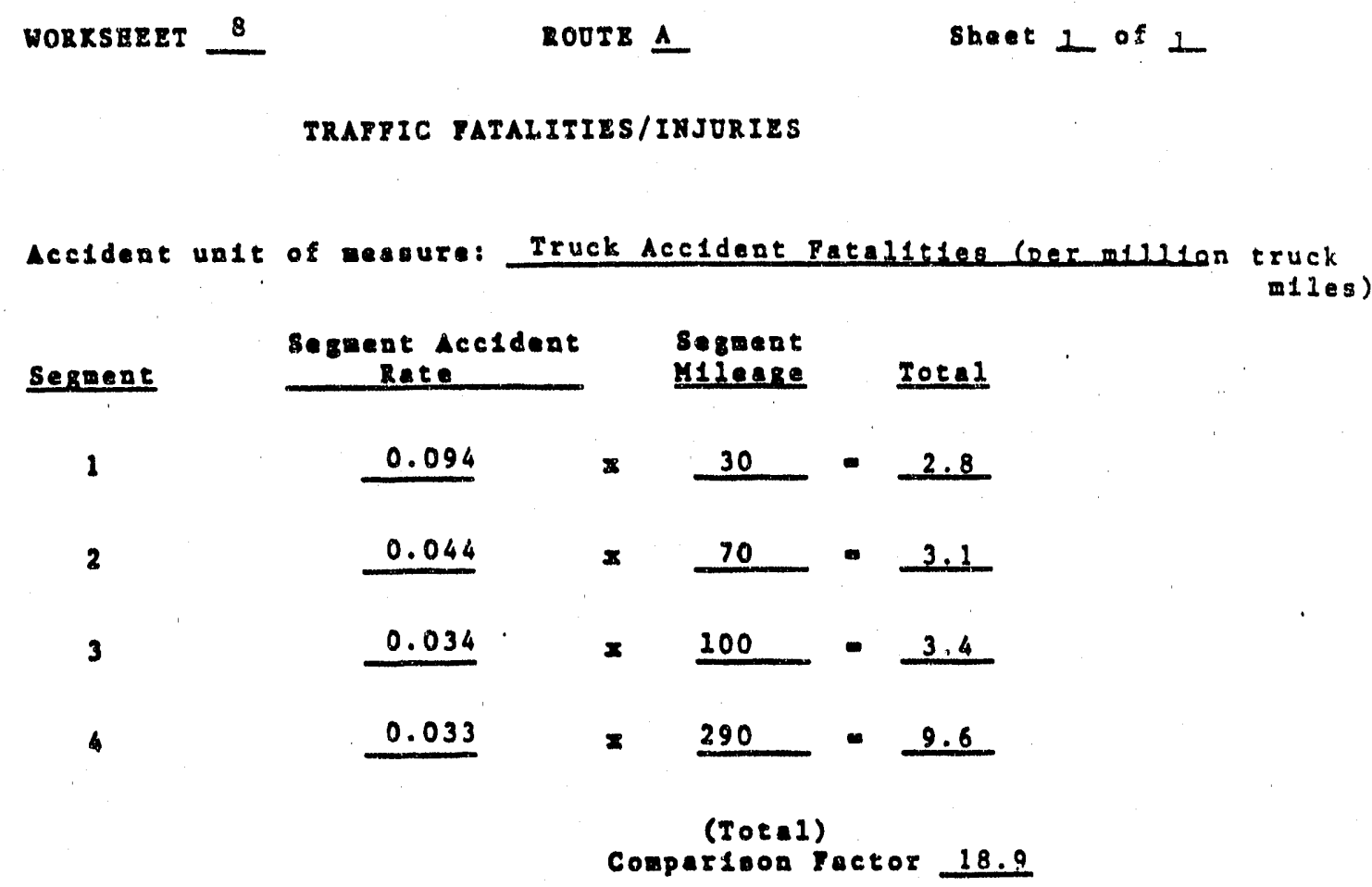


WORXSBEET 2

\section{EMERGENCE RESPONSE AND ETACDATION}

\section{EMERGENCY RESPOHSE}

Land Developiant Irpe

Area in $0-5$ m band Route We 1 ght

c1es Ses 1 Seg 2 Ses 3 Ses 4 Total Eract10n We1ght Total $35-35-0.01 \times 7-0.07$

rova 60

Rurad

3045 $60 \quad 0.02=10=0.19$

Induetral 60

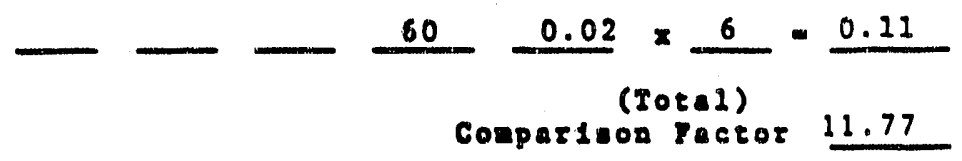

\section{EVACUATION}

Land Derelopuent Irpe

aural 1

Suburbar

Drbaa

Consercial

Induetrial
Area $10 \quad 0-5 \quad 1$ bend Noute HeIBht Seg 1 Ser $2 \operatorname{Seg} 3 \operatorname{Seg} 4$ Total Pract1on Ne1ght Total

3045 $3045 \quad 0.95 \times 11-10.45$ 60

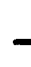
$60 \quad 0.02 \times 13-0.25$

35 $35 \quad 0.01 \times 28=\underline{0.28}$ 30 $30 \quad 0.01 \times 15 \div 0.15$ 30 30 


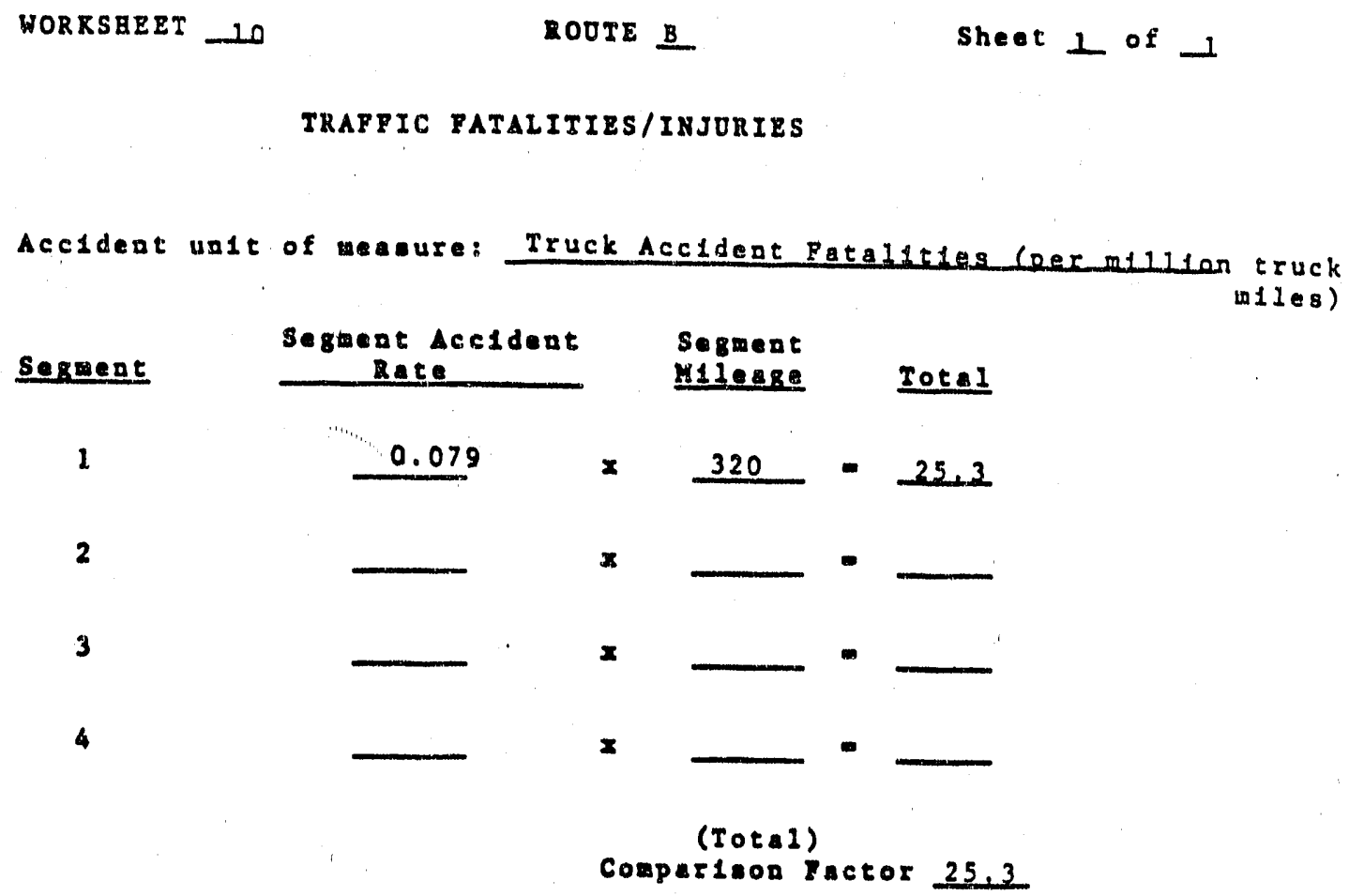




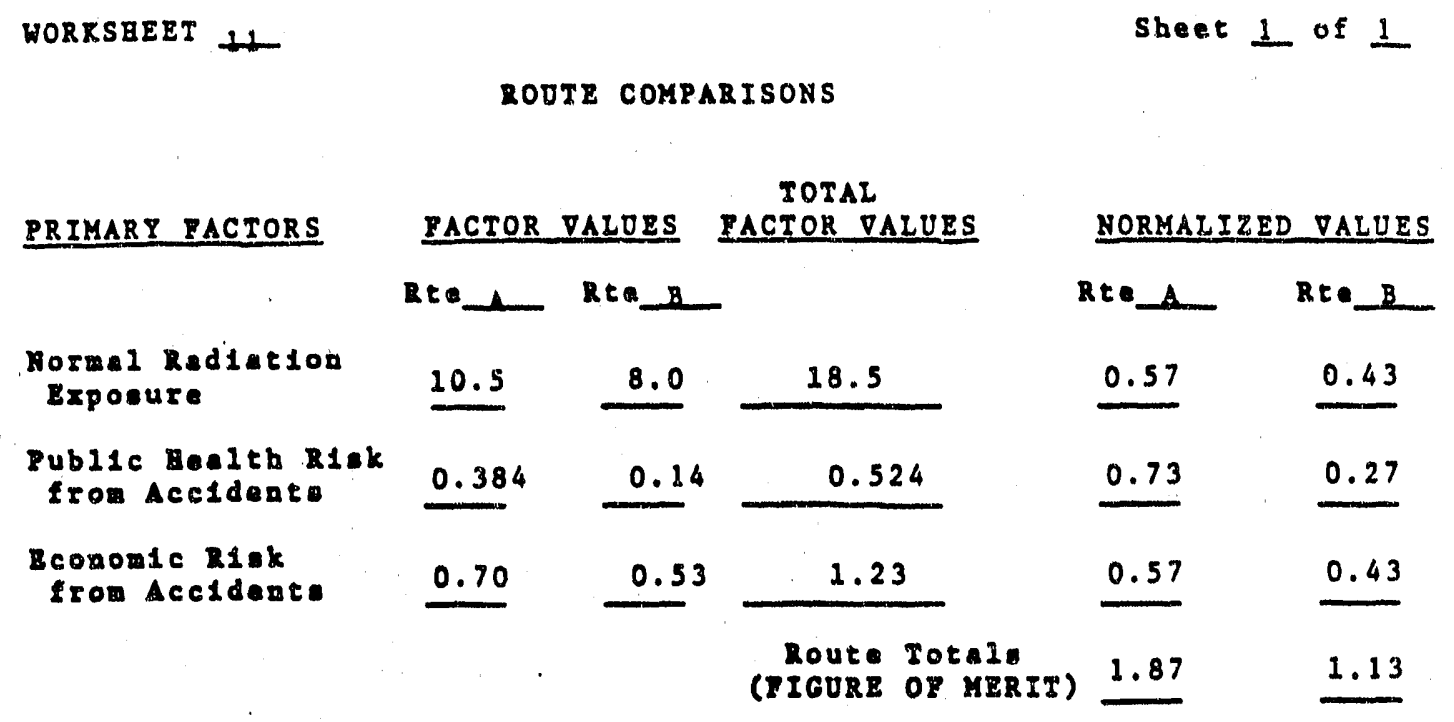

TOTAL SECONDARY FACTORS PACTOR VALOES ZACTOR VALDES HORMALIZED VALDES

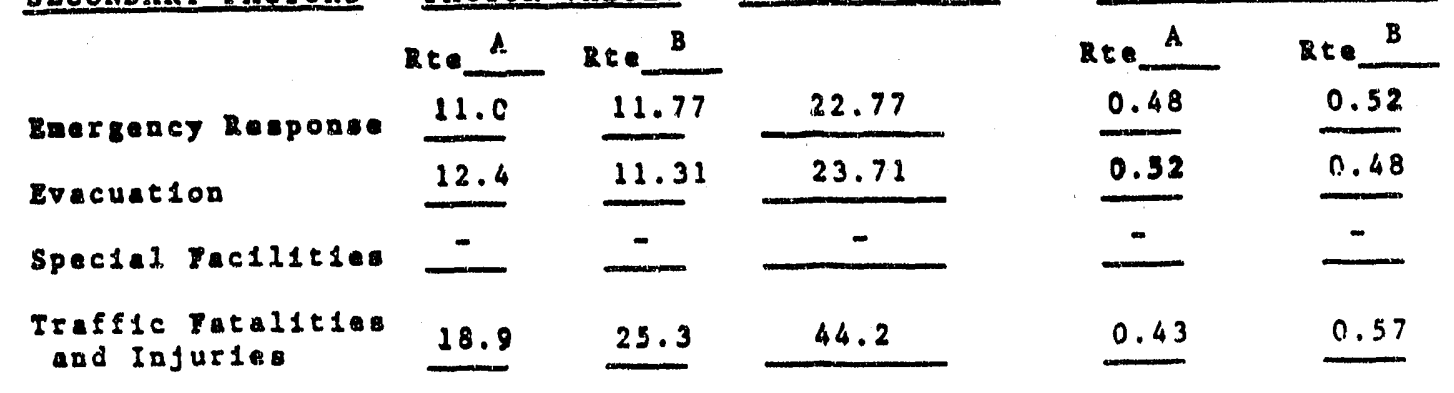


APPENDIX A

WORKSHEETS FOR APPLYING ROUTING GUIDELINES

Route Identification Chart

Normal Transport Exposure

Public Health Risk

Economic R1sk

Emergency Response and Evacuation

Special Facilities

Traffic Fatalities/Infuries

Route Comparison Chart 

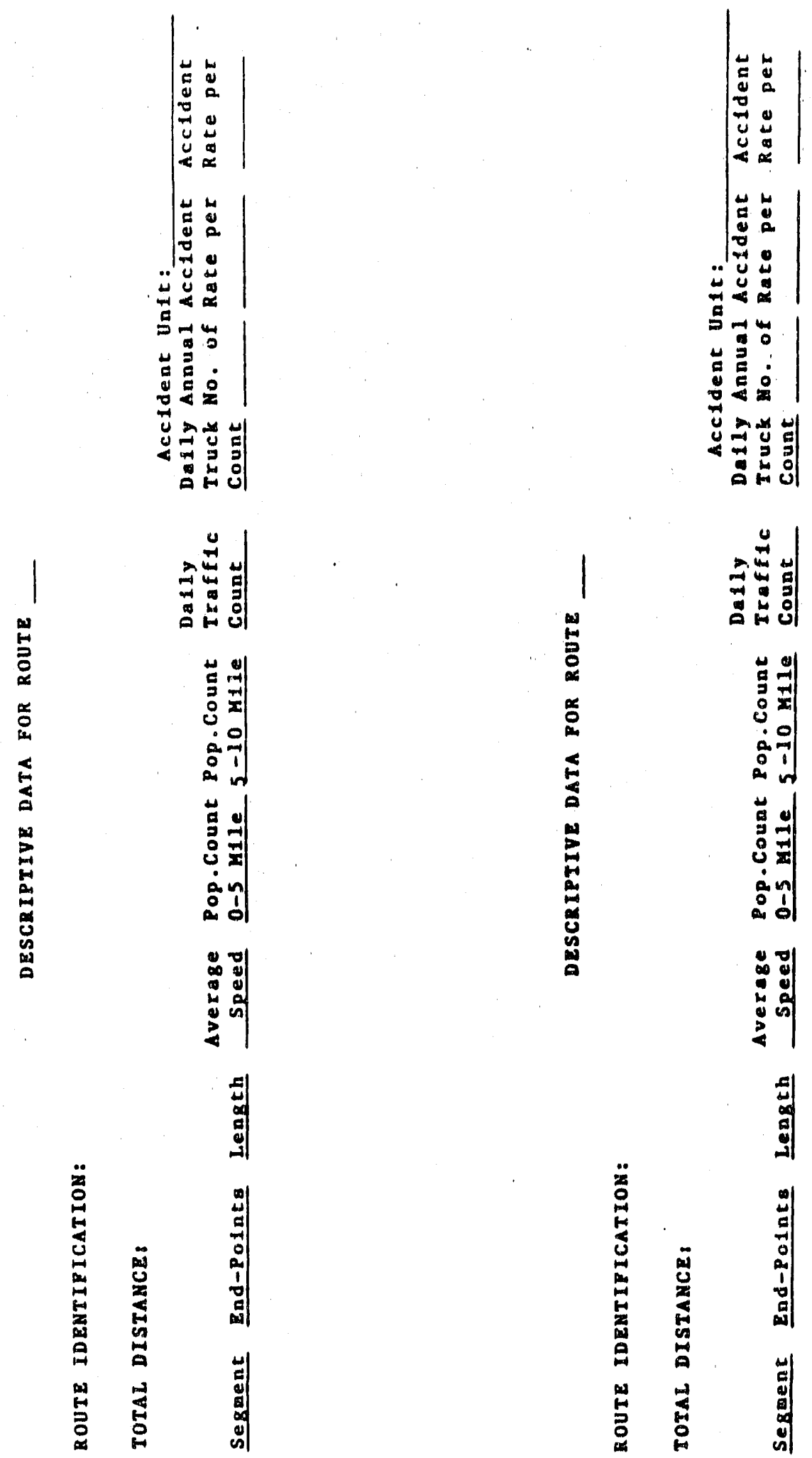
WORRSBEET

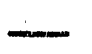

RO0TE

Sbent - of -

MORMAL TRANSPORT EXPOSURE

$$
D=\frac{P L}{v} c_{1}+\frac{L T}{\nabla} c_{2}+\frac{L T}{\nabla} c_{3}+\frac{L}{v}
$$

\section{Segment 1}

\section{P. \\ L. \\ $\checkmark \cdot$ \\ I -}

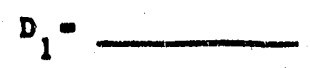

Sesment 2

$$
\begin{aligned}
& P= \\
& 2= \\
& I=
\end{aligned}
$$$$
\mathrm{D}_{2}=
$$

sesment 3

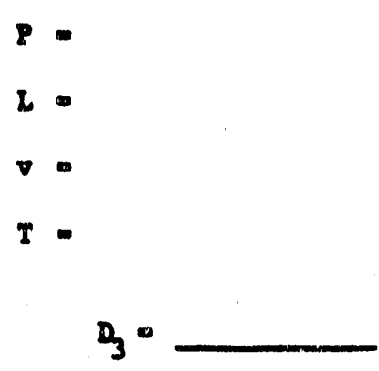

\section{Segment 4}

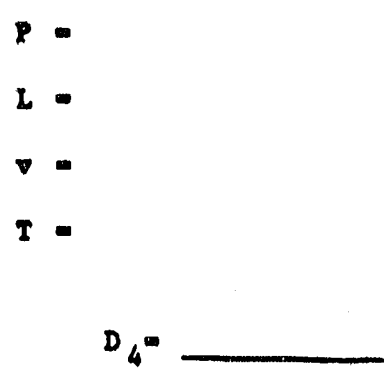

$$
\begin{aligned}
& c_{1}=6.7 \times 10^{-5} \\
& \text { Ave D18t Opposigg Lanes - } \\
& \left.c_{2} \text { (Table } 3.2-1\right)= \\
& \text { Av8 Veb Soparation D1ot - } \\
& c_{3}(\text { Tab1. 3.2-1) }=
\end{aligned}
$$

$c_{1}=6.7 \times 10^{-5}$

Avg D1et Oppoe1ng Laves.

$c_{2}$ (Iable $\left.3.2-1\right)$.

Avg Vah Separation DIat -

$c_{3}(x \times b 1.3 .2-1)=$

$c_{1}=6.7 \times 10^{-3}$

Avg Diet Oppoedng Lanes.

$c_{2}$ (Table 3.2-1) =

Avg Veb Separation DIst -

$c_{3}($ Tabla $3.2-1)=$

$c_{1}=6.7 \times 10^{-5}$

ATE DAEt Opposing LaDeA -

$c_{2}(\operatorname{Tab} 1 \cdot 3 \cdot 2-1)=$

Ars PeÉ separation Ddet -

$c_{3}(x a b l \cdot 3.2-1)$.

Roots rotal $D_{1}+D_{2}+D_{3}+D_{4}=$

$A-3$ 
WORRSBEET

Sheet _ of

PUBIIC BEALTE RISR

Release Consequence

$0-5$ M11e Band

Sesment Pop.Count Mult1pl1er Total

1

2

3

4

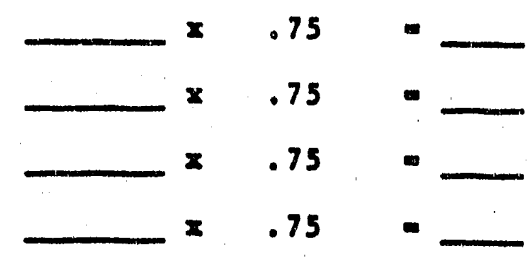

\section{5-10 M11e Band}

Pop.Count Mult1p11ar Total

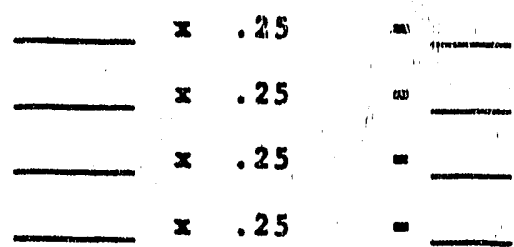

\section{SOMMARY}

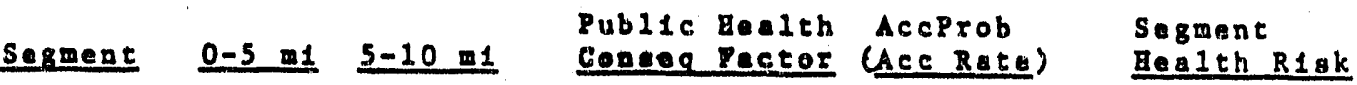<smiles>[13CH3]</smiles>

2

$+$
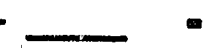

$+$

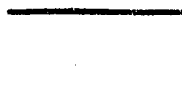

4 $+$
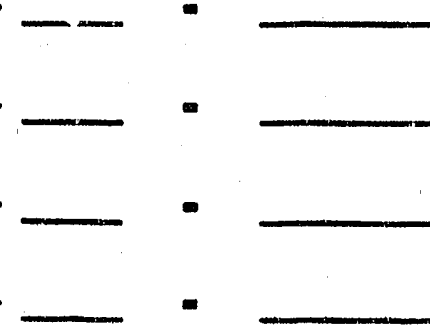

$x$

$\mathbf{x}$

*

38

ROUTE TOTAL

$A-4$ 
WORRSEEET

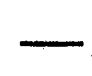

ROOTE

sbeet 1 of 2

ECONOMIC RISK

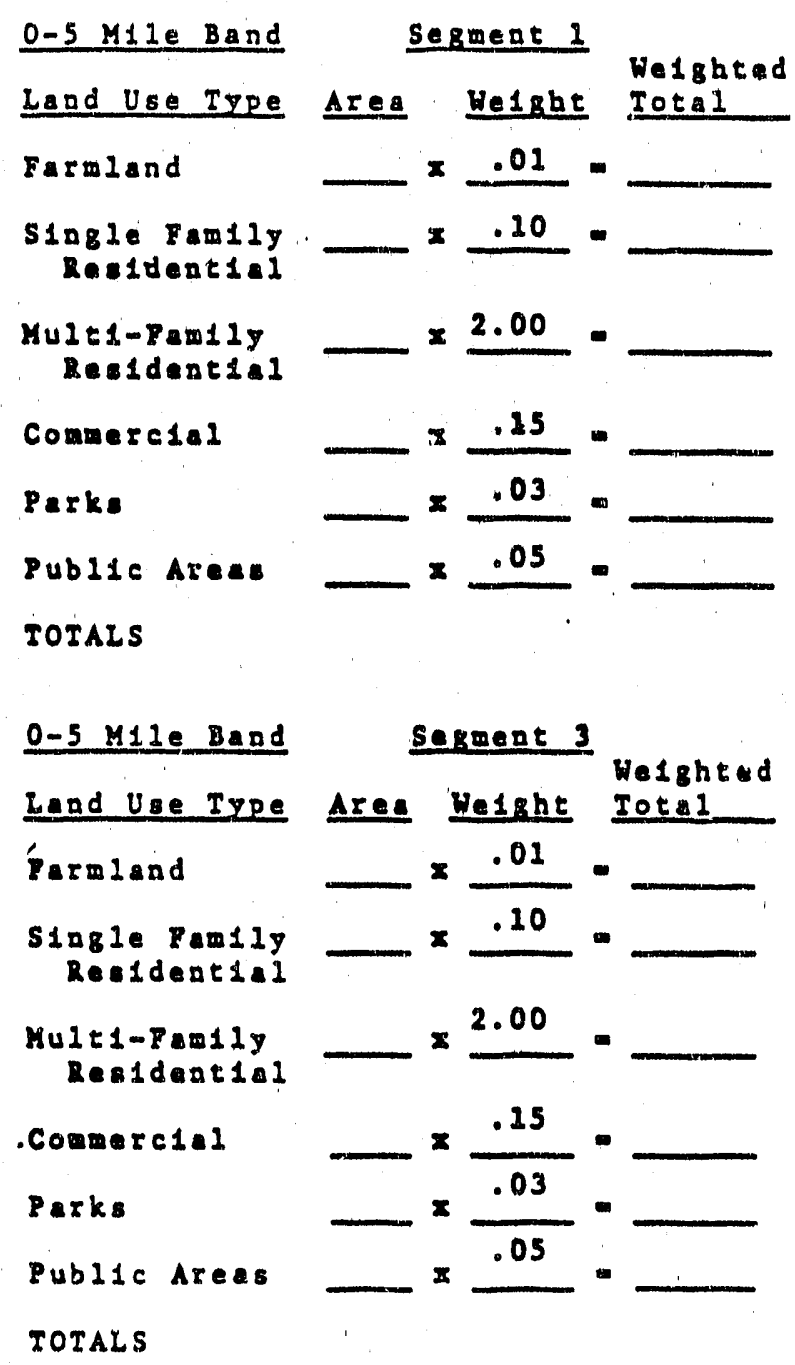

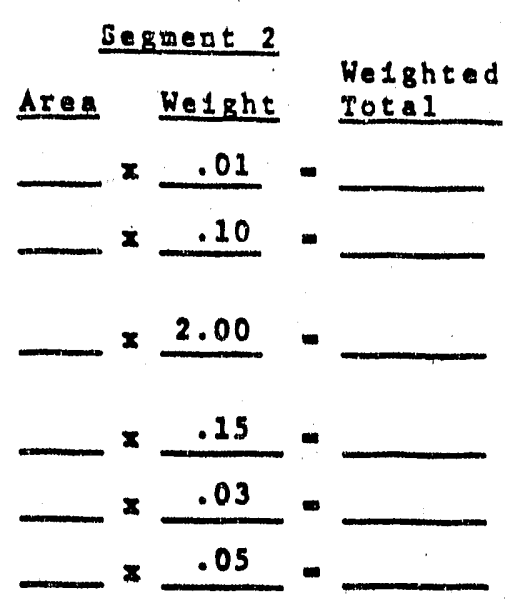

\section{Segment 4}

Atea We1ght Totghtad
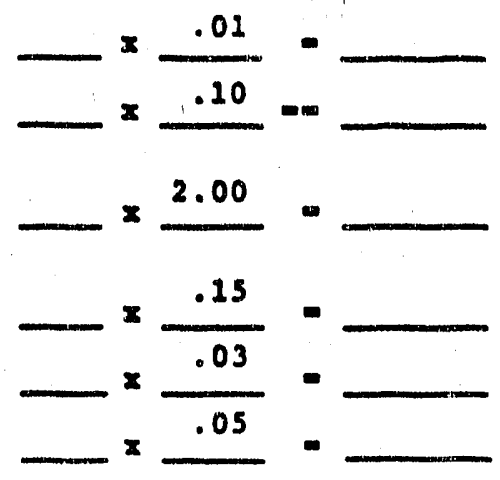

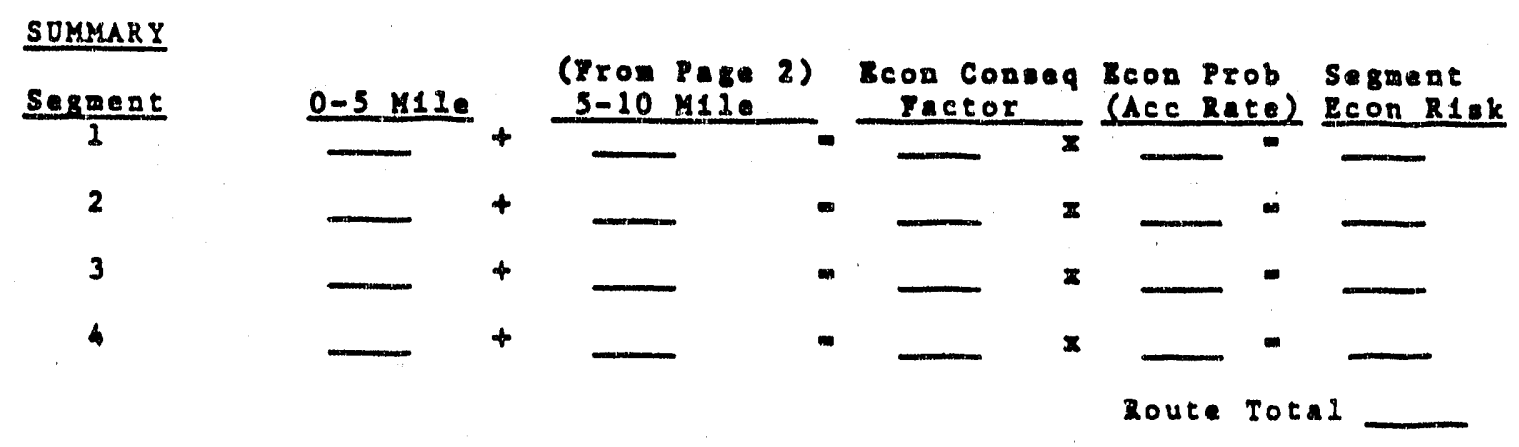




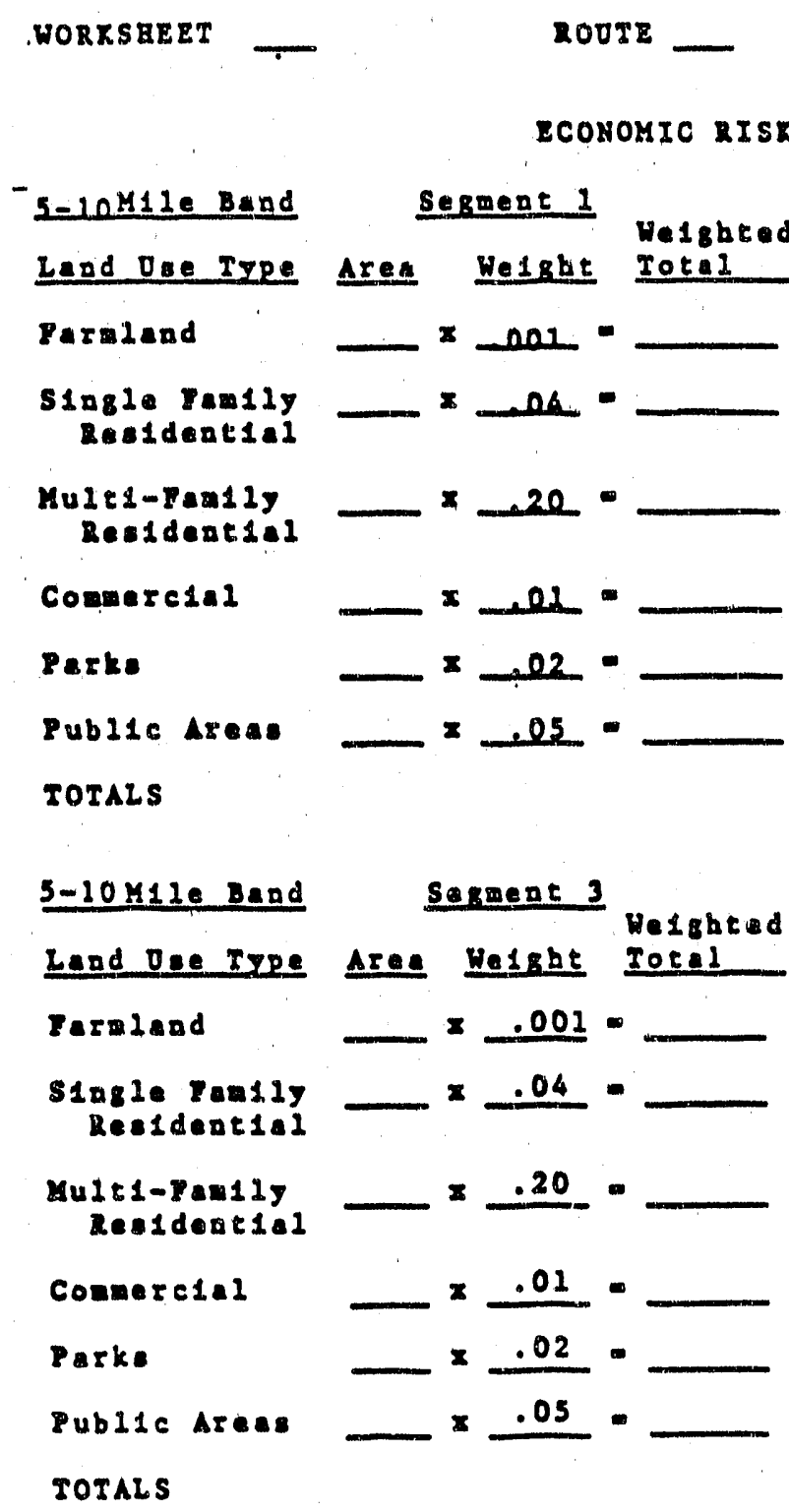

Shest 2 of 2

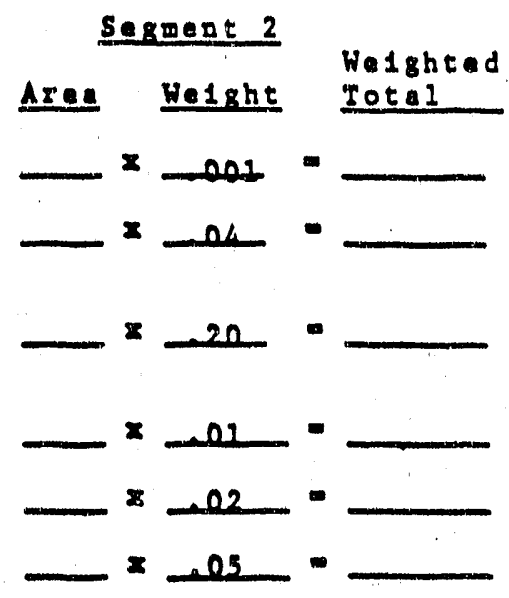

\begin{tabular}{l} 
Sergeot \\
Wea We1ght Totgled \\
\hline
\end{tabular} Area We1sht Total

$-\times .001=$

$-.04=$

$-.20=$

$-\frac{.02}{.02} \times=-$ 


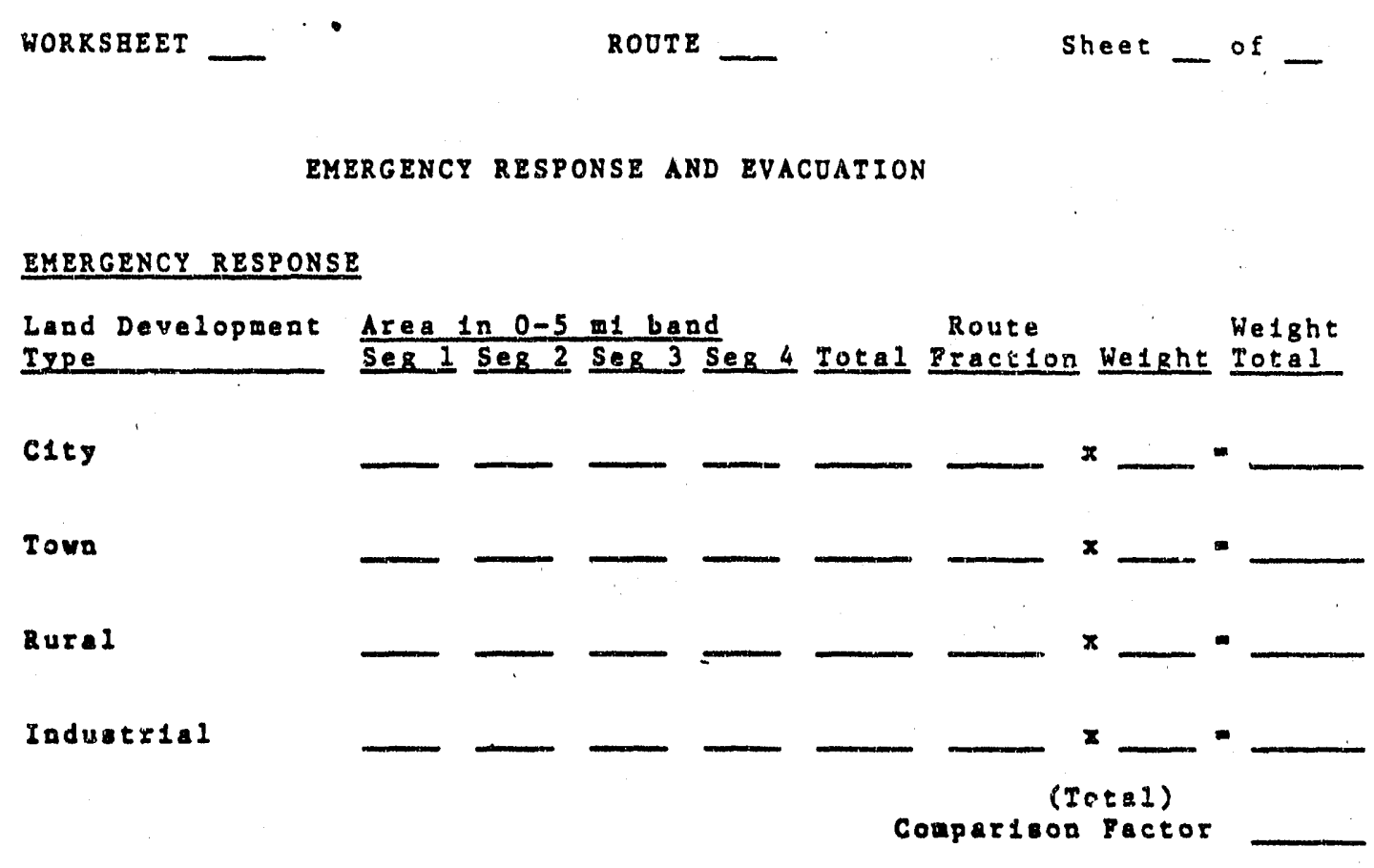

\section{EVACUATION}

Land Developmeat Irpe

Area $\ln 0-5$ in band

Route

Welght

Seg 1 Seg 2 Seg 3 Seg 4 Total Praction We1ght Total

Rural

Suburbad

Urban

$$
\widetilde{-1}
$$

Commerclal

Induetr1: 1

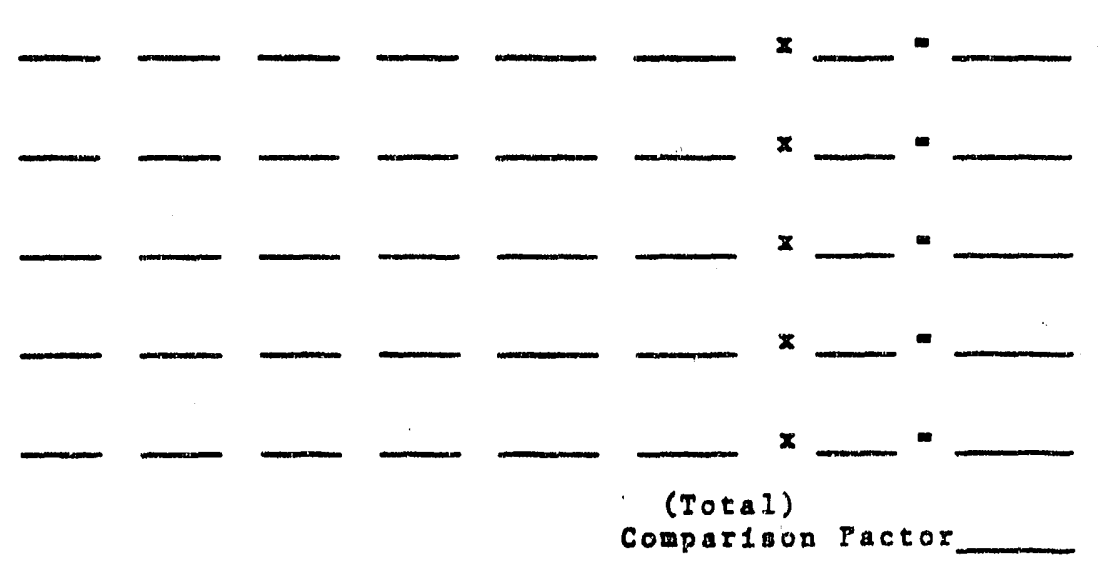

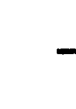

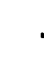


HORRSBEET

Trpe of Fac111ty

Cb1ddrea' Hoep1tal

Mosp 1 ta 1

Pr1son

Durs1ag Hone

Sehool

Church

stodium

Shopplag Center

Theater
ROUTE

$-$

Sheet _ of

SPECIAL FACILITIES

Number of Welghting Pactor

Pec1l1t1e (reble 3.2-6)

Total

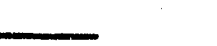

$\mathbf{z}$

2

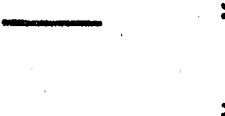

x.

2
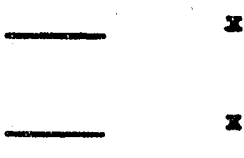

$\mathbf{x}$

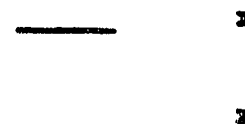

2

$x$
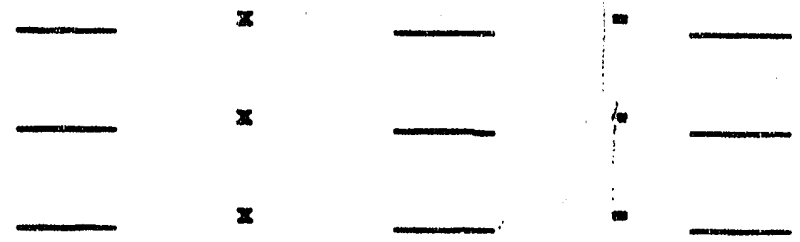

(Tota1)

Comparison Factor 


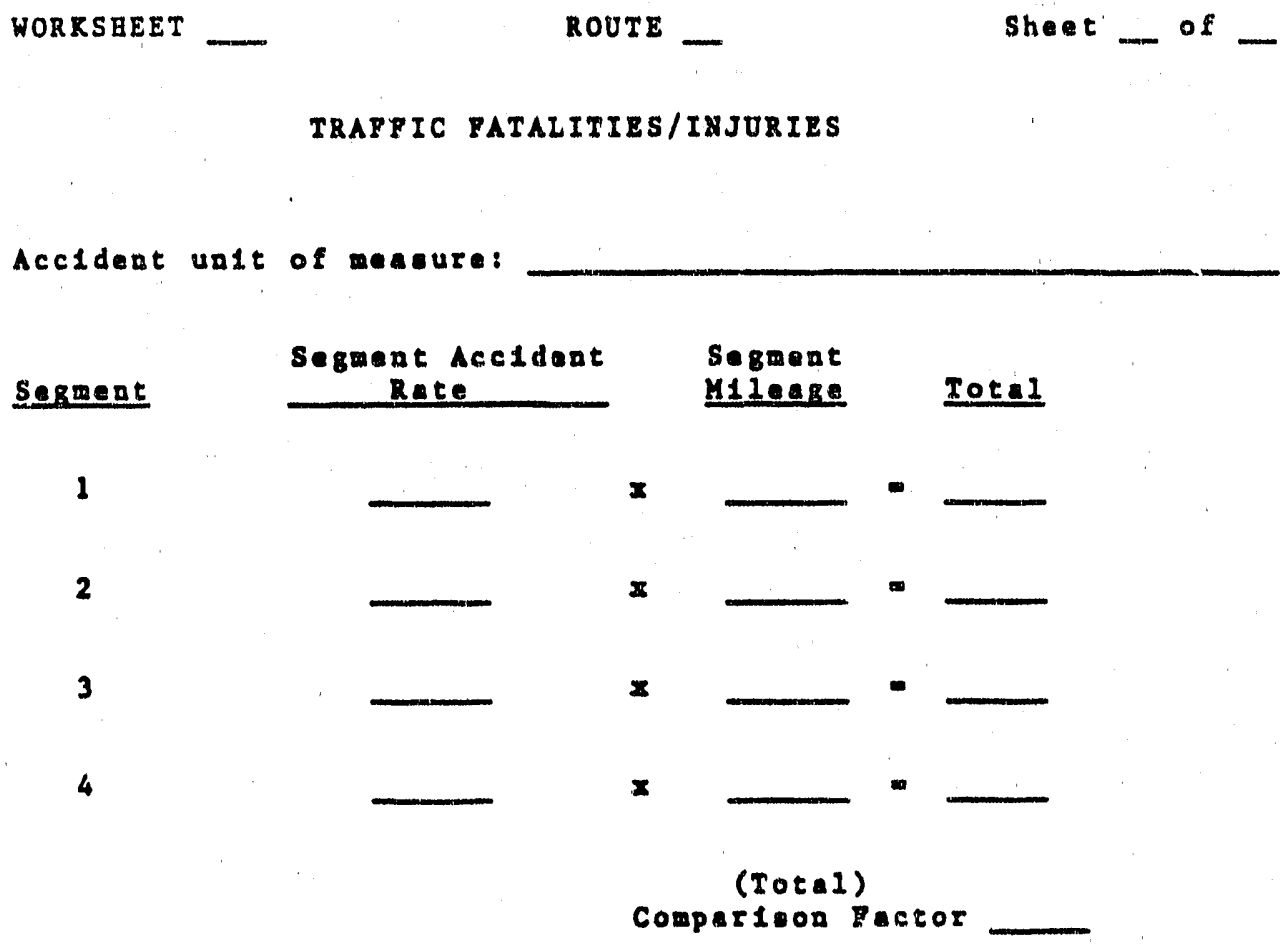

A -9 
ROOTE COMPARISONS

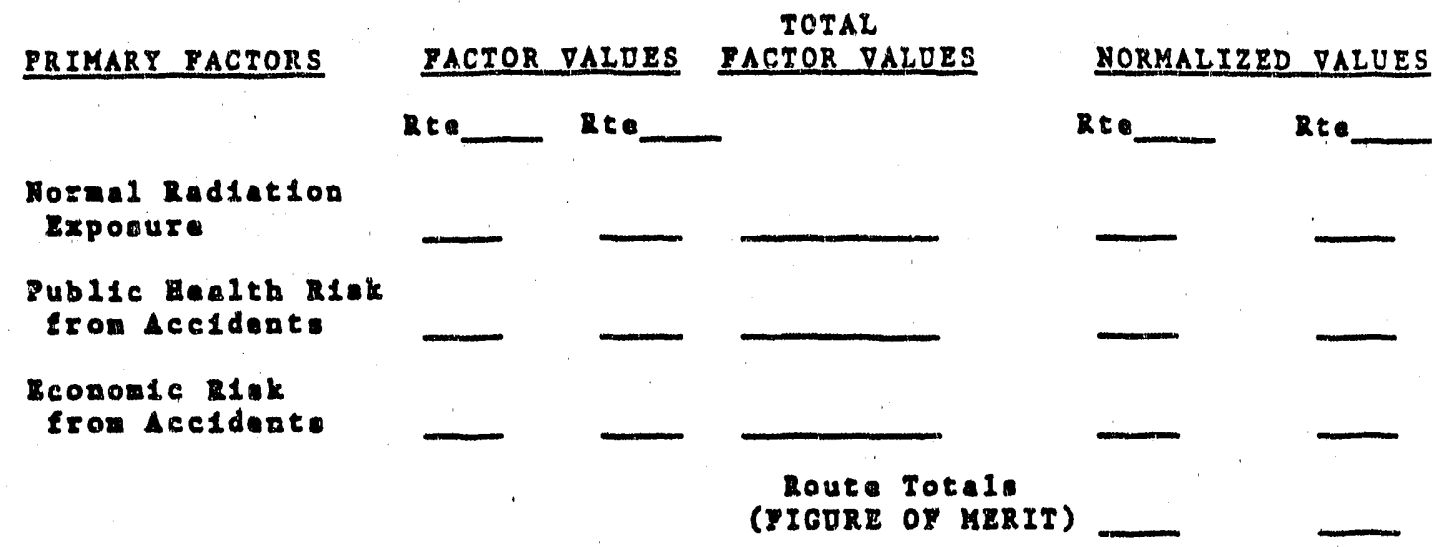

TOTAL

BECOHDART PACTORS YACTOR VALOES FACTOR TALOES WORMALIZED PALOES

$$
\text { Res. }
$$$$
\text { Le? }
$$

Rte

Rte

Imergency Reapone
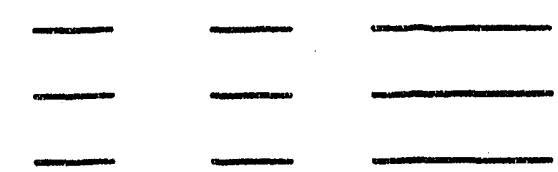

Evacuation

spocial Fag111t1es

Traffic Patel1t1e

and Ingurleo

$A-10$ 


\section{APPENDIX B}

\section{DER IVATION OF RELEASE CONSEQUENCE ESTIMATE}

\section{Release Consequences}

In this analysis, the estimation of the consequences of an accidental release of radioactive material is based upon a linear relationship between dose and health effects. The health effects estimated in this analysis are latent cancer fatalities due to short duration expesure to airborn radionuclides. A reasonable estimate of health effects can be made by determining the inhalation dose received over the duration of the release (A. L. Franklin 1980). Estimates of the inhalation dose can be made by applying a standard atmospheric dispersion model to various atmospheric conditions and radioactive material release rates (D. B. Turner, 1970). Because this routing decision analysis is concerned with identifying a route preference, exact determination of the health effects is not necessary. This allows the methodology to be generalized somewhat. It will not be necessary to identify the specific material being shipped and which organs are most sensitive to that material. Also the conversion of dose to health effect will not be necessary since the same material will be shipped over each route and no physical differences are expected in the populations along the pathway. With these simplifying assumptions, exact calculation of health effects can be reduced to calculating the dose to the general public. The dose to the general public will be directiy related to the quantity of material inhaled. The quantity of material that can be inhaled by a group of individuals will primarily depend upon their orientation with respect to the release site and wind direction. Figure B.l shows several possible orientations for individuals near a release of radioactive material. 


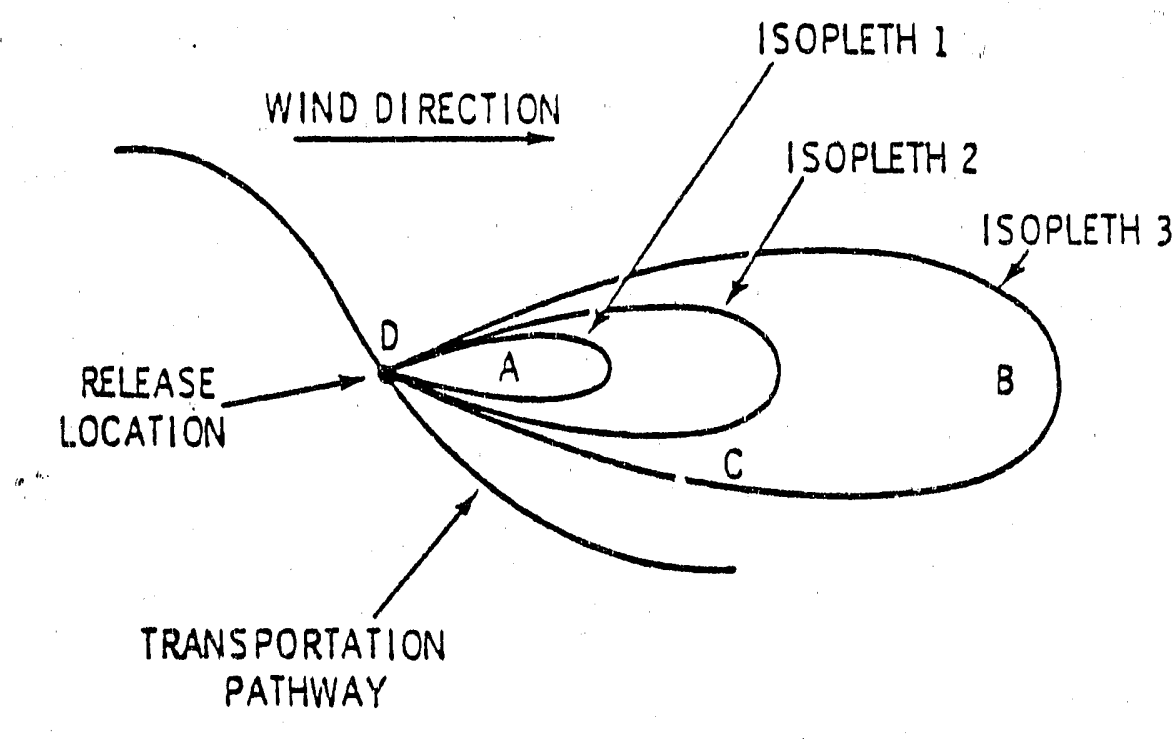

FIGURE B.1. Dispersion Isopleths

The isopleths, shown in Figure B.1, are lines of constant atmospheric concentration. Isopleth 1 identifies a line of higher concentration than isopleths 2 or 3 . Isopleth 3 is a lower concentration than isopleth 2 and may represent the lower limit of exposure consideration. Past isopleth 3 the material may be considered as totally dispersed (below hazardous concentrations). Four individuals $A, B, C$, and $D$ are presented in Figure B.1. Individual $A$ is standing directly downwind from the release and will receive an inhalation dose proportional to the airborn concentration of radioactive material at that point. Individual $B$ is also standing directly downwind but will receive a smaller dose than $A$ because his distance from the release location is greater. This allows the material to disperse more before reaching $B$. Individual $C$ is closer to the release location than $B$ but will receive a dose similar to $B$ because he is not standing directly downwind. Finally, individual $D$ is closer to the release location than any of the other individuals but will receive essentially no exposure because the isopleths converge on the release location. This person is not standing in the dispersion pattern.

Figure $B .1$ demonstrates that the determination of inhalation dose is highly dependent upon the wind direction and the distance from the release location. To apply this dispersion pattern to a general population 
along a transportation pathway, the position dependent concentrations need to be combined with the number of persons at each position. This was done by dividing the isopleths into a grid pattern. The average airborn concentration in each cell is multiplied by the area of the cell to yield a two-dimensional exposure parameter. This parameter is summed along the crosswind direction of the isopleths to produce an exposure parameter that is a function of downwind distance alone. Possible wind direction orientations with respect to the pathway are accounted for by repeating this process for 16 evenly spaced wind directions. Each direction is considered to be equally probable. These 16 calculations are then combined to yield a probabilistically weighted parameter that is proportional to the anticipated inhalation dose at any point along the transportation route. This curve is shown in Figure B.2.

The data in Figure B.2 have been normalized to show the fraction of the total inhalation dose received by the public as a function of distance from the pathway. The data on the curve is cumulative along the downwind distance so that eventually, as $x$ increases, $100 \%$ of the inhalation dose is accounted for. The curve stops at 10 miles and $0 \%$ of the total dose 1 ies beyond this distance.

The boundary, dividing the $10 \mathrm{mi}$. exposure distance into two bands, is chosen to be at $5 \mathrm{mi}$. This distance is relatively small yet represents the $75 \%$ point on the exposure curve. The band boundaries and their incremental contributions to public dose are given in Table B.1. The increment contributions can be used as multipliers to produce a figure of merit that will be proportional to the anticipated public health consequence of an accidental release of radioactive material.

\section{TABLE B.1 Heal th Consequence}

Band Mlutipliers

Population Band

Boundary

$0-5 \mathrm{mi}$

$5-10 \mathrm{mi}$
Heal th Consequences

Band Multipliers

0.75

0.25 
To apply this consequence evaluation method, the number of persons within each of the population bands in the table is determined from maps, census data, or other available information. Counting by thousands or tens of thousands will not affect the results provided each of the routes under consideration is courited in the same way. (Note that the bands cover the indicated distance on either side of the highway, i.e., the first band is 10 miles wide, centered on the highway.) In many applications of the route selection methodology, the number of people in each band can be determined by adding the population of cities, towns, and villages that lie within the band. The population in rural areas would be neglected, but this is not expected to significantly affect the results of the route comparison. This method will usually be appropriate when relatively long routes are being compared that pass through or near a number of population centers of various sizes. More detailed data, using census districts, for example, may be required when comparing shorter routes. This type of analysis would yenerally be associated with comparisons of through routes with possible bypass routes for a major city.

The number of people in each band is multiplied by the appropriate consequences multiplier for that band and these products are sumed to achieve a figure of merit for each route. This figure is proportional to the expected health consequences from a release. This consequence factor is then multiplied by the release frequency measure for the route to determine the public health risk measure for that route. 


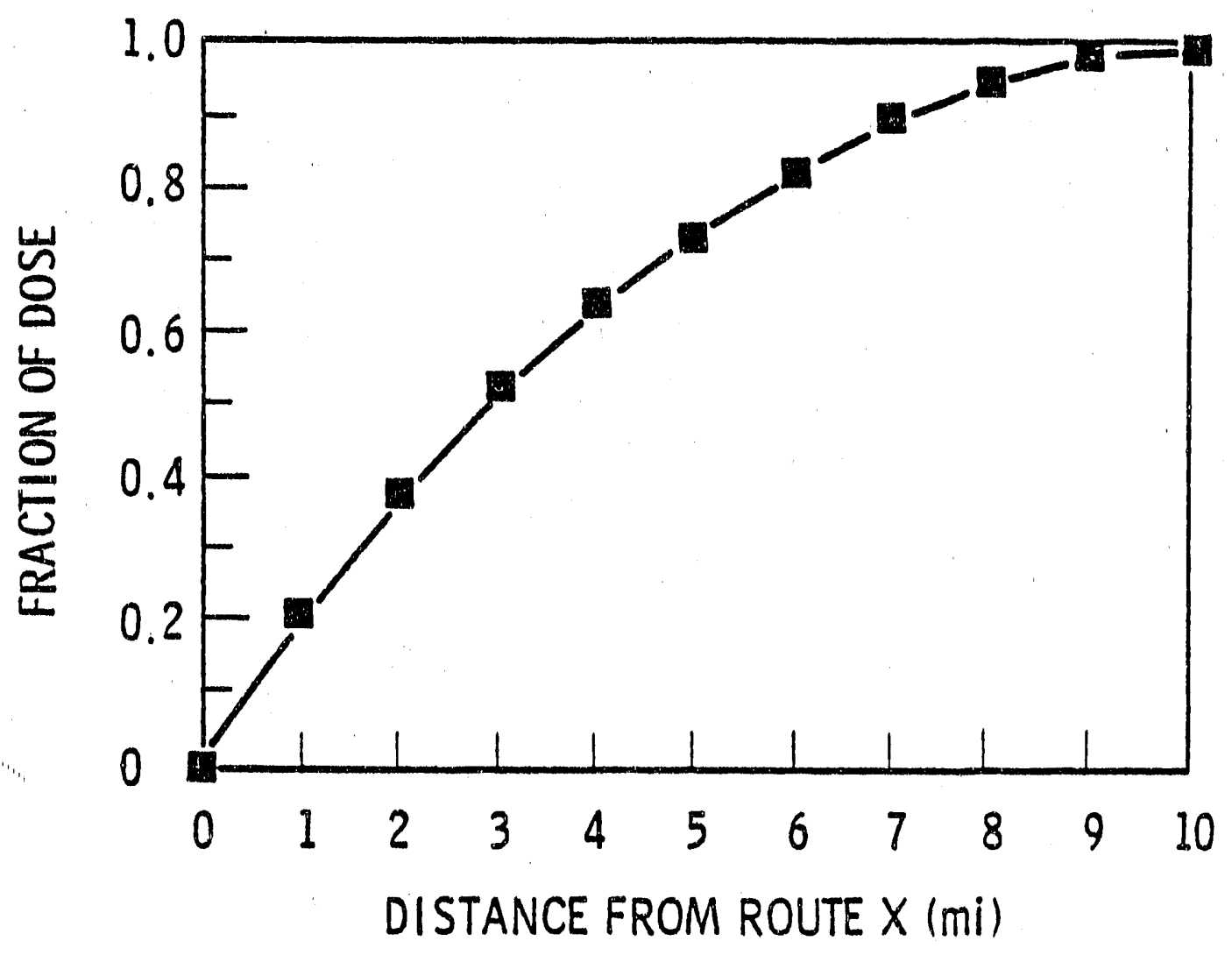

FIGURE B-2. Dose Contribution

$B-5$ 
If radioactive materials are released in a severe transportation accident, property in the vicinity of the accident could become contaminated with radioactive materials. When contamination exceeds safe levels, it would have to be removed or otherwise reduced to safe levels before the property could be returned to normal use. The expenses associated with decontamination are expected to be the primary economic impact of a transportation accident that releases radioactive materials.

Decontamination costs vary with the type of property being decontaminated (Reactor Safety Study, 1975). The decontamination costs for several land developments types are given in Table C.1. Costs are presented for two levels of decontamination that are assumed to be required following a release. A decontamination factor is defined as the starting contamination level divided by the contamination level following decontamination activities.

TABLE C.1. Land Use Decontamination costs

Land Use Type

Farmland

Single Family

Dwelling

Multiple Family

Dwelling

Cormercial

Parks

Public Areas

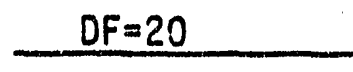

$\$ 230 /$ acre

$\$ 9000 /$ dwelling

$\$ 280 /$ capita

$\$ 315 /$ capita

$\$ 38 /$ capita

$\$ 420 /$ capita
$D F=2$

$\$ 23 /$ acre

$\$ 5000 /$ dwelling

$\$ 30 /$ capita

$\$ 2.1 /$ capita

$\$ 30 /$ capita

$\$ 40 /$ capita

The values shown in Table C.1 are chosen to be representative of the ranges of the values listed in the Reactor Safety Studies document. Representative values were used rather than the ranges given to make the routing evaluation methodology easier to apply. To further simplify the methodology application, 
the values were converted to cost per square mile. This required making several assumptions concerning the number of persons per structure and the number of structures per acre. These assumptions were based upon the descriptions of the developmient types given in the Reactor Safety Studies document. The results of this conversion are given in Table C.2. To make the economic consequences comparison factor a convenient sized number, the values were further modified to represent millions of dollars per hundred square miles.

TABLE C-2 Decontamination Costs per Square Mile

\begin{tabular}{lcr} 
& \multicolumn{1}{c}{ Decontamination Costs $\left(\$ \mathrm{~K} / \mathrm{mi}^{2}\right)$} \\
\cline { 2 - 3 } Land Use Type & $\frac{\mathrm{DF}=20}{150}$ & $\frac{\mathrm{DF}=2}{15}$ \\
Farmland & & \\
Residential & 11,210 & 3,600 \\
$\quad$ Single Family & 205,000 & 22,000 \\
$\quad$ Multi-Family & 20,000 & 1,300 \\
Commercial & 3,200 & 1,900 \\
Parks & 50,000 & 4,700 \\
Public Areas & &
\end{tabular}

To apply the economic consequence methodology to the routing decision analysis, the decontamination factors need to be interpreted into a measurable distance from the pathway. The "DF equals 20 " region will lie closer to the pathway than the "DF equals 2" region. This is due to higher deposition rates of airborn radioactive material, resulting from higher airborn concentrations, near the release location. The boundaries for these regions have been selected to coincide with the bands for the public health consequence evaluation. A decontamination factor of 20 will be assumed to be required to return land in the 0-5 mile band to normal use after an accident. $A$ decontamination factor of 2 will be assumed for the 5-10 mile band. It is assumed that no decontamination will be required past 10 miles from the shipping route. With these last simplifying assumptions, the economic consequence muitipliers take on the value given in Table C.3. 
TABLE C.3. Economic Consequence Multipliers

Economic Consequence Multipliers

Land Use Types

Farmland

Residential

Single Family

Mutli-Family

Commercial

Parks

Public Areas
Band $0-5 \mathrm{mi}$

0.001

0.1

2.0

0.15

0.03

0.5
Band $5-10 \mathrm{mi}$

0.0001

0.04

0.2

0.01

0.02

0.05

To apply this method, the amount of area with each band occupied by each of the six land use types is determined from maps, local land use planning information or other available data. The area may be ..leasured in square miles, square kilometers, acres or any other convenient unit. The measures must be consistent over the entire route, for all land use types and between alternative routes. The land use areas are multiplied by the appropriate consequence multiplier for that band. These products are summed for both bands to yield the overall figure of merit for economic impact. 
The method for determining the normal radiation exposure factor for use in the route selection process was developed from a transportation radiation exposure model used in a previous Battelle study (Greenborg, et. a1., 1980) of the routine radiation exposure from spent fuel shipments. In this model, radiation exposure from truck shipments is divided into six population groups. These groups include:

- Persons residing along the shipping route

- Travelers in the opposite direction

- Travelers going in the same direction as the shipment

- The truck crew

- People at truck stops

- Personnel handling the shipments at origin and destination.

For purposes of comparing potential routes, the latter category can be neglected, because it does not change with the shipping route used. The dose comparison factor for each route then becomes: $D=\begin{aligned} & \text { dose to persons } \\ & \text { along route }\end{aligned} \quad \begin{aligned} & \text { dose to passengers } \\ & \text { in vehicles traveling } \\ & \text { in opposite direction }\end{aligned}+\begin{aligned} & \text { dose to passengers in } \\ & \text { vehicles traveling in } \\ & \text { same direction }\end{aligned}+\begin{aligned} & \text { dose to to } \\ & \text { truck crew }\end{aligned}$

dose to people at truck stops

Doses to each of these groups will be referred to as $I D_{7}$ through $I D_{5}$, respectively for the remainder of the discussion.

The dose to persons residing along the transport route $\left(I D_{1}\right)$ is given by the following equation:

$n$

$$
I D_{1}=\sum_{i=1} \frac{4 \cdot P_{j} \cdot L_{i} \cdot k \cdot I_{2}(d)}{v_{i}}
$$

where the summation is over the number of segments that the route has been divided into for purposes of the analysis. Route segments are generally selected to correspond to significant changes in population densities. Other factors in the equation are defined as follows: 
$P=$ population denstity $\left(\right.$ people $\left./ \mathrm{m}^{2}\right)$

$L=$ route segment length $(m)$

$k=$ dose factor $\left(m R \cdot m^{2} / h r\right)$

$v=$ truck velocity

$I_{2}(d)=\begin{aligned} & \text { an integral that estimates the dose at a given point from a moving } \\ & \text { source. }\end{aligned}$

The dose factor, $k$, is dependent on the characteristics of the material being shipped and the particular shipping container being used. For route comparison purposes, a representative value can be used for this parameter because tt wili not change from one route to another. A value of $28 \mathrm{mR} \cdot \mathrm{m}^{2} / \mathrm{hr}$ was used, corresponding to the dose factor for a shipment of one-year-old spent fuel in a current generation legal-weight truck cask (Greenborg et. a1., 1980, page $3-10$ ).

$I_{2}(d)$ is a function of the distance (d) from the truck carrying the radioactive shipment to the area along the route normally occupied by people. It corresponds roughily to the right of way for the highway segment being analyzed. $I_{2}(d)$ is plotted as a function of $d$ in Figure 0.1 . The plot shows that $I_{2}(d)$ is a slowly varying function of $d$. For purposes of this analysis, a representative value of $I_{2}(d)$. was chosen, corresponding to a distance of 10 meters (about $30 \mathrm{ft}$ ) from the vehicle traffic lane to the edge of the normally-populated zone along the road.

Substituting these values into equation(2), and assuming that only one route segment is being analyzed,

$$
I D_{1}=448 \frac{\mathrm{PL}}{\mathrm{V}}
$$

Converting $P, L$, and $v$ to more convenient units for use in the route selection process,

$$
I D_{1}=1.7 \times 10^{-4} \frac{P L}{V}
$$

where $P$ has units of people $/ \mathrm{mi}^{2}, L$ has units of miles, and $v$ is given in mph.

The dose to travelers in the opposite direction to the radioactive material shipment $\left(\mathrm{ID}_{2}\right)$ is given by the expression:

$$
I_{2}=\frac{K \cdot L \cdot N \cdot T}{v^{2}} I_{1}(y)
$$

where $K=$ dose conversion factor

$L=$ route length $(m)$

$N=$ average number of people/vehicle 


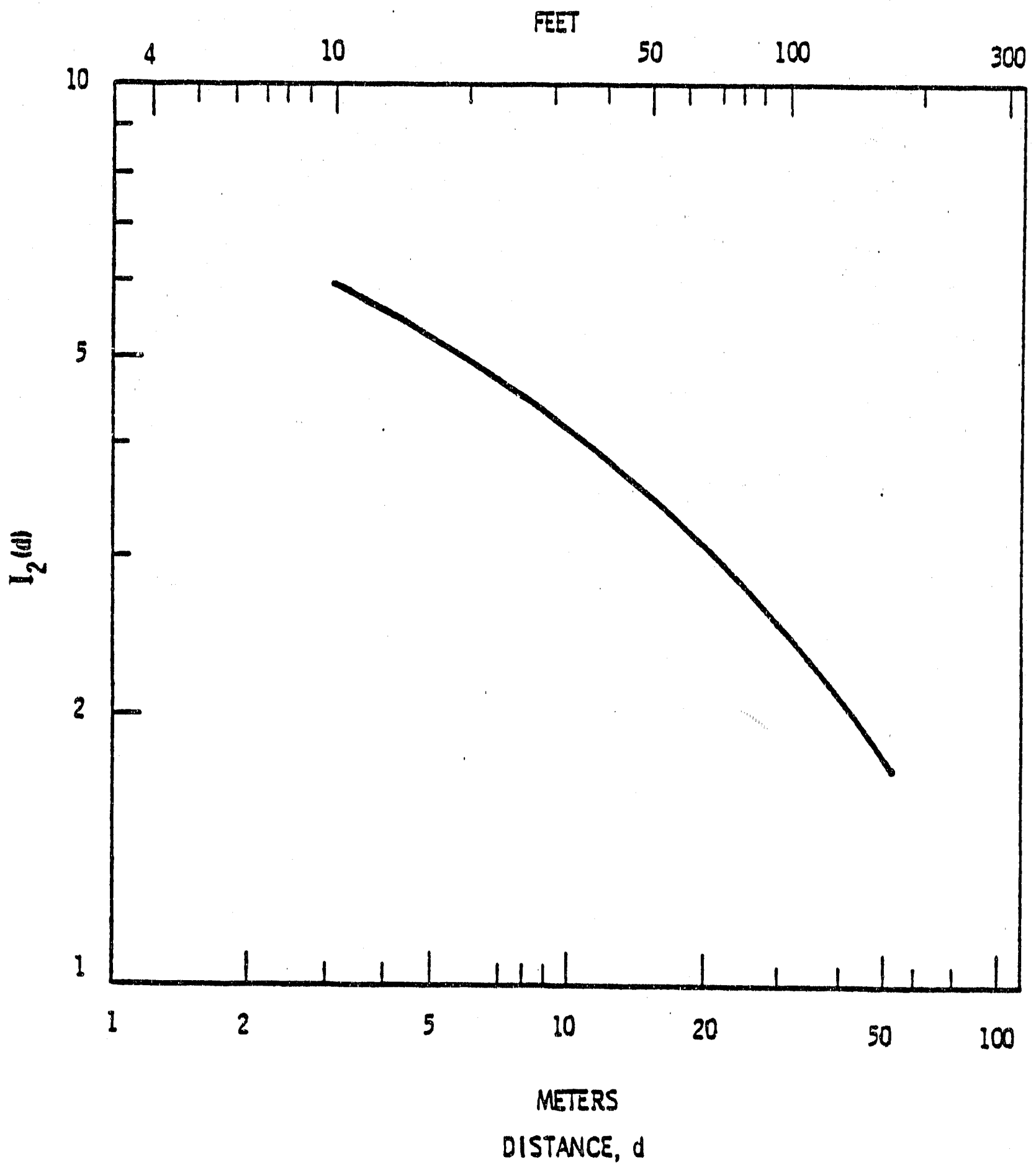

FIGURE D-1. $\quad I_{2}(d)$ as a Function of $d$ 
$T=$ traffic count (vehicle/hr)

$v=$ truck velocity

$I_{1}(y)$ is an integral that estimates the dose to a moving target from a moving source. It is a function of the distarice $(y)$ from the source to the target. This distance corresponds to the distance from the center of one lane of traffic to the center of the lane of traffic moving in the opposite direction. $I_{f}(y)$ is plotted as a function of $y$ in Figure $D-2$.

The dose factor, $k$, in this equation ( 3 ) is identical to the dose factor used in $\mathrm{ID}_{1}$ and is again assigned a value of $28 \mathrm{mR} \cdot \mathrm{m}^{2} / \mathrm{hr}$. A representative value of $N$ can also be used, because this tends to not vary significantly between routes. A value of 1.4 passengers/vehicle was selected. This is a national average for vehicles on freeways. Converting $v$ and $L$ to more convenient units, equation ( 3 ) then becomes

$$
I D_{2}=9.3 \times 10^{-9} \frac{L T}{v^{2}} I_{1}(y)
$$

where $L$ is in miles, $T$ in vehicles/hr and $v$ in $\mathrm{mph}$.

The dose to travelers in the same direction as the radioactive material shipment $\left(\mathrm{IO}_{3}\right)$ is given by the expression

$$
I D_{3}=\frac{2 K L N T}{v^{3}} F(s)
$$

where $k, L, N, T$ and $v$ are defined as before and $F(s)$ is a function $F$ that estimates the dose to passengers in all vehicles near the truck carrying the radioactive cargo. $F$ is a function of the average vehicle separation distance $(s)$ on the route segment. $S$ is equal to the average vehicle speed on the route, divided by the traffic count. $F(s)$ is plotted as a function of $s$ in Figure $0-3$. Substituting for $N$ and $k$, and again converting units, equation (4) becomes:

$$
I D_{3}=3 \times 10^{-5}\left(\frac{L T}{v^{3}}\right) F(s)
$$

where $L$ is in miles, $T$ is in vehicle/hr and $v$ is in mph.

The dose to the truck crew $\left(I_{4}\right)$ is given by the following equation:

$$
I D_{4}=2 R_{1}\left(\frac{L}{V}\right)
$$

where $L$ and $v$ are defined as before, and $R_{j}$ is the dose rate (mR/hr) in the truck cab. It has been assumed that there are 2 drivers in the truck. 
FEET

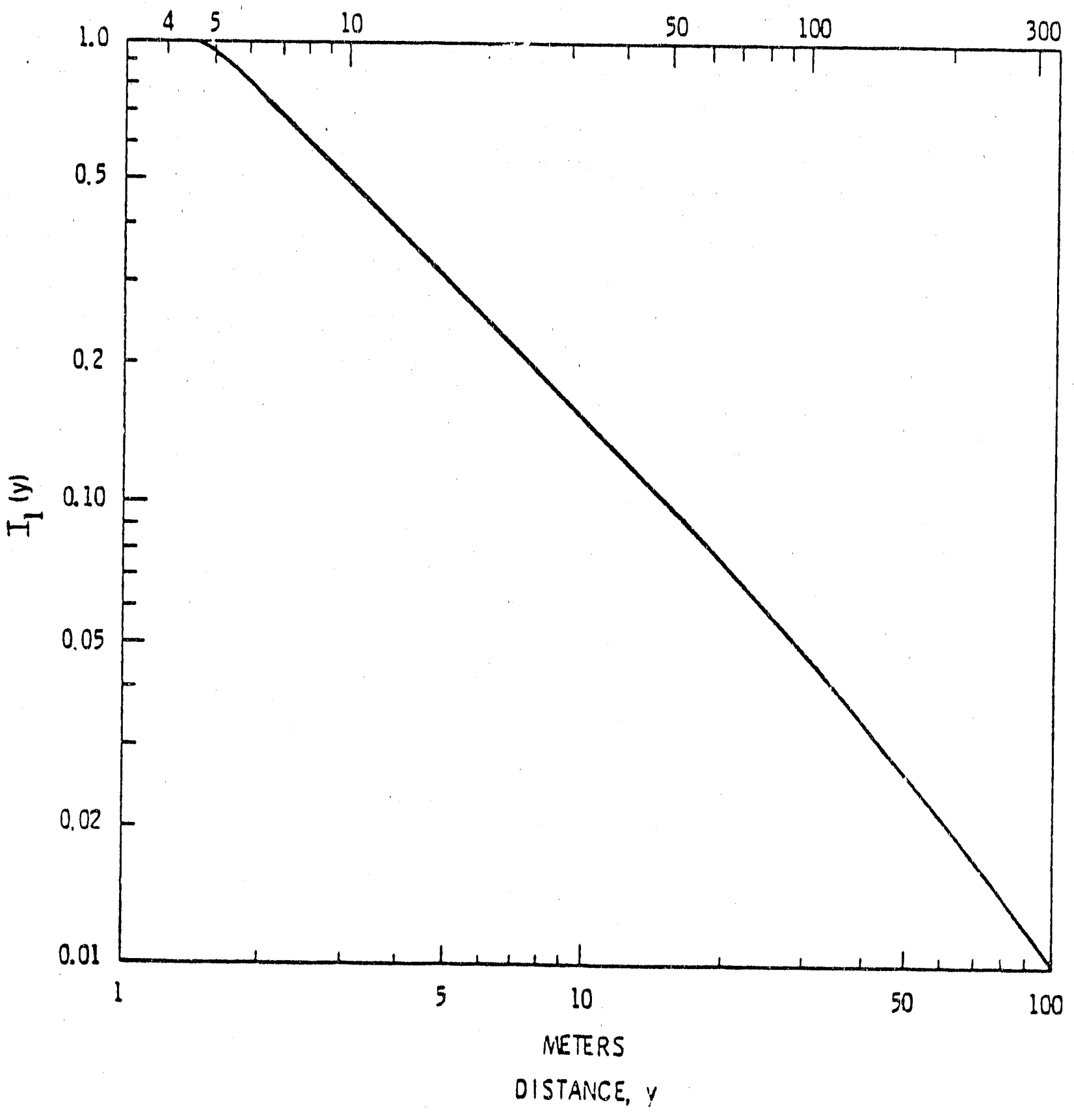

FIGURE $0-2$. $\quad I_{1}(y)$ as a Function of $y$ 
FEET

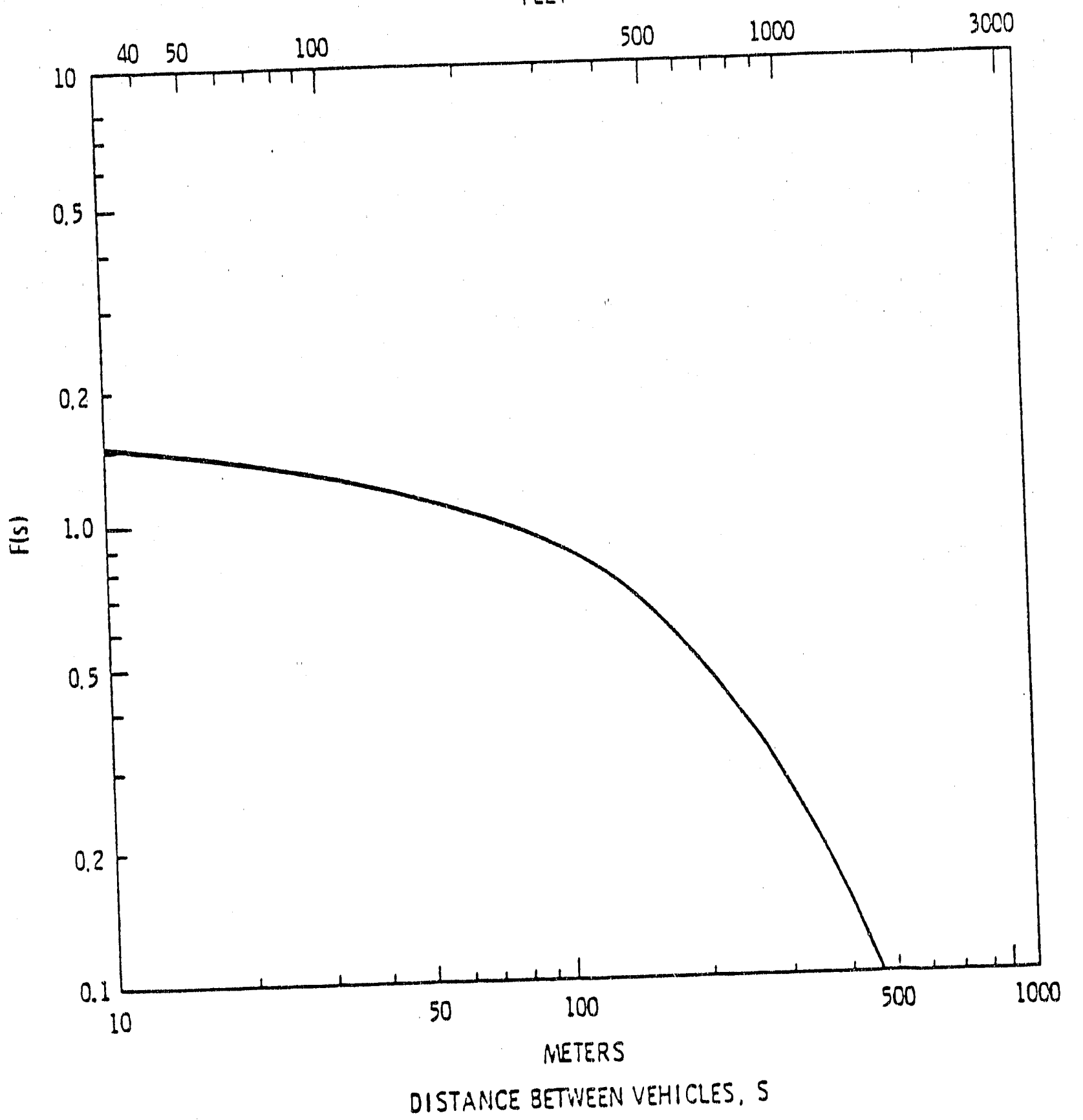

FIGLIRE D-3. $\quad F(s)$ as a Function of Vehicle Separation Distance 
A representative value of $R_{1}$ of $1 \mathrm{mr} / \mathrm{hr}$ has been used in this analys is because $R_{1}$ will not change from one route to another. (The maximum dose permitted in the cab by DOT regulations is $2 \mathrm{mR} / \mathrm{hr}$. Typical values are much less than this.) Equation (5) then becomes:

$$
I D_{4}=\frac{2 L}{V}
$$

where $L$ is in miles and $v$ in mph.

The dose to people at truck stops $\left(I_{5}\right)$ is given by the expression

$$
I D_{5}=\left[\frac{R_{2}}{4}+9.1 \times 10^{-2_{k}}\right] \text { Integer }\left(\frac{L}{4 V}\right)
$$

where $R_{2}$ is the dose at $10 \mathrm{ft}$ from the package of radioactive material, $k_{1}$ is another dose conversion factor and $L$ and $v$ are defined as before. $R_{2}$ is used to estimate the dose to service station attendents, who are assumed to be in the vicinity of the truck for about 15 minutes at each stop. A representative value for $R_{2}$ of $2 \mathrm{mR} / \mathrm{hr}$ was used for this analysis. $R_{2}$ is a function of the shipment characteristics, and not of the route used. The dose conversion factor, $k_{1}$, is used in estimating the dose to other people at the truck stop. This would include, for example, people eating in a restaurant at the stop. The value of $\mathrm{k}_{\mathrm{f}}$ used in this analysis was $18 \mathrm{mR} \mathrm{m}^{2} / \mathrm{hr}$. This corresponds to the value of $k$ used previously in $\mathrm{ID}_{1}$ and $\mathrm{IO}_{2}$. The integer expression estimates the number of stops made by the truck in traveling a route of length $L$. It is assumed that refueling and crew comfort stops are made every four hours. To simplify the expression for the route selection process, the integer part of the equation has been ignored. This has the effect of counting fractional stops, but should not significantly affect the route comparison process. Equation (6) then becomes.

$$
I D_{5}=\frac{0.5 L}{V}
$$

where $L$ is in miles and $v$ in mph.

Substituting these expressions for $I D_{1}$ through $I D_{5}$ into equation (1),

$$
D=1.7 \times 10^{-4} \frac{P L}{v}+9.3 \times 10^{-9} \frac{L T}{v^{2}} I_{e}(y)+3.0 \times 10^{-5} \frac{L T}{v^{3}} F(s)+2.5 \frac{L}{v}
$$

Because $D$ needs to be only proportional to the normal radiation exposure on each route, constants can be factored out to simplify the expression. 
Factoring out 2.5 gives

$$
D=C_{1} \frac{P L}{v}+C_{2} \frac{L T}{v^{2}}+C_{3} \frac{L T}{v^{3}}+\frac{L}{v}
$$

where, $c_{1}=6.7 \times 10^{-5}$

$$
\begin{aligned}
& c_{2}=3.7 \times 10^{-9} I_{1}(y) \\
& c_{3}=1.2 \times 10^{-5} F(s)
\end{aligned}
$$

Values for $c_{2}$ and $c_{3}$ as a function of $y$ and $s$ are given in Table $0-1$.

TABLE D-1. Conversion Factors for Use in Estimating Routine Radiation Exposure Factor

Distance Between Opposing Traffic Lanes ( $f t$ )

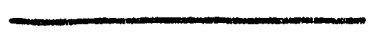

10

20

30

40

50

60

70

80

90

100

150

200

300

\begin{tabular}{cc}
$c_{2}$ & $\begin{array}{c}\text { Vehicle Separation } \\
\text { Distance }=\frac{V}{T}(\mathrm{ft})\end{array}$ \\
\hline $1.9 \times 10^{-9}$ & 10 \\
$9.5 \times 10^{-10}$ & 50 \\
$6.0 \times 10^{-10}$ & 100 \\
$4.4 \times 10^{-10}$ & 200 \\
$3.7 \times 10^{-10}$ & 300 \\
$2.9 \times 10^{-10}$ & 400 \\
$2.5 \times 10^{-10}$ & 500 \\
$2.2 \times 10^{-10}$ & 600 \\
$1.9 \times 10^{-10}$ & 700 \\
$1.6 \times 10^{-10}$ & 800 \\
$1.0 \times 10^{-10}$ & 900 \\
$7.4 \times 10^{-11}$ & 1000 \\
$4.0 \times 10^{-11}$ & 1200
\end{tabular}

$\mathrm{C}_{3}$

$1.8 \times 10^{-5}$

$1.6 \times 10^{-5}$

$1.5 \times 10^{-5}$

$1.3 \times 10^{-5}$

$1.0 \times 10^{-5}$

$8.6 \times 10^{-6}$

$7.3 \times 10^{-6}$

$6.0 \times 10^{-6}$

$5.0 \times 10^{-6}$

$4.0 \times 10^{-6}$

$3.3 \times 10^{-6}$

$3.0 \times 10^{-6}$

1. $3 \times 10^{-6}$ 


\section{DERIVATION OF EVACUATION COMPARISON FACTOR}

Public health consequences from accidents involving radioactive materials are due to mechanical forces generated by the accident and exposures of populations to ionizing radiation if a release of material occurs. Accident forces are the only effects with potential for immediate public heaith impacts. Public exposure to radiation during a transportation accident would not result in immediate fatalities due to the relatively low individual doses that would be produced. Public dose can be further reduced, however, through evacuation of persons in the affected areas.

Factors contributing to an effective evacuation include the type of area to be evacuated (i.e., residential, industrial, etc.), means of egress, implementation of plans by authorities and the nature of the threat. Little research has been done to measure the effect of these parameters on evacuation results. Evacuation results can be measured in terms of the number of persons who choose not to evacuate, time required to evacuate, and impacts on the evacuating population. A study by EPA (Hans and Se11, 1974) was used in this project to gain insight on evacuation mechanisms.

Hans and Sell gathered all available historic data on evacuations. This included information on planned evacuations for civil defense, natural disasters, special facility evacuations and precautionary evacuations in response to potential threats. Several conclusions were developed on public behavior during an evacuation. First, the frequency of death or injury is approximated by motor vehicle accident statistics because $99 \%$ of all evacuations were made using motor vehicles. Second, a state of panic does not exist. Low speeds and orderly movement of vehicles were observed. Third, evacuation planning is essential to identify potential problems. Fourth, special facilities such as schools, hospitals, and penal institutions require specific plans for their evacuation. Fifth, evacuation times vary with population density. Areas of lower density required longer to evacuate. Finally, even when faced with a threat, an average of $6 \%$ of the people refuse to evacuate. 
Much higher refusal rates were observed for situations where the threat was not apparent. Radioactivity is not detectable by human senses. Therefore, evacuations to avoid exposure may be met with resistance without adequate communication from officials.

Persons who refuse to evacuate should be encouraged to take measures to improve the protection afforded by their homes. Studies of toxic gas infiltration for typical homes in the Netherlands (Directorate-General of Labour, Netherlands) indicates that concentrations inside are about $1 / 3$ of those outside for 0.5 hours following gas contact with the house. When makeshift seals were installed, this time was extended to 2.5 hours.

Data from Hans and Sell was used in a study of chlorine risks (Andrews et. al., 1980) to predict evacuation times as a function of population density. Descriptions of evacuations for nine transportation accidents were used to develop the following relationship:

$\log$ (evacuation time in hours $)=-0.16 \log \left(\right.$ persons $\left./ \mathrm{km}^{2}\right)+0.94$

Rural areas averaging 50 persons $/ \mathrm{km}^{2}$ are predicted by this relationship to requite 5 hours for evacuation. Evacuation times are reduced to 3 hours for urban areas with population densities of 1000 persons $/ \mathrm{km}^{2}$. 
A listing of reference materials that may be useful to state officlals in applying the guidelines and in presenting the results of the route selection process to the public is presented below. Most reports contained in this list are avallable through the National Technical information Services (NTIS), 5285 Port Royal Rd., Springfield, VA 22151.

GENERAL RADIOACTIVE MATERIAL INFORMATION

PNL-SA-7072. A. M. Platt, J. L. McElroy. Management of High-Level Nuclear Wastes. Pacific Northwest Laboratory, Richland, Washington, September 1979.

J. Kastner. Nature's Invistble Rays. U.S. Energy Research and Development Administration, Office of Public Affairs, Washington, D.C., 1973.

Department of Energy. How to Find Information on Nuclear Waste Isolation. Office of Waste Management, Division of Waste Isolation, Washington, D.C. 1980.

U.S. Department of Energy. Nuclear Power from Fission Reactors - An

Introduction. Office of NucTear Energy Programs, Washington; D.C. November 1979.

U.S. Environmental Protection Agency. Radioactive Wastes. Office of Public Affairs (A-107), Washington, D.C.

RADIOACTIVE MATERIAL TRANSPORTATION INFORMATION

DOE/EV-0003. Everything You Always Wanted to Know About Shipping High Level Nuclear Wastes. U.S. Department of Energy, Division of Environmental Control Technology, Washington, D.C. January 1978.

BNWL-1846. T. I. MCSweeney and J. R. Hall, et al. An Assessment of the Risk of Transporting Plutonium nxide and Liquid Plutonium Nitrate by Truck. Pacific Northwest Laboratory, Richland, Washington, 1975.

BNWL-1996. R. J. Hall, et al. An Assessment of the Risk of Transporting Plutonium Dioxide and Liquid Plutonium Nitrate by Train. Pactfic Northwest Laboratory, Richland, Washington, 1977.

DOE-EIS-0046F. Final Environmental Impact Statement. Management of Commerctally Generated Radioactive Waste. U.S. Department of Energy, Washington, D.C. October 1980.

PNL-3261. J. Greenborg, et a 1. Application of ALARA Princlples to Shipment of Spent Nuclear Fuel. Pacific Northwest Laboratory, Richland, Washington, 1980. 
NUREG/0170. Final Enytronmental Statement on the Transportation of Radioactive Material by Alr and Other Modes. U.S. Regulatory Commission, Washington, D.C. 1977.

PNL-2030. T. I. McSweeney and J. F. Johnson. An Assessment of the Risk of Transporting Plutonium Dioxide by Cargo Aircraft. Pacific Northwest Laboratory, Richland, Washington, 1977.

PNL-2211. C. A. Geffen, et a1. An Assessment of the Risk of Transporting Urantum Hexafluoride by Truck and Train. Pacific Northwest Laboratory, Richland, Washington, 1978.

PNL-2588. H. K. Elder, et a1. An Assessment of the Risk of Transporting Spent Nuclear Fuel by Truck. Pacific Northwest Laboratory, Richiand, Washington, 1978.

PNL-3208. A. L. Franklin. TREC II: A Computer Program for Transportation Risk Assessment. Pacific Northwest Laboratory, Richland, Washington, 1980.

\section{MISCELLANEOUS SOURCES}

BEIR Report. The Effects on Populations of Exposure to Low Levels of Ionizing Radiation. Report of the Advisory Committee on the Biological Effects of Ionizing Radiation, National Academy of Science, 1972.

Turner, D. B. Workbook of Atmospheric Dispersion Estimates. Department of HEW, 1970.

WASH 1400 (NUREG-75/104). Reactor Safety Study - An Assessment of the Accident Risks of the U.S. Commerclal Nuclear Power Plants. U.S. Nuctear Regulatory Commission, Washington, D.C. 1975.

PNL-2133. R. E. Rhoads, et a1. An Assessment of the Risk of Transporting Gasoline by Truck. Pacific Northwest Laboratory, Richland, Washtngton, November 1978.

PNL-3308. C. A. Geffen, et al. An Assessment of the Risk of Transporting Propane by Truck and Train. Pacific Northwest Laboratory, Richland, Washington, September 1980.

PNL-3376. W. B. Andrews, et a1. An Assessment of the Risk of Transporting Liquid Chlorine by Rail. Pacific Northwest Laboratory, Richland, Washington, March 1980.

Experiments with Chlorine. Directorate-General of Labour of the Ministry of Social Affairs, PO Box 69, Voorburg, the Netherlands, 1975. 
EPA-520. J. M. Hans and T. C. Sell. Evacuation Risks - An Evaluation.

U.S. Environmental Protection Agency, Office of Radiation Programs, Las Vegas, Nevada, 1974.

FHWA-IP-80-20. Peat, Marwick, Mitchell and Co. E. J. Barber and L. K. Hildebrand. Guidelines for Applying Criteria to Bes lanate Routes for Transporting Hazardous Materials - Implementation Package. U.S. Department of Transportation, Federal Highway Administration, 1980.

$F-3$

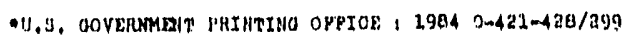


TRANSPORTATION IMPACTS ON

THE TENNESSEE HIGHWAY SYSTEM

PROPOSED MONITORED RETRIEVABLE STORAGE

\section{SUMMARY}

Role of Tennessee Highways with MRS

Role of Tennessee Highways without MRS

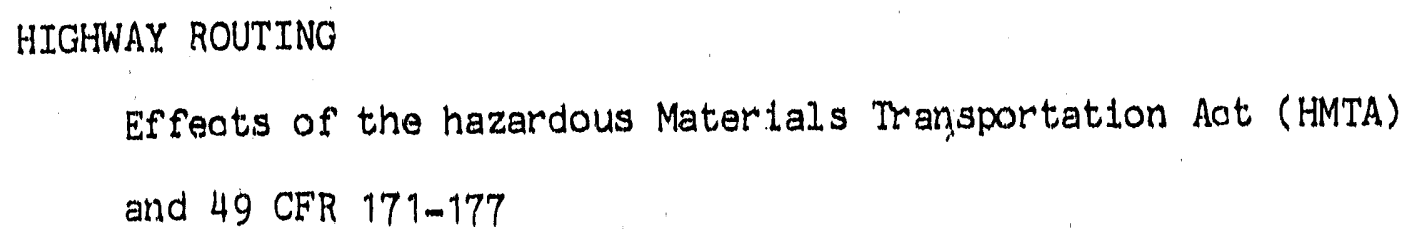

ROLE OF TDOT

Routing of Movements

Regulating Movements

Permits

CONCLUSION

HIghway Improvements

POsition of TDOT

APPENDIX A

APPENDIX B 


\section{TRANSPORTATION IMPACTS ON \\ THE TENNESSEE HIGHWAY SYSTEM \\ PROPOSED MRS FACILITY}

\section{Summary:}

The Monftored Retrievable Storage Facllity (MRS) as proposed by the U.S. Department of Energy (DOE) would aot as an Intermediate spent fuel rod consolidation faollty interposed between nuolear power plant sites and a final geologio repository. Primary estimates are the MRS would recelve, when fully operational, approximately three (3) shipments of spent fuel rod assemblies per day or approximately elghty-five (85) shipments per month by highway transportation.

The proposed facility would reduce the shipment mileage by approximately $65 \%$, by consolidating fuel assembiles into fewer shipments instead of a larger number of shipments of unconsolidated assemblies direct from the power plant to the final repository, thus reducing the acoident opportunity to the traveling public.

Role of Tennessee Highways with MRS:

Should an MRS facility be authorized and constructed, primary hf.ghway routes would be the Interstate highway system to a designated access route leading from the Interstate to the plant site.

\section{Oak Ridge}

An MRS facility looated at either of the two (2) possible sites in the Oak Ridge area (Map 6) would involve the majority of Tennessee's Interstate Highway System (Map 2). 
With input from the Publio Servioe Comission, the Tennessee Emergenoy Management Agency and the CIInoh River MRS Task Force, it would appear the general consensus is "SR-58 or SR-95" would be the preferred aocess route or routes from Interstate 40 to the vicinity of the MRS site (Map 6). These two (2) routes would involve a more rural setting and lower population density than other routes in the area.

Hartsville

An MRS facility at the abandoned TVA Nuclear Power site also would extensively Involve the Tennessee Interstate Highway System (Map 3). Primary routing would be over the Interstate Highway System to a designated access route leading to the MRS site.

Two possible routes which could entertain designated access status are SR53 from I-40 to US-70 N (SR-24) to SR-25 and then SR-25 to the Hartsville site, also US-231 (SR-10) from its junction with I-40 at Lebanon to the junction with SR-25 \& SR-10 then SR-10 to Hartsville and then SR-25 to the TVA site (Map 7).

The second possible designated route is not an attractive consideration due to the population density encountered in the Lebanon area. However, population denslty should not be a total determent, because any shipment would be forced to pass through or near large populated areas of the state before arriving at the access point (1.e. Knoxville, Chattanooga, Nashville, Memphis, Jackson).

Role of Tennessee Highways without MRS:

Should the MRS proposal not be implemented in Tennessee, for whatever reason, with spent nuclear fuel being shipped directly from the power plant site to the final repository, Tennessee Highways would still be involved (Map 4 \& 5).

The Interstate Highway System would serve as the primary routing through the state. 

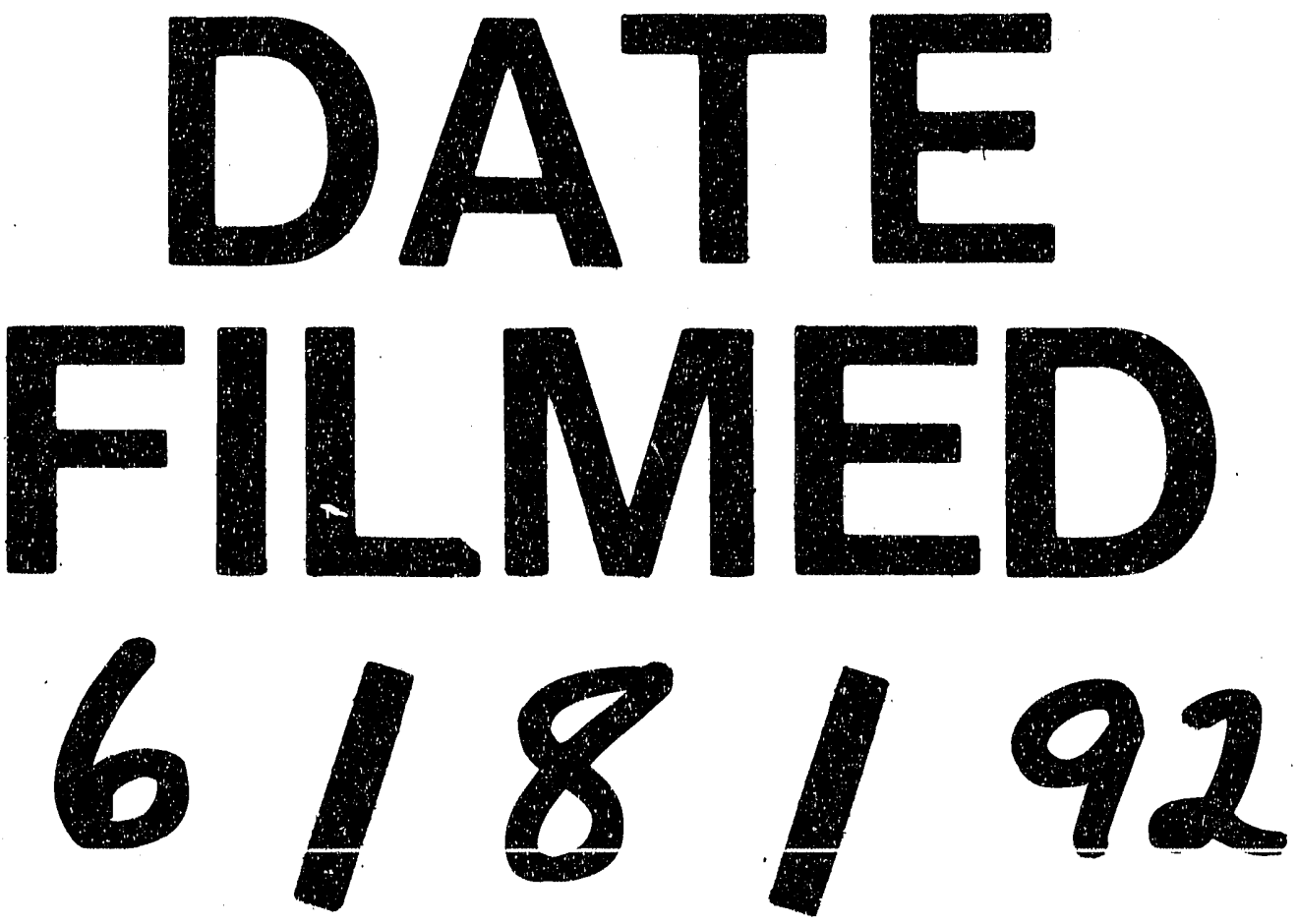
